\title{
Diffusion Welding of Alloys for Molten Salt Service - Status Report
}

D. E. Clark

R. E. Mizia

M. V. Glazoff

P. Sabharwall

M. G. McKellar

September 2012

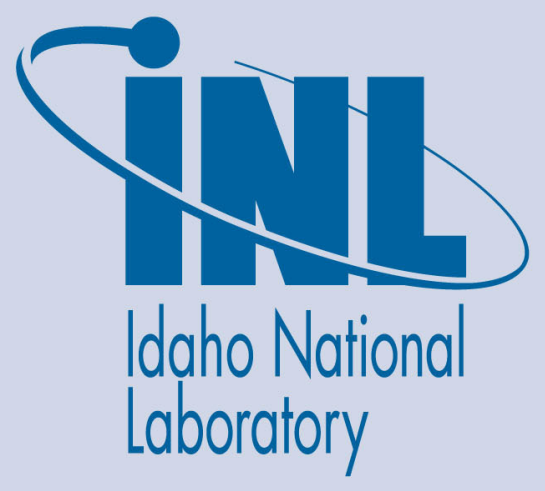

The INL is a U.S. Department of Energy National Laboratory operated by Battelle Energy Alliance 


\section{DISCLAIMER}

This information was prepared as an account of work sponsored by an agency of the U.S. Government. Neither the U.S. Government nor any agency thereof, nor any of their employees, makes any warranty, expressed or implied, or assumes any legal liability or responsibility for the accuracy, completeness, or usefulness, of any information, apparatus, product, or process disclosed, or represents that its use would not infringe privately owned rights. References herein to any specific commercial product, process, or service by trade name, trade mark, manufacturer, or otherwise, does not necessarily constitute or imply its endorsement, recommendation, or favoring by the U.S. Government or any agency thereof. The views and opinions of authors expressed herein do not necessarily state or reflect those of the U.S. Government or any agency thereof. 
INL/EXT-12-24589

Revision 1

\title{
Diffusion Welding of Alloys for Molten Salt Service - Status Report
}

\author{
D. E. Clark, R. E. Mizia \\ M. V. Glazoff, P.Sabharwall \\ M. G. McKellar
}

September 2012

Idaho National Laboratory

Idaho Falls, Idaho 83415

http://www.inl.gov

\author{
Prepared for the \\ U.S. Department of Energy \\ Office of Nuclear Energy \\ Under DOE Idaho Operations Office \\ Contract DE-AC07-05ID14517
}



Diffusion Welding of Alloys for Molten Salt Service Status Report

INL/EXT-12-24589

September 2012

Approved by:

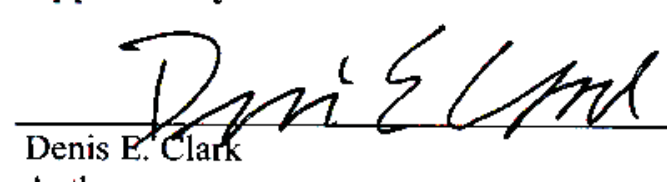

Author

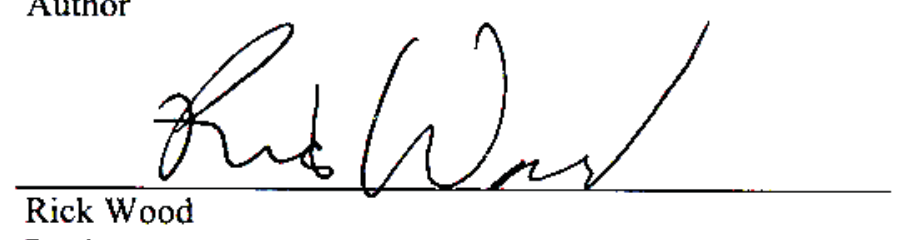

Reviewer

Mutant s.mitalla

Michael McKellar Approver

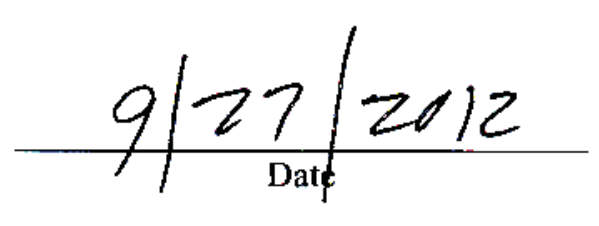

$9 / 27 / 2012$

$\frac{9 / 27 / 20 / 2}{\text { Date }}$ 



\begin{abstract}
This report addresses present work concerned with heat exchanger development for molten salt service, including the AHTR (Advanced High Temperature Reactor), which uses molten salt for cooling and process heat transfer. These results are an outgrowth of recent work done under the Next Generation Nuclear Plant (NGNP) Project, which was concerned with the diffusion welding of Alloys $800 \mathrm{H}, 617$, and similar materials for oxidation resistance at operating temperatures up to $900{ }^{\circ} \mathrm{C}$. The molten salt systems discussed herein use other alloys such as Alloy $\mathrm{N}$ and 242, which show corrosion resistance to molten salt at nominal operating temperatures up to $700{ }^{\circ} \mathrm{C}$. These alloys were diffusion welded, typically at $1150{ }^{\circ} \mathrm{C}$ for 3 hours under applied loads of $\sim 5 \mathrm{MPa}$ using the Gleeble thermomechanical testing machine. Thermocalc/DICTRA models were developed to predict diffusion, and compositions of welds with a $15 \mu \mathrm{m}$ nickel foil interlayer were measured after welding for comparison. Calculated and experimental values were in good agreement. Test specimens were prepared for exposing diffusion welds to molten salt environments. Alloy $\mathrm{N}$ and 242 were found to be weldable by diffusion welding, with ultimate tensile strengths about $90 \%$ of base metal values. Both diffusion welds and sheet material in Alloy $\mathrm{N}$ were corrosion tested in $58 \mathrm{~mol} \% \mathrm{KF} / 42 \mathrm{~mol} \% \mathrm{ZrF}_{4}$ at 650,700 , and $850{ }^{\circ} \mathrm{C}$ for 200,500 , and 1000 hours. Corrosion rates were similar between welded and nonwelded materials, typically $<10$ mils per year.
\end{abstract}




\section{CONTENTS}

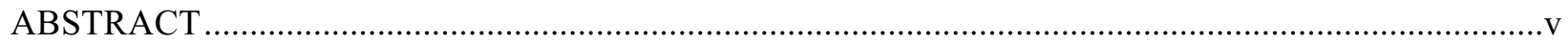

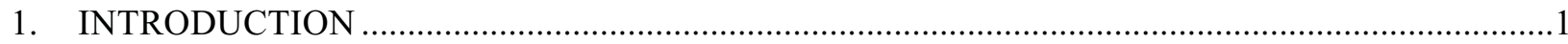

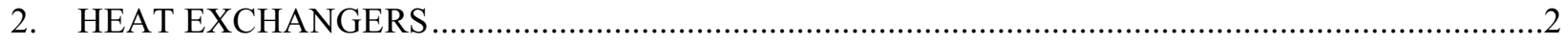

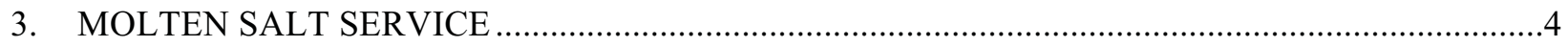

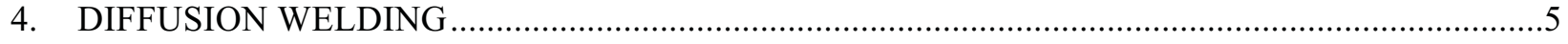

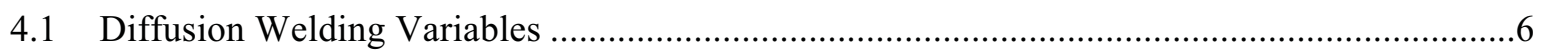

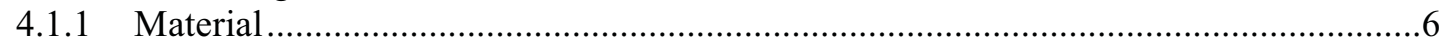

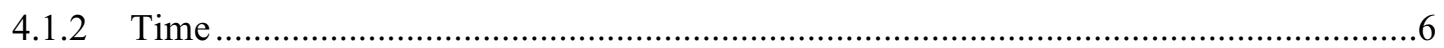

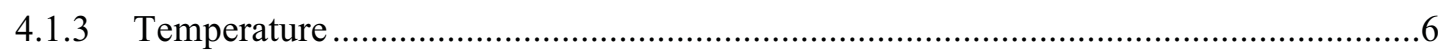

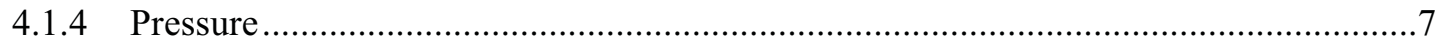

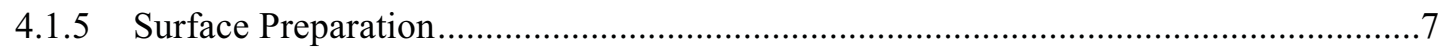

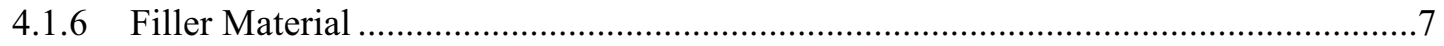

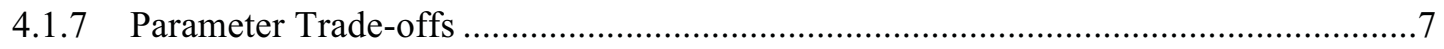

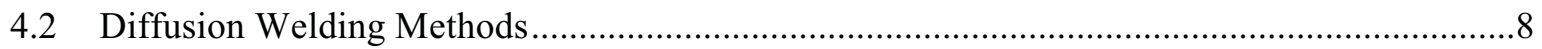

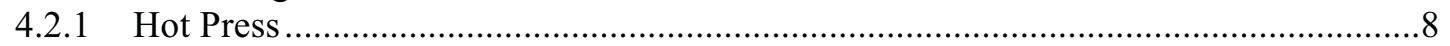

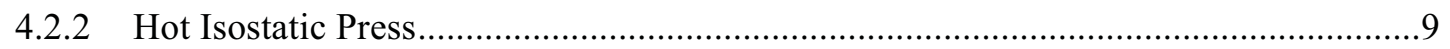

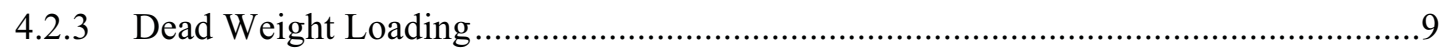

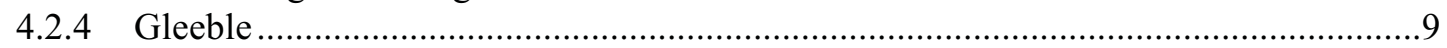

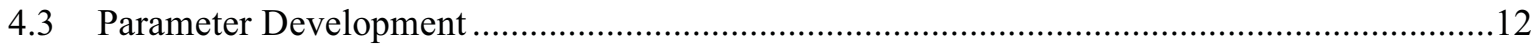

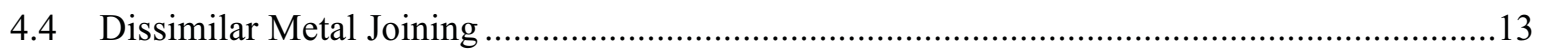

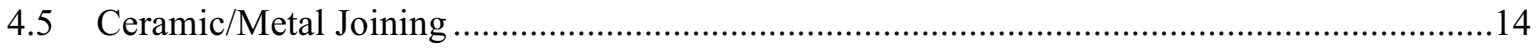

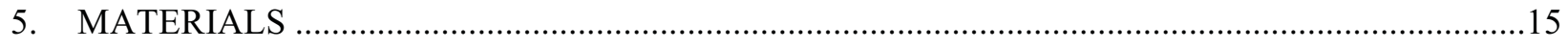

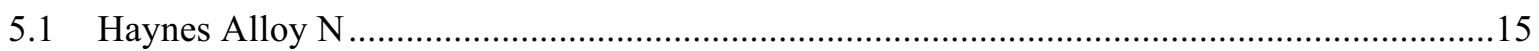

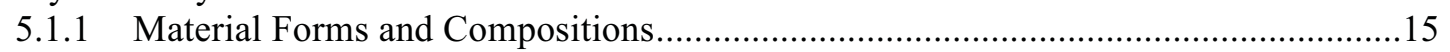

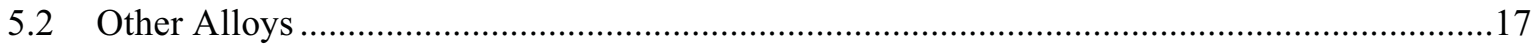

5.3 Importance of Surface Preparation................................................................................... 18

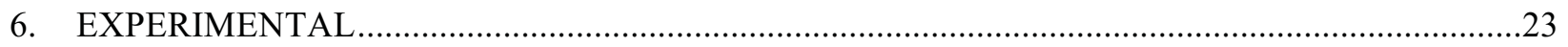

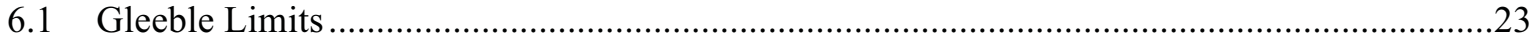

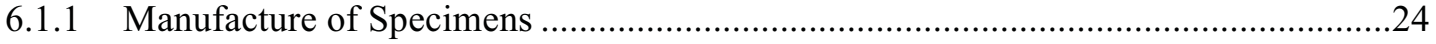

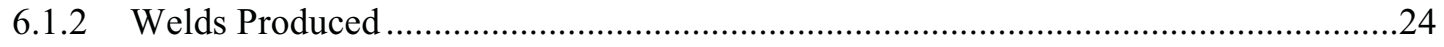

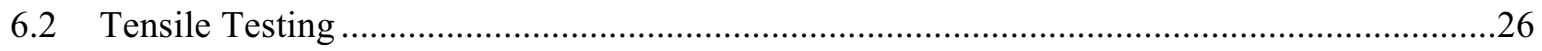

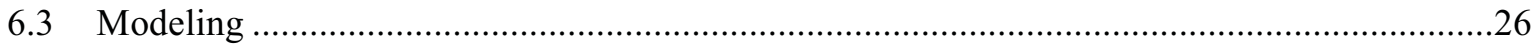

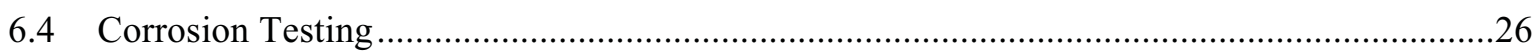

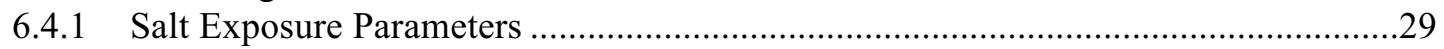

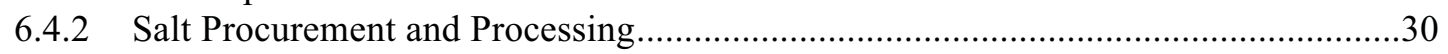

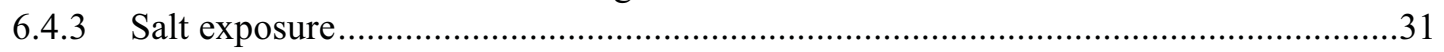

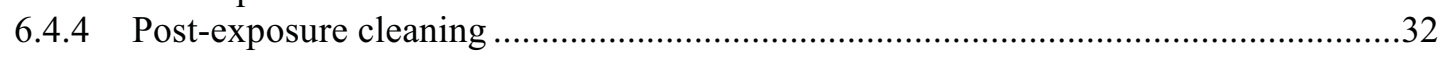

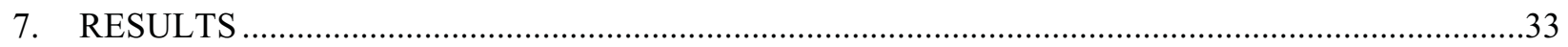

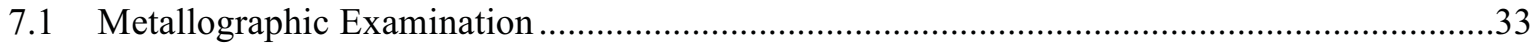




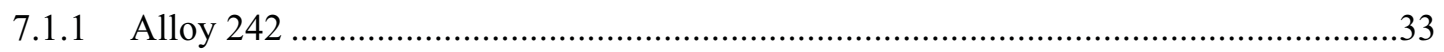

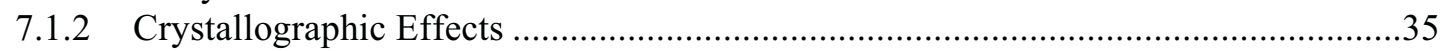

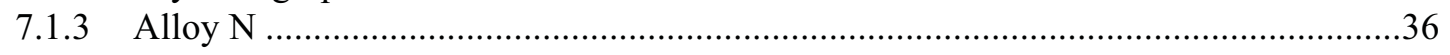

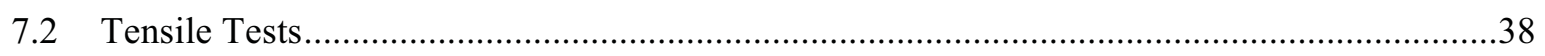

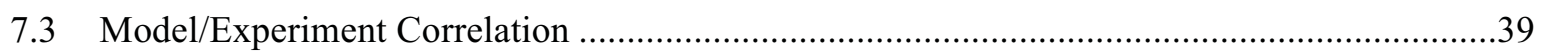

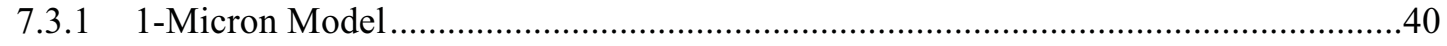

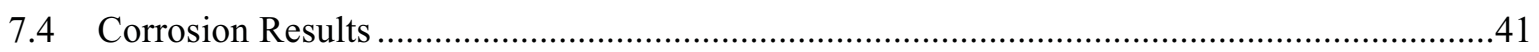

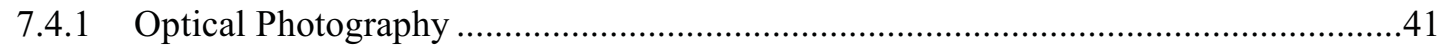

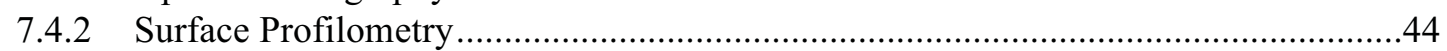

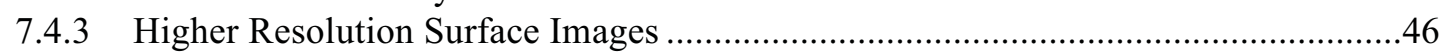

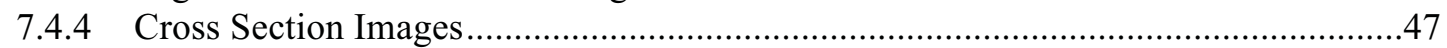

7.4.5 Corrosion Rates from Weight Loss and Area Measurements...................................48

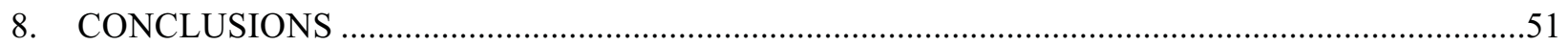

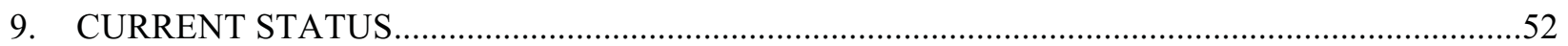

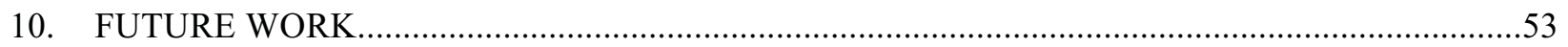

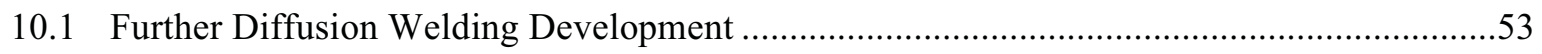

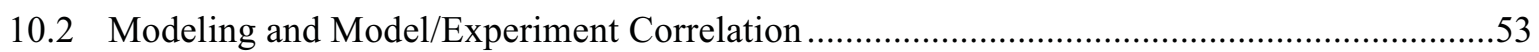

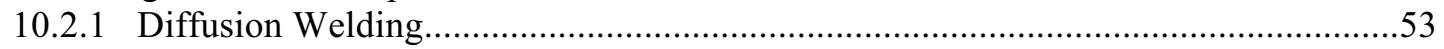

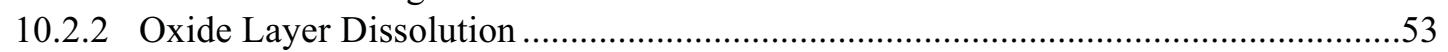

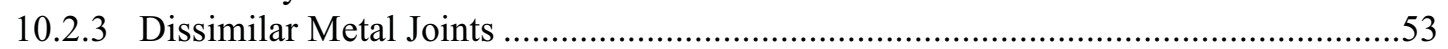

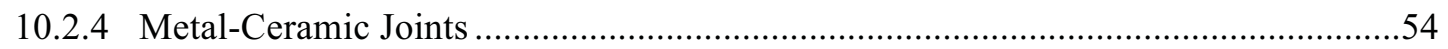

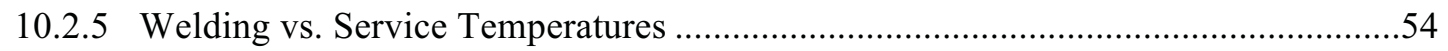

10.2.6 Vacuum Hot Press Welding at Oregon State University .........................................54

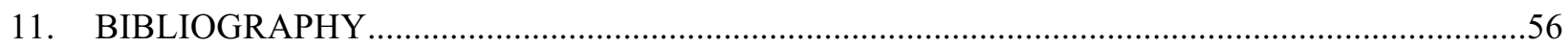

\section{FIGURES}

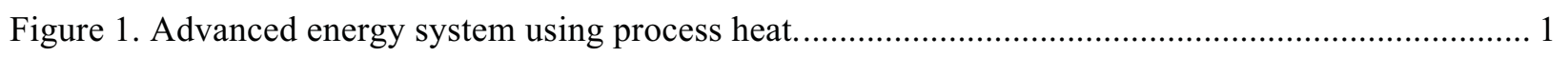

Figure 2. Schematic of compact heat exchanger construction........................................................ 2

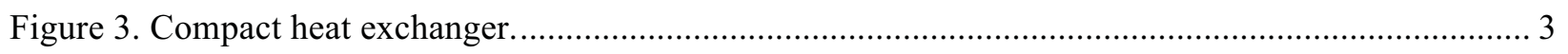

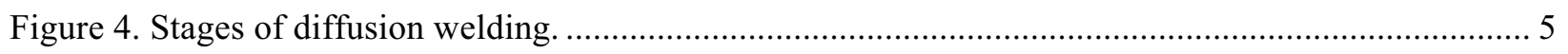

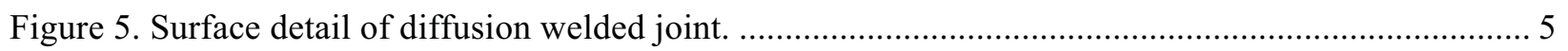

Figure 6. (a) Vacuum hot press at Oregon State University, used for diffusion welding of $2 \times 2$ inch stacks for the INL programs; (b) stack of sheet material after welding, showing

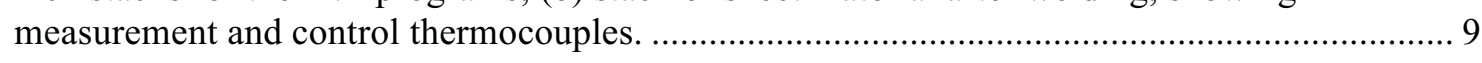

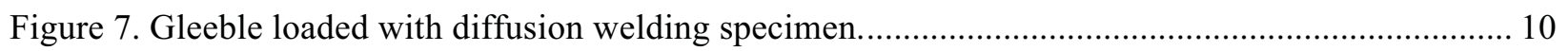

Figure 8. Gleeble principle of operation: specimens are gripped in water-cooled copper jaws, heated by Joule heating and feedback from welded thermocouple....................................... 10

Figure 9. Records of Gleeble diffusion welding cycles. (Left) Stress over 3-hour weld time; (Right) stress and stroke at beginning of weld. 
Figure 10. (a) Alloy $\mathrm{N}$ base metal with Alloy $\mathrm{N}$ inserted sheets, diffusion weld in progress in the Gleeble; (b) same weld completed; (c) Alloy $800 \mathrm{H}$ weld with nickel foil interlayer.

Figure 11. Haynes Alloy N slabs form billets used in the present work.................................................. 16

Figure 12. As-received microstructure of Alloy N 0.041 inch sheet. ........................................................ 17

Figure 13. Surface profiles (area approximately 4.4 x $4.6 \mathrm{~mm}$, color coded for surface height in $\mu \mathrm{m}$ ) for Alloy $800 \mathrm{H}$ material (a) as received; (b) after processing with double-acting sander through 240 grit and polishing with Scotch-brite abrasive pad; (c) metallographic 600-grit surface for comparison.

Figure 14. Multilayer $800 \mathrm{H}$ diffusion weld after tensile testing ( 3 of 9 layers of sheet material shown) showing effects of surface roughness, including reduced tensile strength. 20

Figure 15. Surface finish, Alloy 6170.062 in. sheet, as received......................................................... 20

Figure 16. Surface finish, Alloy $800 \mathrm{H} 0.062$ in. sheet, as received....................................................... 21

Figure 17. Surface finish, Alloy N 0.041 in. sheet, as received........................................................... 21

Figure 18. Surface finish, Alloy N 0.041 in. sheet, after vendor surface finishing. ................................ 22

Figure 19. 1-inch diameter Gleeble diffusion welded joint. .................................................................. 23

Figure 20. Nine sheets of Alloy $800 \mathrm{H}$ material joined to form simulated CHX stack. ........................... 23

Figure 21. Gleeble diffusion weld Y20315B, Alloy N, nickel-plated, as welded. ................................. 24

Figure 22. Weld Y10510, as welded, 1 in. length specimens from slab material. Alignment is

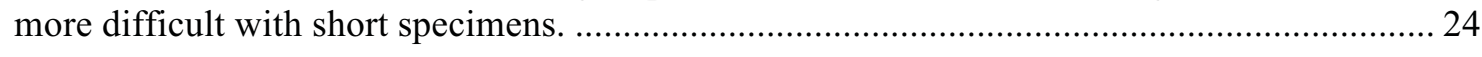

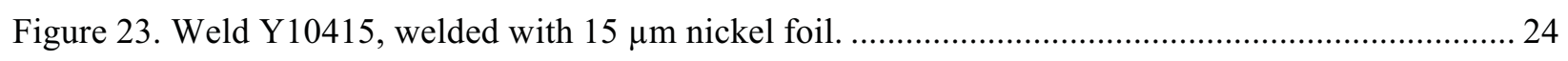

Figure 24. EDM method for obtaining bar stock from plate. .......................................................... 25

Figure 25. Weld specimens for University of Wisconsin corrosion testing. .......................................... 27

Figure 26. Weld Y20314, sectioned for corrosion testing. Center three pieces are corrosion coupons, outer slices reserved for as-welded metallography.

Figure 27. Corrosion specimen from weld Y20314 showing two layers of Alloy N sheet material between Alloy $\mathrm{N}$ base material. As-ground, 600 grit. ............................................................ 28

Figure 28. Coupons of Alloy $\mathrm{N}$ for corrosion testing; may be suspended partially immersed in salt

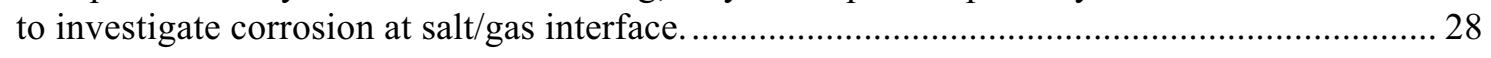

Figure 29. Schematic view of corrosion testing at the University of Wisconsin................................... 29

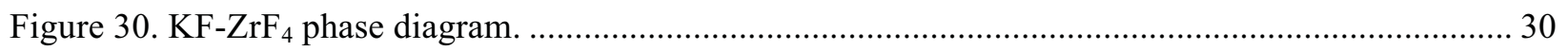

Figure 31. Incomplete (top) and complete (bottom) disappearance of the nickel foil interface in Weld Y10127 in Alloy 242. Marks indicate spots for EDS analysis. ..................................... 34

Figure 32. Composition profiles in less complete (more distinct) and more complete (less distinct) weld areas of Weld Y10127 in Alloy 242 shown in Figure 30 ............................................. 35

Figure 33. Weld in Alloy 242 bar showing different diffusion characteristics, depending on crystal orientation. 36

Figure 34. Weld Y10415 in Alloy N; $15 \mu \mathrm{m}$ foil layer is visible at weld line. 37

Figure 35. Weld Y10415 in Alloy N with EBSD and SE images superimposed to show grain growth across interface, which has essentially disappeared. 
Figure 36. Pulled tensile specimen Y10608. Fracture was near weld line but not coplanar with weld interface.

Figure 37. Correlation between calculated and experimental compositional gradients in Alloy N diffusion weld with $15 \mu \mathrm{m}$ nickel foil interlayer. 39

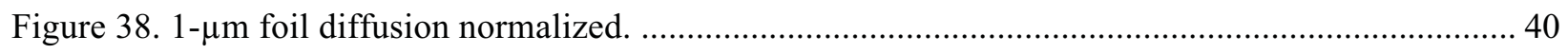

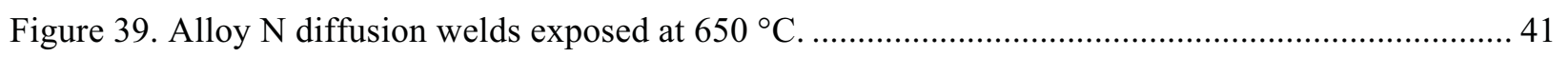

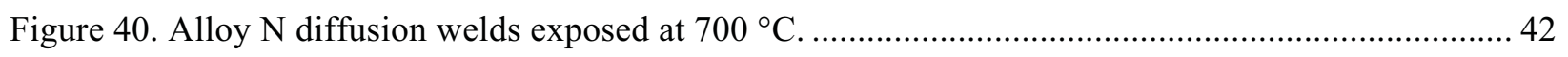

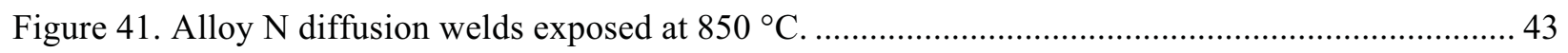

Figure 42. Base material from billet; sheet material from 0.041 in. wrought material............................. 44

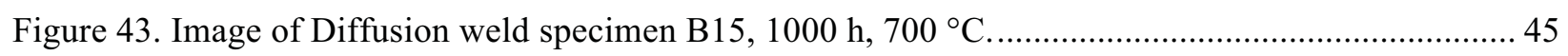

Figure 44. Diffusion weld specimen B15, 1000 h, $700{ }^{\circ} \mathrm{C}$. Magnification is similar to Figure 43, a different area of the same specimen..

Figure 45. Diffusion weld specimen A15 after 1000 hours at $850{ }^{\circ} \mathrm{C}$. Crack is unbonded area at

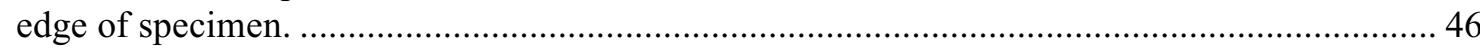

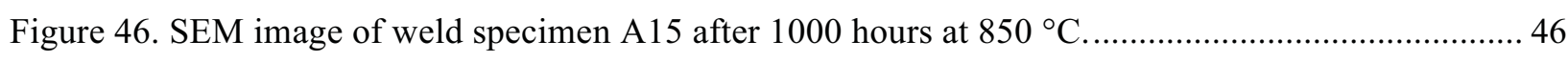

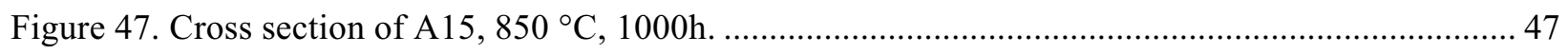

Figure 48. Cross section of $\mathrm{A} 15,850^{\circ} \mathrm{C}, 1000 \mathrm{~h}$, showing elemental changes with corrosion................ 47

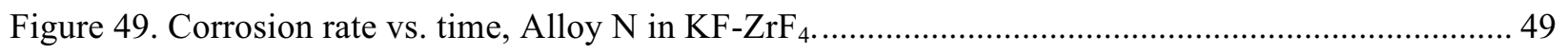

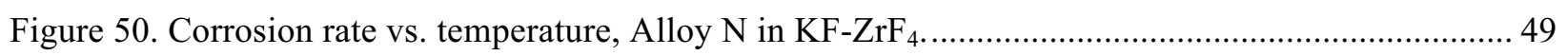

Figure 51. Alloy $800 \mathrm{H}$ stacks, 0.062 in. material with 0.5 in. end caps. ............................................. 55

Figure 52. Tensile bar and micrography specimens from diffusion welded stacks, 2.1 in. on a side......... 55 


\section{TABLES}

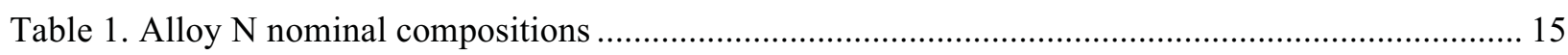

Table 2. Compositions of Alloy $\mathrm{N}$ materials used in the present work. .................................................... 16

Table 3. Composition of Alloy 242 material used in the present work. ................................................. 17

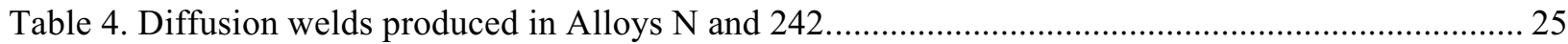

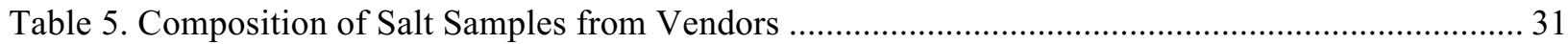

Table 6. Exposure Conditions, $\mathrm{KF}-\mathrm{ZrF}_{4}$ Corrosion of Alloy N Sheet and Welds .................................. 31

Table 7. Nominal composition comparison between Alloys N and 242............................................ 33

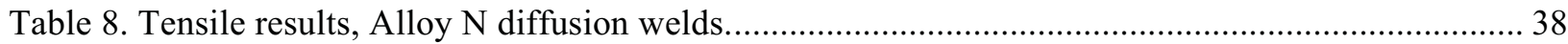

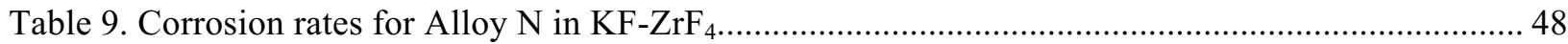




\section{Diffusion Welding of Alloys for Molten Salt Service - Status Report}

\section{INTRODUCTION}

The work presented herein is concerned with secondary heat exchanger development for molten salt service, (Haubenreich \& Engel, February 1970), presently under consideration for the Advanced High Temperature Reactor (AHTR). This work is an outgrowth of recent work done under the Next Generation Nuclear Plant (NGNP) Project; what the two reactor systems have in common is an inherently safe nuclear plant with a high outlet temperature that is useful for process heat as well as more conventional power generation.

The NGNP program was tasked with investigating the application of a new generation of nuclear power plants to a variety of energy needs (NGNP, 2009), (Park, Patterson, Maio, \& Sabharwall, 2009). One baseline reactor design for this program is a high temperature, gas-cooled reactor (HTGR), which provides many options for energy use. These might include the conventional Rankine cycle (steam turbine) generation of electricity, but also other methods such as Brayton cycle (gas turbine) electrical generation and the direct use of the high temperatures characteristic of HTGR output for process heat in the chemical industry as shown in Figure 1. Such process heat is currently generated by burning fossil fuels, and is a major contributor to the carbon footprint of the chemical and petrochemical industries.

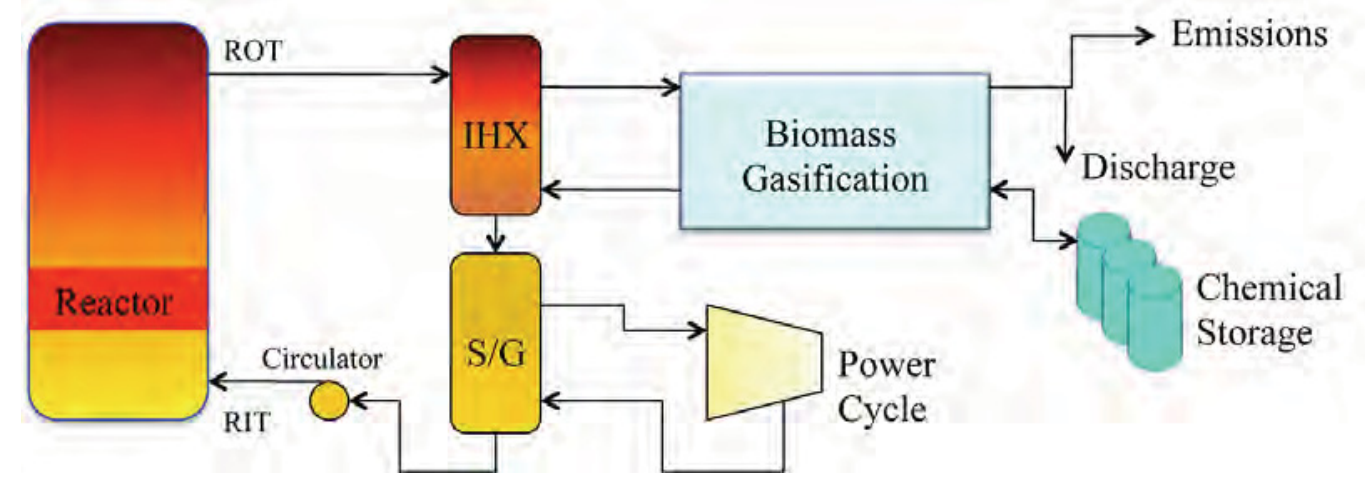

Figure 1. Advanced energy system using process heat.

The HTGR, based on graphite fuel elements, can produce very high output temperatures, ideally $900{ }^{\circ} \mathrm{C}$ or even greater, which has significant energy advantages. Such temperatures are at the frontiers of materials limitations. They are at the upper end of the performance envelope of the metallic materials for which robust construction codes exist; they are within the realm of ceramic materials, the fabrication and joining of which, on the scale of large energy systems, are at an earlier stage of development. A considerable amount of work was done in the diffusion welding of materials of interest for HTGR service with such alloys as 617 and 800H (Mizia, Clark, Galzoff, Lister, \& Trowbridge, December 2011), (Mizia, Clark, Glazoff, Lister, \& Trowbridge, 2011).

The AHTR output temperature is materials limited and projected at about $700{ }^{\circ} \mathrm{C}$ (LeBlanc, 2010). A different set of alloys, such as Alloy $\mathrm{N}$ and 242, are needed to handle molten salts at this temperature. The diffusion welding development work described herein builds on techniques developed during the NGNP work, as applied to these alloys. Dissimilar metal welding is also an issue, since alloys suitable for salt service are generally not suited for service in gaseous oxidizing environments, and vice versa, and welding is required for the Class I boundaries in these systems as identified in relevant ASME codes. 


\section{HEAT EXCHANGERS}

Heat exchangers are required for transferring heat from the primary reactor coolant loop to process loops; the two loops generally need to be separated for radiological reasons. Heat exchangers come in many configurations, but a promising design examined here is the compact heat exchanger or $\mathrm{CHX}-\mathrm{a}$ plate-type heat exchanger in which many relatively thin layers of material containing channels for fluid flow are sandwiched together in an arrangement that provides for efficient countercurrent flow as shown in Figure 2 (Mylavarapu, Sun, Christensen, Unocic, Glosup, \& Patterson, 2011), (Mylavarapu, 2011). The favorable fluid dynamics of such heat exchangers, along with their small size and modularity, makes them attractive as relatively low-cost, robust alternatives to more conventional designs. The particular configuration shown here is also called a printed circuit heat exchanger (PCHE) because the channels are typically formed by a photolithography and etching process similar to those used for electronic printed circuit boards.
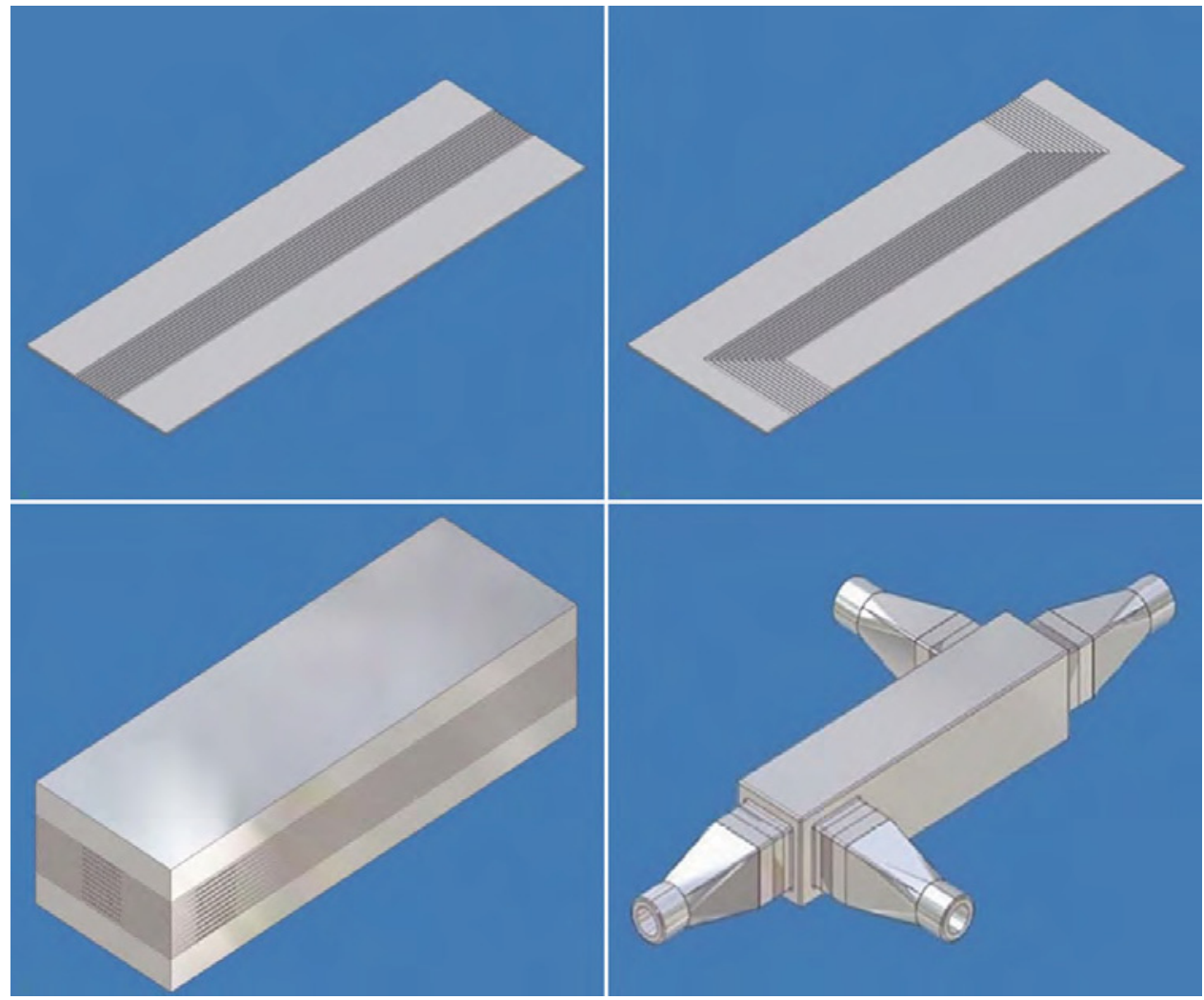

Figure 2. Schematic of compact heat exchanger construction.

Figure 3 (Mylavarapu, Sun, Christensen, Unocic, Glosup, \& Patterson, 2011), (Mylavarapu, 2011) shows an actual PCHE assembled for testing in a helium loop at $900{ }^{\circ} \mathrm{C}$. An actual large-scale energy application might be expected to use many such units assembled in series and/or parallel to achieve the needed heat transfer capacity. 


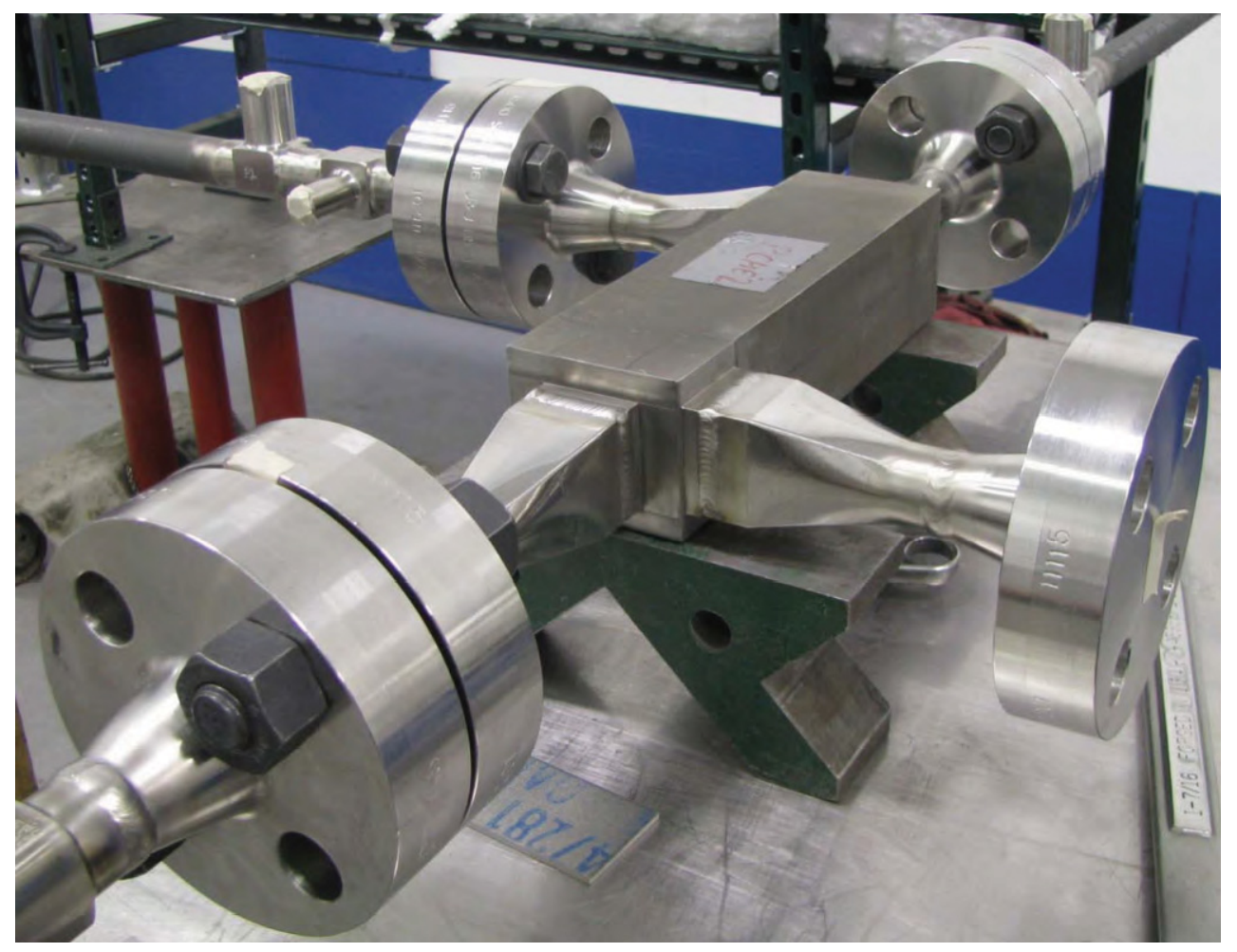

Figure 3. Compact heat exchanger.

The materials from which heat exchangers and connecting pipes are made will vary with the energybearing fluids being used. Energy systems using molten salt as a heat transfer medium (or as a carrier for nuclear fuels, such as the AHTR), require a somewhat different set of materials than energy systems using other media such as steam, water, or gases. These materials have their own weldability challenges, and, in actual systems, will need to be joined to other alloys in dissimilar metal welds. For example, the heat in the molten salt may need to be transferred to a helium loop for process heat or to a steam generator, and these environments have different material performance requirements.

CHX's can be made by a number of processes or by a combination of processes. These might include casting, additive manufacturing (the addition of controlled amounts of material, such as by the laser melting of deposited powder or wire or the ultrasonic welding of multiple sheets), and precisely controlled conventional welding such as laser, electron beam, or arc welding. Diffusion welding, a solid state welding process carried out at high temperatures, is especially suitable for fabricating PCHE-type CHX's. This report addresses the applicability of this process to such energy subsystems.

Regardless of the CHX fabrication process, however, the resulting component must be designed to be welded into the larger frameworks of advanced energy systems. The manufacture of energy systems, particularly energy systems aiming to maximize thermodynamic efficiency by operating at the limits of material performance, typically requires welding. Weldability, including the long-term performance of welded structures, is a key aspect of material selection. 


\section{MOLTEN SALT SERVICE}

Molten salt is a severe environment for alloys. During the early Aircraft Nuclear Propulsion program (LeBlanc, 2010), which proposed using salt as a heat transfer medium, it was found that levels of chromium traditionally used for oxidation resistance in high temperature service showed accelerated corrosion in molten salt. The eventual solution was a nickel-based alloy originally developed at Oak Ridge National Laboratory and eventually produced by Haynes as Hastelloy N, with chromium reduced to about $8 \%$, and a significant addition of molybdenum (16\%) (White, 2010), (Ren, Muralidharan, Wilson, \& Holcomb, July 17-21, 2011), (Sessions \& Lundy, 1969), (Wilson, 2010). 


\section{DIFFUSION WELDING}

Diffusion welding is an old welding process with wide application in many industries (American Welding Society, 2007). Relatively close mating surfaces, held together under moderate pressure and at high temperatures, typically $>0.6 \mathrm{~T}_{\mathrm{m}}$ (melting temperature on an absolute temperature scale), will eventually, through diffusion processes, eliminate surface contaminants and oxides and reduce their surface asperities to isolated pores along the bond line, which are gradually filled. Grain boundary migration and grain growth dynamics can eventually produce a joint that is microstructurally indistinguishable from the base materials, as shown in Figure 4.

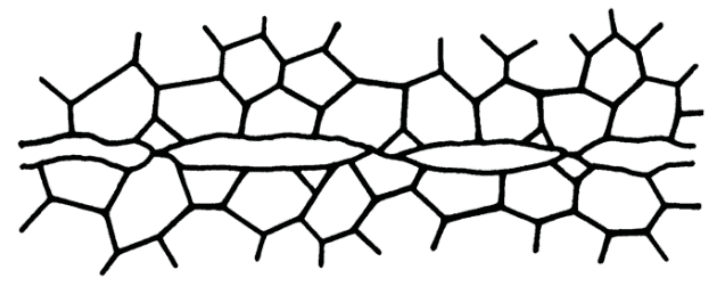

Initial Asperity Contact

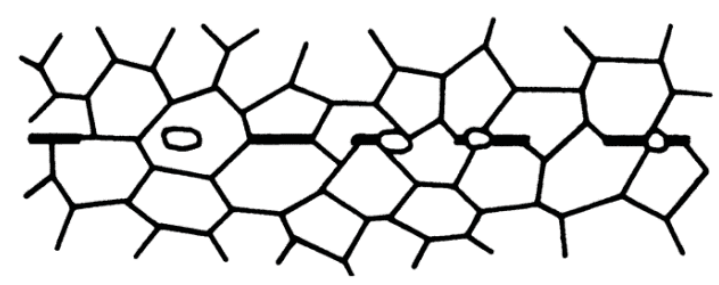

(B) Second Stage-Grain Boundary Migration and Pore Elimination

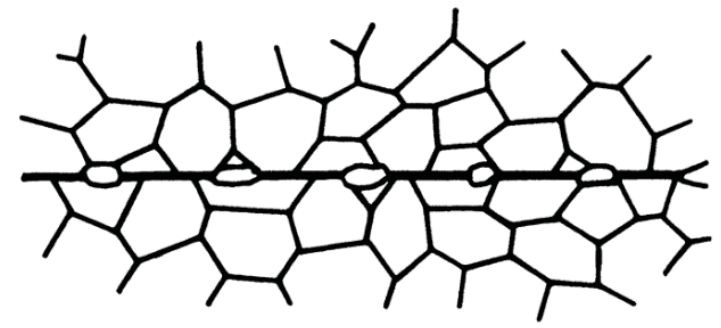

(A) First Stage-Deformation and Interfacial Boundary Formation

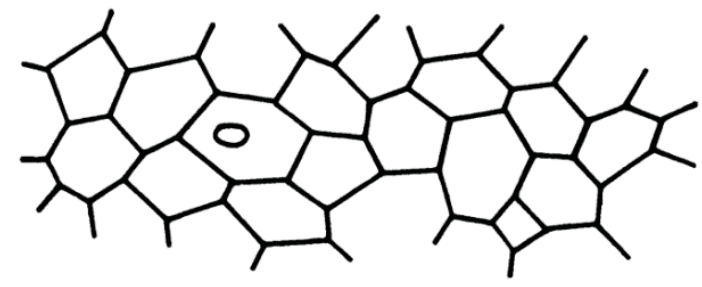

(C) Third Stage—Volume Diffusion Pore Elimination

Figure 4. Stages of diffusion welding.

Even polished surfaces are not smooth on a very fine scale; the irregular contacts that occur when they are brought together for diffusion welding are known as asperities. As can be seen in Figure 5, in addition to the surface roughness of the metal itself, there are oxide and contaminant layers that still form a barrier to diffusion that takes time, temperature, and pressure to overcome.

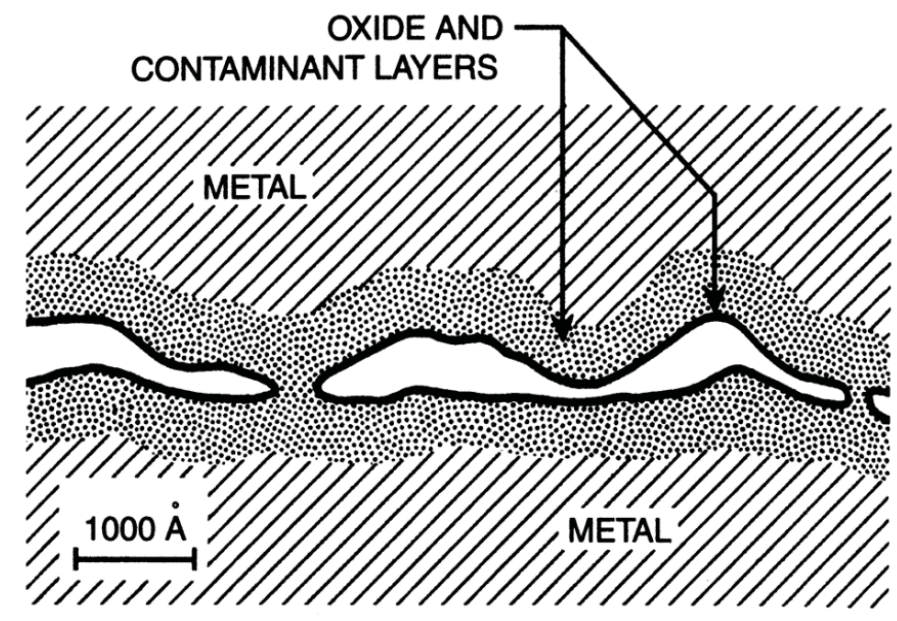

Figure 5. Surface detail of diffusion welded joint. 
Diffusion welding is usually carried out in vacuum, to avoid excessive oxidation. The needed pressure can be applied mechanically or by dead weight loading, or the assembly to be welded can be canned and the pressure applied via hot isostatic pressing (HIP). Typically, the pressures needed are modest, particularly for intricate structures such as heat exchangers. Creep must therefore be avoided on a macro scale. On the other hand, the pressure must be evenly applied, sometimes over large areas and through many layers of material.

Surface preparation is important in diffusion welding. Plated surfaces are sometimes used for oxidation protection during heating, and an interlayer, sometimes referred to as filler metal, typically made from a metal foil, is sometimes used to improve contact by local deformation and to enhance diffusion. Surface treatment with other easily diffusible materials such as boron can also enhance the kinetics of the process.

\subsection{Diffusion Welding Variables}

A successful diffusion weld is controlled by a number of variables. For example, the intrinsic variable of material type is very important in determining the primary process variables of time, temperature, pressure, and surface preparation. These variables are discussed in this section.

\subsubsection{Material}

The thermodynamics of the material or materials involved will set the required temperature and time for a diffusion joint to form. A crucial aspect of this is the behavior of the material with respect to its own oxides. Some elements, like copper and titanium, have a high solubility for their own oxide, and are relatively easy to diffusion weld for that reason. Others, such as nickel, do not strongly form stable oxides. This is not true for chromium oxides, which form a protective layer in many alloys of interest for high-temperature service, such as stainless steel and many nickel alloys, which typically have chromium contents around $20 \%$. Except in very specialized high vacuum systems, it is impossible to prevent a thin layer of chromium oxide from forming on these materials in air at ambient temperature, and, as diffusion welding temperatures are approached, the residual water vapor and oxygen and controlled atmosphere furnaces can accelerate this process.

The alloys under study here were designed for high temperature service, so they have high strengths at high temperatures and contain approximately $20 \%$ chromium, designed to develop protective oxides. They are thus somewhat more challenging to diffusion weld than other alloys because deformation is lower at a given temperature and pressure. Many austenitic stainless steels with similar chromium levels are commonly diffusion welded, so the basic technology is promising even if some adaptation is needed.

\subsubsection{Time}

Required diffusion welding time is traditionally a matter of trial and error; recent work with the Gleeble system (described below) has suggested the time of about three hours at $1150{ }^{\circ} \mathrm{C}$ produces full grain growth across the interface. The thermodynamic and kinetic modeling, described below, indicate that, in terms of diffusion alone, this process occurs more quickly than that. Other processes, however, also consume time, such as the closing of the pores representing the spaces between the original asperity contacts, or the dissolution of oxide layers.

\subsubsection{Temperature}

Temperature is typically normalized to the melting temperature of the material, with diffusion welding occurring in the same range as re-crystallization, about 0.6 to $0.7 \mathrm{~T}_{\mathrm{m}}$ on an absolute temperature scale. As noted below, however, in the case of high-temperature alloys, the temperature may need to be as high as 0.8 to $0.9 \mathrm{~T}_{\mathrm{m}}$, owing to the increased creep resistance of these materials. 


\subsubsection{Pressure}

A certain amount of compressive stress is needed to produce intimate contact between opposing asperities. The upper bound for this pressure is where macroscopic creep occurs, which can be fairly accurately predicted from established creep curves for the materials in question. Pressure can be applied in several ways. In the Gleeble method, which is the primary process described here, pressure is applied hydraulically. In the typical vacuum hot press, pressure can also be applied hydraulically, pneumatically, or by dead weight. HIP is sometimes used to diffusion bond large parts; it requires the canning of the assembly in a thin, hermetically sealed sheet metal container to keep the high-pressure gas (of the order of $10,000 \mathrm{psi}$ ) from penetrating into the diffusion weld interface.

Applying the appropriate pressure can become difficult for high-temperature alloys, since they are generally designed for strength and high temperature. For example, austenitic stainless steels are seldom used in service above $600{ }^{\circ} \mathrm{C}$, and the common rule of thumb for the diffusion welding of them $1000{ }^{\circ} \mathrm{C}$ for 1000 minutes (Miller, 2011) - is adequate because the diffusion welding temperature is considerably above the service temperature and relatively low stresses will bring about full contact. In the case of Alloy 617, however, which is contemplated for service use at 900 to $950{ }^{\circ} \mathrm{C}$, the asperities still have substantial strength at these very high temperatures, and even higher welding temperatures and/or pressures may be needed.

\subsubsection{Surface Preparation}

A common technique for protecting the surface is a thin layer of electroplated or vacuum deposited material such as pure nickel. With appropriate polarization of the plating bath or sputter cleaning in the vacuum deposition system, a clean surface is available from the start, and the nickel layer, typically on the order of $1 \mu \mathrm{m}$ thick, protects the underlying chromium bearing surface while it is being heated. The thin layer of nickel rapidly diffuses away.

Surface preparation was identified early as an important factor in the diffusion welding of the alloys of interest in this program as described in detail below.

\subsubsection{Filler Material}

Diffusion welding is usually done without filler material beyond plating or surface treatments, but fillers can be used to achieve the goal of a completely uniform joint, indistinguishable from the base metal. The advantage of using a filler is that it serves as a buffer to promote conformance of the mating surfaces, and might serve as a better sink for surface contamination and oxides than the base materials.

In high temperature service, the existence of a different material at the interface could have both advantages and disadvantages. Typically one would prefer homogeneous material, but layering different materials is an option that might prove useful for multiple heat transfer environments.

Some of the present work was done with nickel foils ranging from 5 to $15 \mu \mathrm{m}$ thick. Interestingly, this allows a quantitative measurement of diffusion rates and sets up a simple geometry for such calculations that is easy to describe with thermodynamic models, as discussed below.

\subsubsection{Parameter Trade-offs}

Most welding processes have trade-offs. For example, in arc welding, high currents and deposition rates lead to high productivity in a tonnage sense but may lead to other problems because of weld defects or undesirable microstructures. The same applies to diffusion welding, and one of the goals of the present program is to identify some of these.

The energy systems under consideration here are designed for long service at high temperatures, sometimes under difficult corrosion and nuclear material damage conditions. For example, one would expect a weld in Alloy $\mathrm{N}$ to perform for many thousands of hours at $700{ }^{\circ} \mathrm{C}$ while exposed to molten salts and perhaps high neutron fluxes. The diffusion welding temperatures used experimentally here were 
typically $1150{ }^{\circ} \mathrm{C}$, which allowed asperities to be eliminated and complete welding (grain growth across the joints) to occur in reasonable times at pressures around $5 \mathrm{MPa}$ (low welding pressures would be needed to avoid distorting the fine-scale structures of PCHE's at high temperatures). Diffusion welding work in other nickel alloys, such as 690, has also been carried out at temperatures between 800 and $1025^{\circ} \mathrm{C}$ and pressures around $50 \mathrm{MPa}$ (Hochanadel, et al., 2005).

A further issue involves the effect of long holds at high temperatures on the phase composition and stability of nickel alloys; this is a complex field in which thermodynamic modeling may play a role in further development of optimal diffusion welding parameters.

\subsection{Diffusion Welding Methods}

A number of methods are used to apply pressure and heat under a controlled atmosphere. The choice depends mainly on production needs and component size. Since the pressures are modest $(<50 \mathrm{MPa})$ in most diffusion welding, temperatures are often the limiting factor in equipment design.

\subsubsection{Hot Press}

A relatively simple vacuum hot press is a standard method for diffusion welding. The apparatus at Oregon State University, used for some of the diffusion welding in INL programs, is shown in Figure 6. Furnace elements in the blue canister (graphite in this case) can heat samples up to $1200{ }^{\circ} \mathrm{C}$. Samples to be welded are arranged between the press elements, often with graphite spacer blocks (coated with boron carbide, $\mathrm{B}_{4} \mathrm{C}$, to avoid unintentional bonding). The canister containing the heating elements is slid down onto a vacuum seal, and the high vacuum pumps are actuated.

A variation of hot pressing can be achieved with a standard vacuum press and dead weights to apply the loads for diffusion welding. Since large vacuum furnaces are available (meters in dimension), this might be an appropriate method for making assemblies such as compact heat exchangers, provided the requisite loads for higher temperature materials can be applied in this way. 

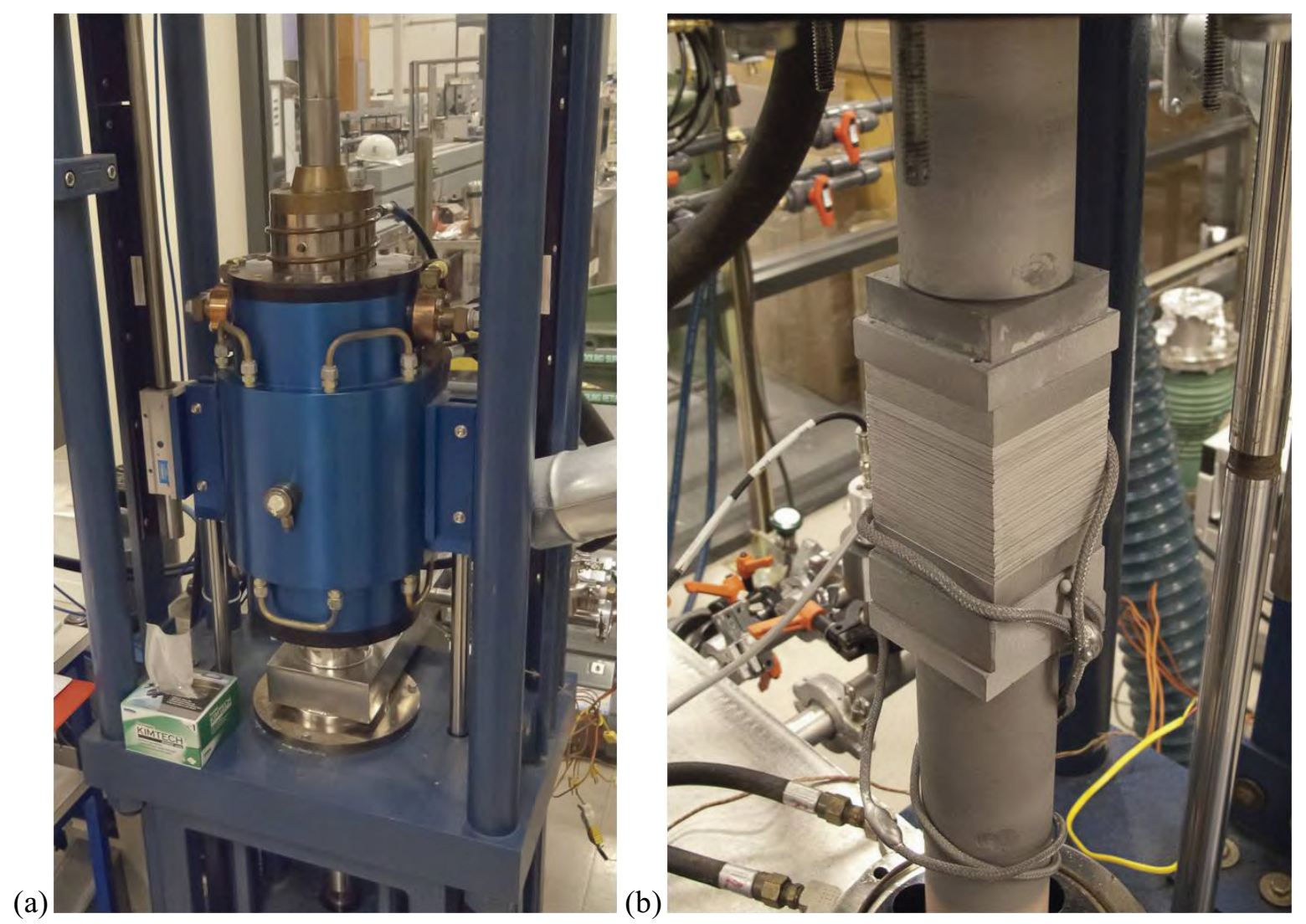

Figure 6. (a) Vacuum hot press at Oregon State University, used for diffusion welding of $2 \times 2$ inch stacks for the INL programs; (b) stack of sheet material after welding, showing measurement and control thermocouples.

\subsubsection{Hot Isostatic Press}

The HIP applies high pressures and temperatures and is often used for consolidating powder material and pressing material with porosity to densify it. It can be used for diffusion welding if the assembly to be welded is canned so that the pressure is applied to the outside of the assembly rather than penetrating the joints to be welded. Quite large sizes are possible. Typically the pressure vessel containing the high pressure gases is kept cold (to maintain strength) by heat shields between the heating elements and the vessel wall. Again, since the pressures in diffusion welding are modest, the high pressure capabilities of commercial HIPs are typically not needed, and one can conceive of a purpose-built HIP for diffusion welding that might be more economical than those required to contain very high pressures at temperature.

\subsubsection{Dead Weight Loading}

Pressure for diffusion welding can be applied by dead weight loading in a furnace, perhaps the simplest method. With this, or any loading method, the balance between avoiding macro creep, which would distort a complex part, yet achieving full deformation of asperities, would take considerable experimentation and expertise; methods are considered proprietary and are sometimes not mentioned in literature reporting final properties (Li, Smith, Kinimont, \& Dewson, 2009). Any loading of complex structures such as CHX's will need to be carefully controlled.

\subsubsection{Gleeble}

Most of the diffusion welding reported here was done using the INL Gleeble ${ }^{\circledR}$ shown in Figure 7. The Gleeble is well known for its versatility in many welding metallurgy studies, particularly the rapid 
thermal cycling and loading typical of fusion welding processes. It also turns out to be well equipped for diffusion welding, operating at the lower end of its force capabilities and the upper end of its sustained high temperature capabilities (Hochanadel, et al., 2005). It is a servo-hydraulic machine capable of applying heavy loads at fast stroke (20-ton load cell, $\sim 1 \mathrm{~m} / \mathrm{s}$ stroke rate), and heats specimens by Joule heating as shown in Figure 8. It contains an integrated vacuum system; its vacuum level of mid- $10^{-5}$ torr is not as high as some of the furnaces used for diffusion welding because of the compromises (sliding seals, etc.) needed for most Gleeble work, but proved sufficient for the present work.

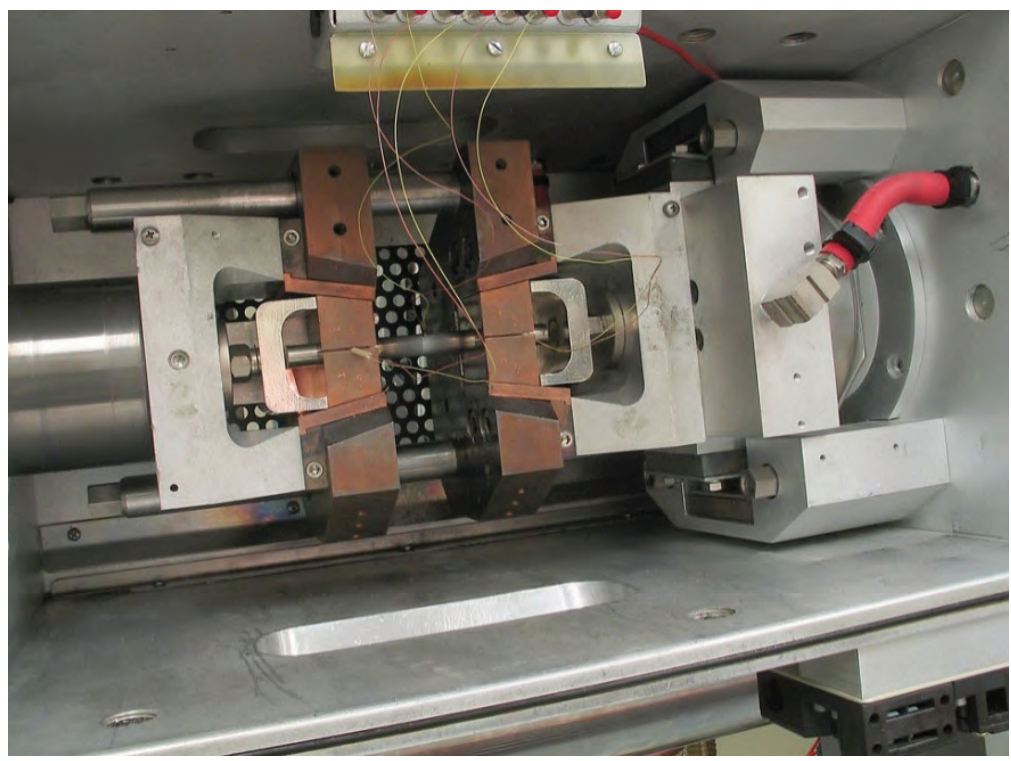

Figure 7. Gleeble loaded with diffusion welding specimen.

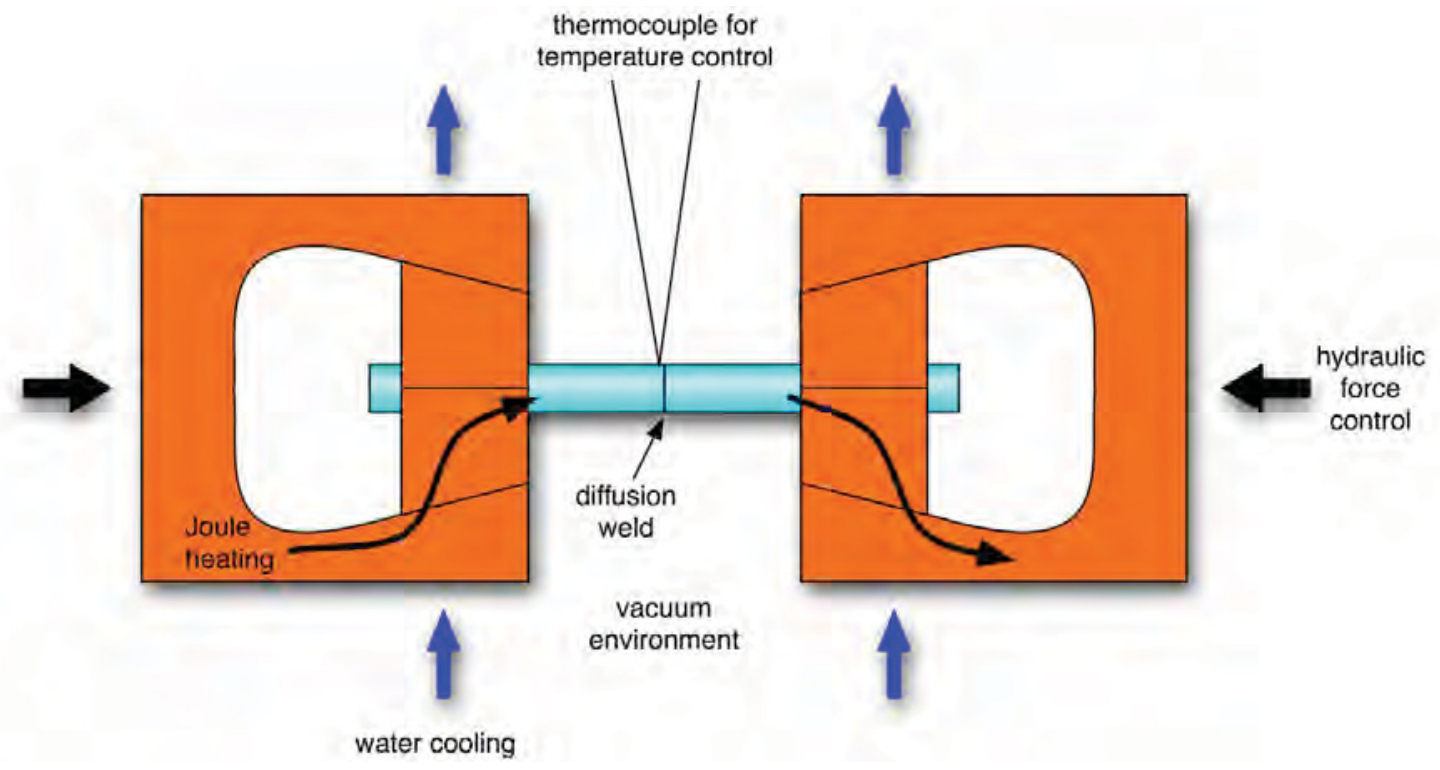

Figure 8. Gleeble principle of operation: specimens are gripped in water-cooled copper jaws, heated by Joule heating and feedback from welded thermocouple.

Diffusion welding requires nothing like these maximal conditions, and it was considered desirable not to run the hydraulic system, for the many hours diffusion welding sometimes requires. The auxiliary air ram system, normally used in positioning the jaws and applying an initial holding force to specimens, was 
used for the diffusion weld loading. Although the air ram is not under automatic feedback control, it was found that loading is stable and small manual adjustments over the several hours of the diffusion weld cycle can keep specimen loading reasonably constant. It was also found that a short, high load applied hydraulically at the beginning of the cycle (up to $40 \mathrm{MPa}, \sim 5,800 \mathrm{psi}$, or $\sim 1,100 \mathrm{lbf}$ for the typical $0.5 \mathrm{in}$. diameter specimens used) tended to seat the specimens and take care of slight misalignments. An example of a typical loading cycle is shown in Figure 9.

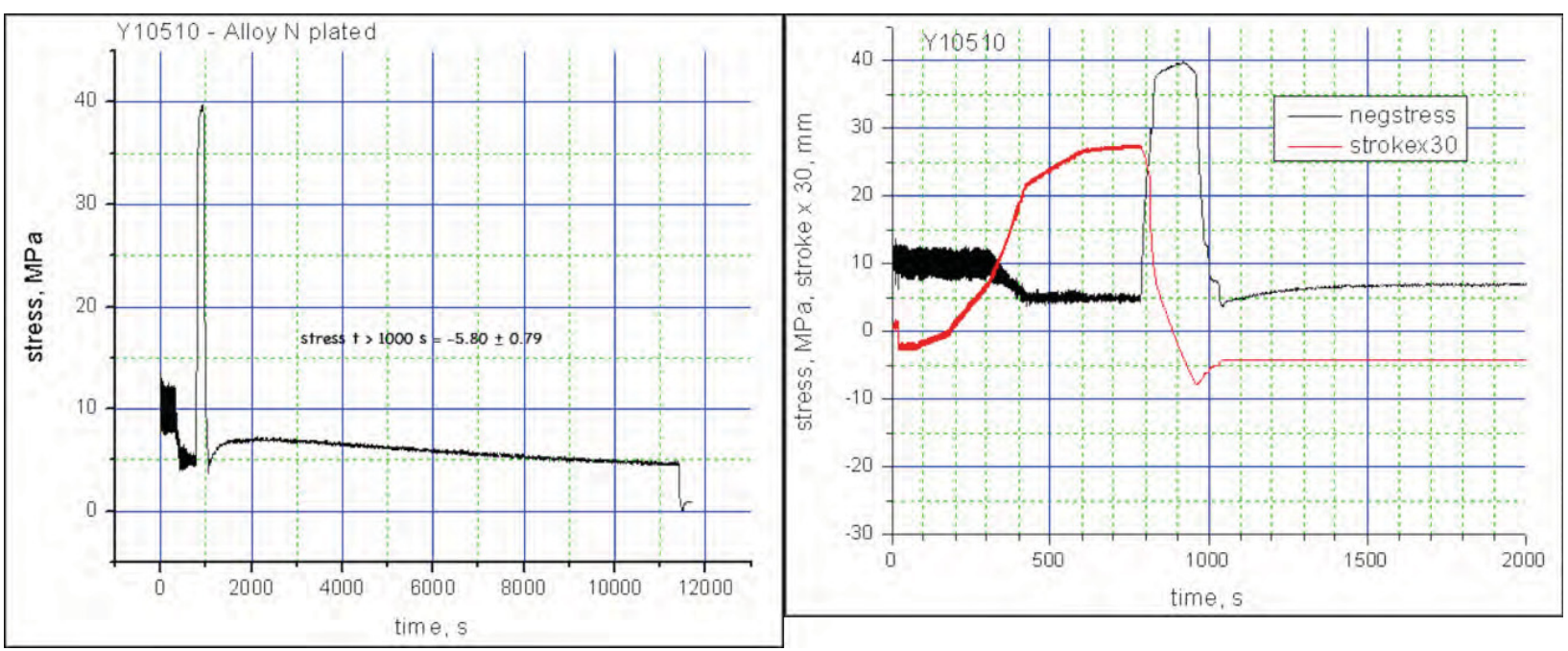

Figure 9. Records of Gleeble diffusion welding cycles. (Left) Stress over 3-hour weld time; (Right) stress and stroke at beginning of weld.

The Gleeble can produce a diffusion weld on a cycle time not too much longer than the actual heating, holding, and cooling times of the welding cycle. This is because of the convenience of preparing specimens of relatively simple geometry and being able to view the process. A control thermocouple is welded (by capacitor discharge welding) near the joint, the specimen in inserted in the jaws, the vacuum chamber evacuated, and the thermal cycle commenced. More thermocouples (the Gleeble can accommodate a total of 4) can be attached to monitor temperature gradients, as needed. A typical specimen after welding is shown in Figure 10. 
(a)

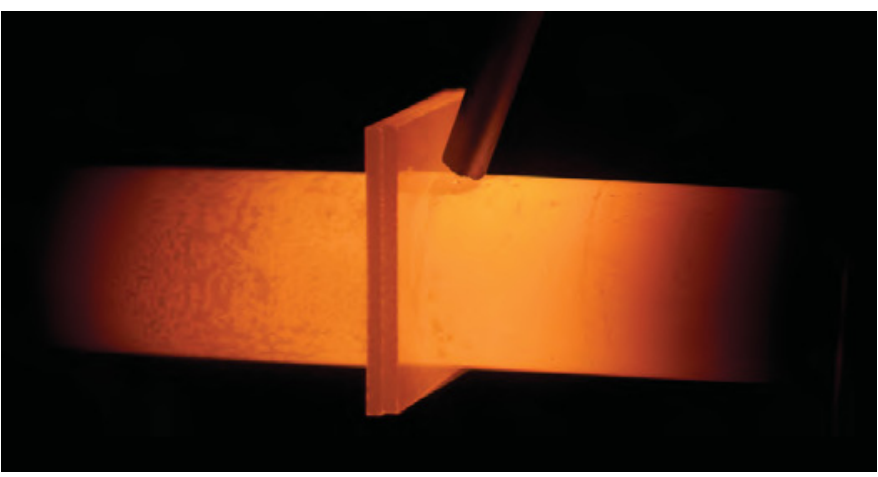

(b)

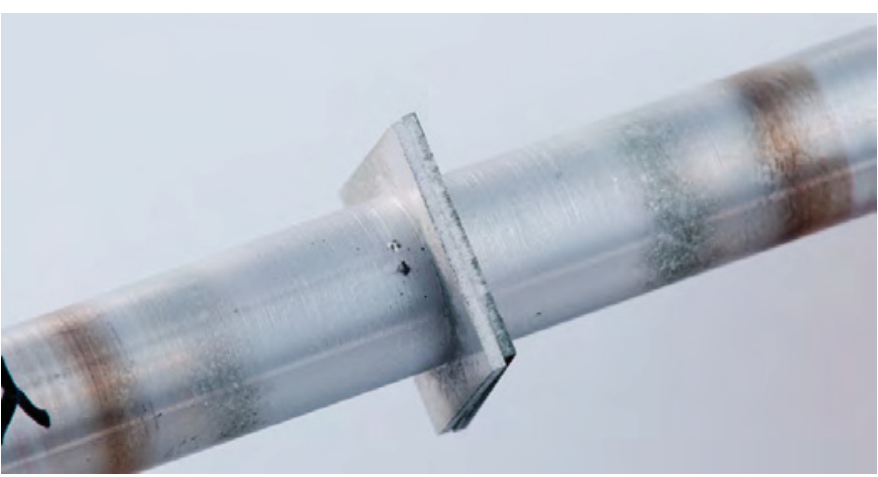

(c)

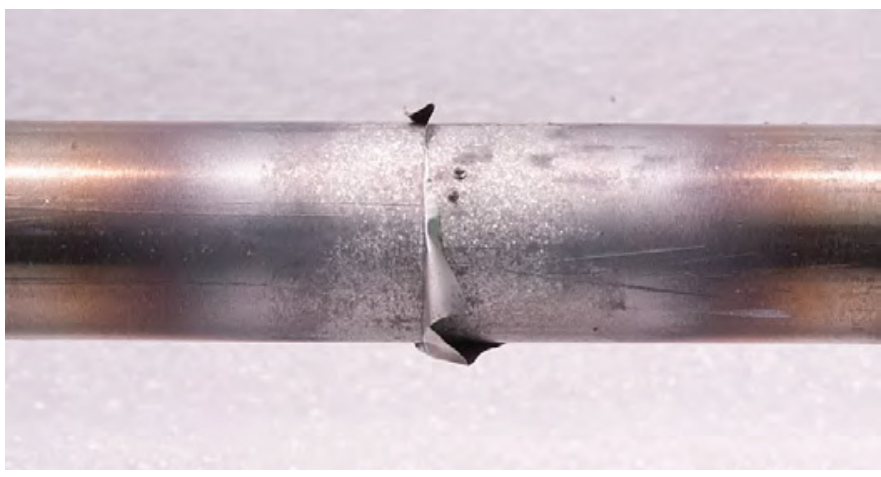

Figure 10. (a) Alloy $\mathrm{N}$ base metal with Alloy $\mathrm{N}$ inserted sheets, diffusion weld in progress in the Gleeble; (b) same weld completed; (c) Alloy $800 \mathrm{H}$ weld with nickel foil interlayer.

\subsection{Parameter Development}

Diffusion welding parameters developed for $800 \mathrm{H}$ and 617 materials in the NGNP program (Mizia, Clark, Galzoff, Lister, \& Trowbridge, December 2011) were transferred to the present Alloy N work, and for the most part seemed to work well. The temperature of $1150{ }^{\circ} \mathrm{C}$ for 3 hours with a pressure in the range of 3-7 $\mathrm{MPa}$ (400-1,000 psi, and a load of 80-200 lbf on a 0.5 in. diameter specimen) produced complete bonds with microstructural development across the interface.

During the welding of $800 \mathrm{H}$ and 617 materials, a loading technique was developed that compensated for any slight misalignment in the specimens and allowed most of the welding cycle to occur under the application of pneumatic rather than hydraulic pressure as shown in Figure 9(b). The process begins under hydraulic load control to maintain contact during heating. The stroke, as measured by a linear variable differential transformer, or LVDT, actually moves in a tensile direction as the specimen expands on heating. Once the temperature is stabilized at the welding temperature, the hydraulics are turned off and the Gleeble's pneumatic system applies a load. 
The parameter development, metallurgical, and modeling work reported here was done on the Gleeble. In general, compared with furnace methods, the Gleeble provides a faster turnaround with smaller specimens and a degree of observability during welding as shown in Figure 10(a). Figure 10(b) shows a completed weld containing two sheets of inserted material, and Figure 10(c) shows a completed weld with a nickel-foil interlayer.

Vacuum hot press diffusion welding performed as part of the present work and stacks of Alloy $800 \mathrm{H}$ material meant to approximate the geometry of compact heat exchangers are discussed below under the heading of further work. The size of these stacks is 2.1 inches on a side, a limit imposed by the size of the hot press used. This is an intermediate size between the large press or HIP, which would be used to fabricate actual heat exchanger modules, and the Gleeble, which has a practical upper limit of about 1 inch in diameter.

The Gleeble grips specimens in water-cooled jaws and applies thermal cycles by Joule heating using feedback from a thermocouple welded to the specimen, close to the diffusion joint (see Figure 4). There is thus a temperature gradient away from the joint that does not exist, for example, in furnace or HIP diffusion welding, and it might be expected to be steeper than that observed in vacuum hot press welding. Measurements with a second TC located $7 \mathrm{~mm}$ from the joint shows a temperature drop of about $20^{\circ} \mathrm{C}$. Since the diffusion distances involved are on the order of $200 \mu \mathrm{m}$, the temperature gradients are assumed to insignificant. In most cases, conditions directly at the bond line are of interest and the TC is a good record of this temperature history.

\subsection{Dissimilar Metal Joining}

Dissimilar metal joining has not been extensively evaluated thus far in this project. A few welds similar to the weld in Figure 10(a) have been made using Hastelloy X sheets between $800 \mathrm{H}$ bars. There is little difficulty in setting up and making such welds; one attractive aspect of diffusion welding is that different materials, which might have severe incompatibilities because of solidification mechanics (e.g., copper and aluminum, or copper and stainless steel), can be diffusion welded together.

The difficulty comes in the solid state reactions that occur during welding or in service (Dupont, Lippold, \& Kiser, 2009), (Totemeier, Tian, Clark, \& Simpson, 2005). Intermetallic compounds can form that are brittle and allow the joint to fracture with low energy; typically these can be predicted from phase diagrams. Differences in thermal expansion or response to corrosive environments can also cause failure in service. These considerations for similar alloys such as Alloy $\mathrm{N}$ and $800 \mathrm{H}$ or 617 may be muted, but there are still thermodynamic considerations. Second phases can embrittle a joint, either during the welding cycle or in service, or Kirkendall porosity can form, reducing strength, when diffusion fluxes are out of balance.

Rather than trying many combinations, this is a fertile area for the application of thermodynamic and kinetic first principles models such as Thermocalc and DICTRA (Shi \& Sundman, 2010), (Thermo-Calc, 2010), which are discussed below. 


\subsection{Ceramic/Metal Joining}

If dissimilar metals have certain problems, joining ceramic materials to metals is even more difficult, and have not been attempted thus far in the program. These materials are structurally very different (metallic vs. covalent bonding) and have very different lattice parameters and, typically, coefficients of thermal expansion.

Yet ceramics have unique properties of interest in high temperature energy systems: very high strength at high temperatures, resistance to creep, and resistance to oxidation (since they are typically oxides). Most (there are exceptions like $\mathrm{SiC}$ ) are electrical insulators, and hence not susceptible to easy joining experiments with the Gleeble. Some paths forward have been identified for further research as discussed below. 


\section{MATERIALS}

\subsection{Haynes Alloy $\mathbf{N}$}

Haynes Alloy N was developed in the 1950s for molten salt service in the Aircraft Nuclear Propulsion program. Conventional high temperature alloys containing about $20 \%$ chromium proved susceptible to corrosion by the proposed molten salt heat transfer medium. It was successfully used in the ORNL Molten Salt Reactor Experiment in the 1960s. Some variations of Alloy N, for example, adding titanium, (McCoy, et al., 1970) were developed for easier weldability and better performance in the high radiation environments of reactors. Nominal compositions are shown in Table 1.

Table 1. Alloy N nominal compositions

\begin{tabular}{|ccc|}
\hline Element & Standard & Modified \\
\hline $\mathrm{Ni}$ & Bal. & Bal. \\
$\mathrm{Mo}$ & 16 & 12 \\
$\mathrm{Cr}$ & 7 & 7 \\
$\mathrm{Fe}$ & 4 & 0.5 \\
$\mathrm{Mn}$ & 0.5 & 0.2 \\
$\mathrm{Si}$ & 0.5 & 0.1 \\
$\mathrm{C}$ & 0.05 & 0.05 \\
$\mathrm{Ti}$ & - & 2 \\
$\mathrm{Re}$ & - & 0.01 \\
\hline
\end{tabular}

\subsubsection{Material Forms and Compositions}

Although about 200,000 pounds of Alloy N were used in the ORNL Molten Salt Reactor Experiment, only about 3,000 lb per year are currently made in various product forms (plate, wire, tubing, sheet), being rather specialized (and seemingly proprietary) in use (White, 2010). We were fortunate to be able to obtain two slabs (different heats) of Alloy N material, as shown in Figure 11. They are about $5 \times 18$ inches in size, and about 1 inch thick. They are slabs cut from the ends of billets, so the " $Z$ " rolling direction is through the 1 -inch dimension. We also purchased sheet stock ( $0.041 \mathrm{in}$. thick) from one of these heats. Compositions are shown in Table 2.

The slabs are not really intended for service in their current state of hot work, and relatively coarse microstructures can be seen in some of the micrographs included below, with fairly large molybdenumrich particles visible. These particles persist through further material breakdown and are also found in the 0.041 in. sheet material as shown in Figure 12. 

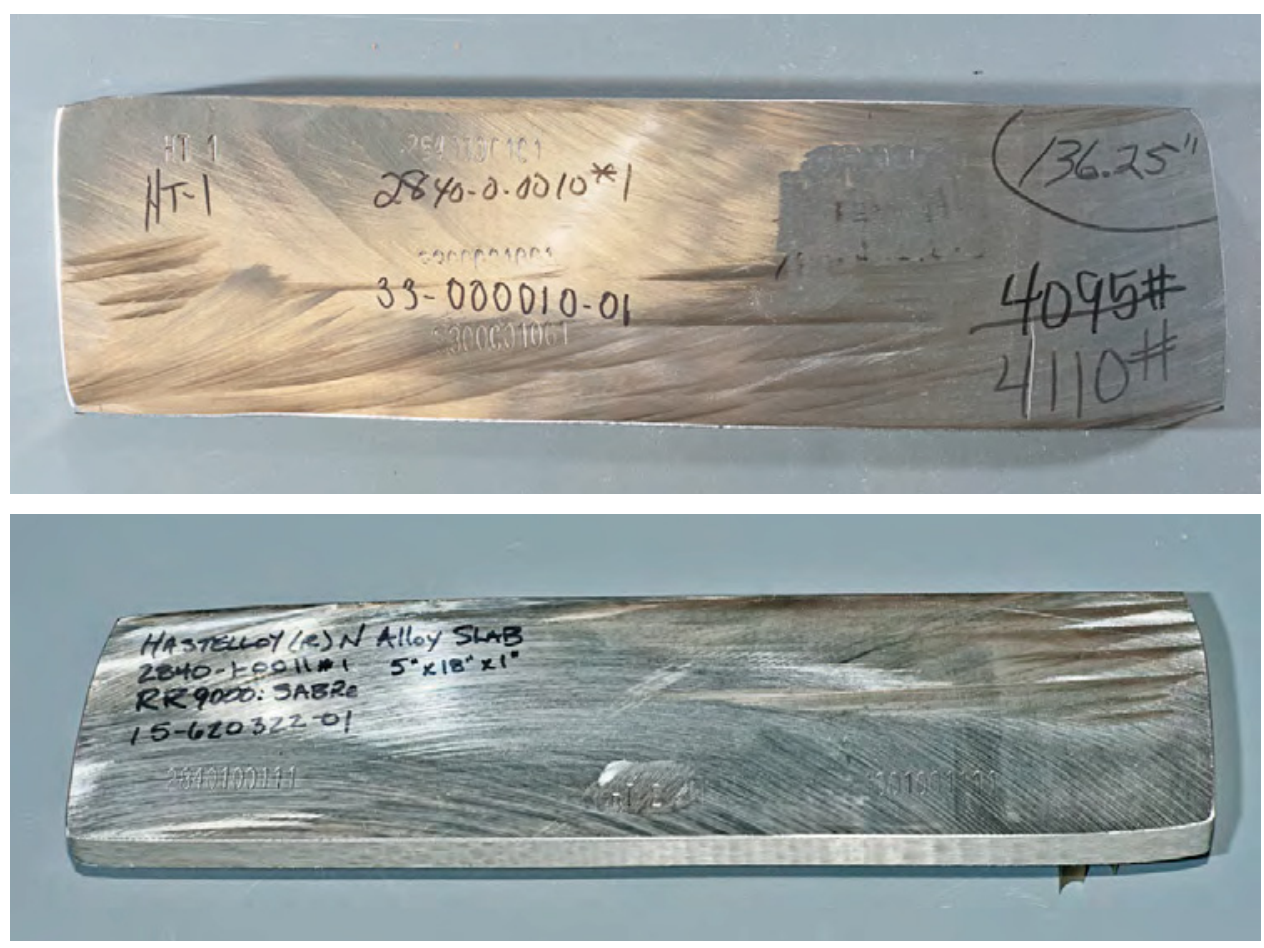

Figure 11. Haynes Alloy N slabs form billets used in the present work.

Table 2. Compositions of Alloy $\mathrm{N}$ materials used in the present work.

\begin{tabular}{|l|l|l|}
\hline \multicolumn{1}{|c|}{ Heat number } & \multicolumn{1}{|c|}{284010011} & \multicolumn{2}{c|}{284000010} \\
\hline Form & 0.041 in. sheet and butt end slab & Butt end slab (2 analyses supplied) \\
\hline $\mathrm{Ni}$ & $\mathrm{Bal}$ & 70.8799 \\
\hline $\mathrm{Cr}$ & 6.96 & 7.145 \\
\hline $\mathrm{Mo}$ & 16.91 & 16.8372 \\
\hline $\mathrm{Fe}$ & 4.24 & 4.1432 \\
\hline $\mathrm{C}$ & 0.060 & 0.06 \\
\hline $\mathrm{Si}$ & 0.27 & 0.3087 \\
\hline $\mathrm{Mn}$ & 0.51 & 0.4652 \\
\hline $\mathrm{P}$ & $<0.002$ & 0.004 \\
\hline $\mathrm{S}$ & $<0.002$ & $<0.002$ \\
\hline $\mathrm{B}$ & 0.006 & 0.006 \\
\hline $\mathrm{Co}$ & $<0.1$ & $<0.1$ \\
\hline $\mathrm{Cu}$ & 0.06 & 0.0429 \\
\hline $\mathrm{W}$ & $<0.1$ & $<0.1$ \\
\hline $\mathrm{Al}+\mathrm{Ti}$ & 0.280 & 0.15 \\
\hline $\mathrm{Al}$ & & 0.1539 \\
\hline $\mathrm{Ti}$ & & $<0.01$ \\
\hline $\mathrm{V}$ & & $<0.05$ \\
\hline $\mathrm{Mg}$ & & $<0.002$ \\
\hline & & \\
\hline
\end{tabular}




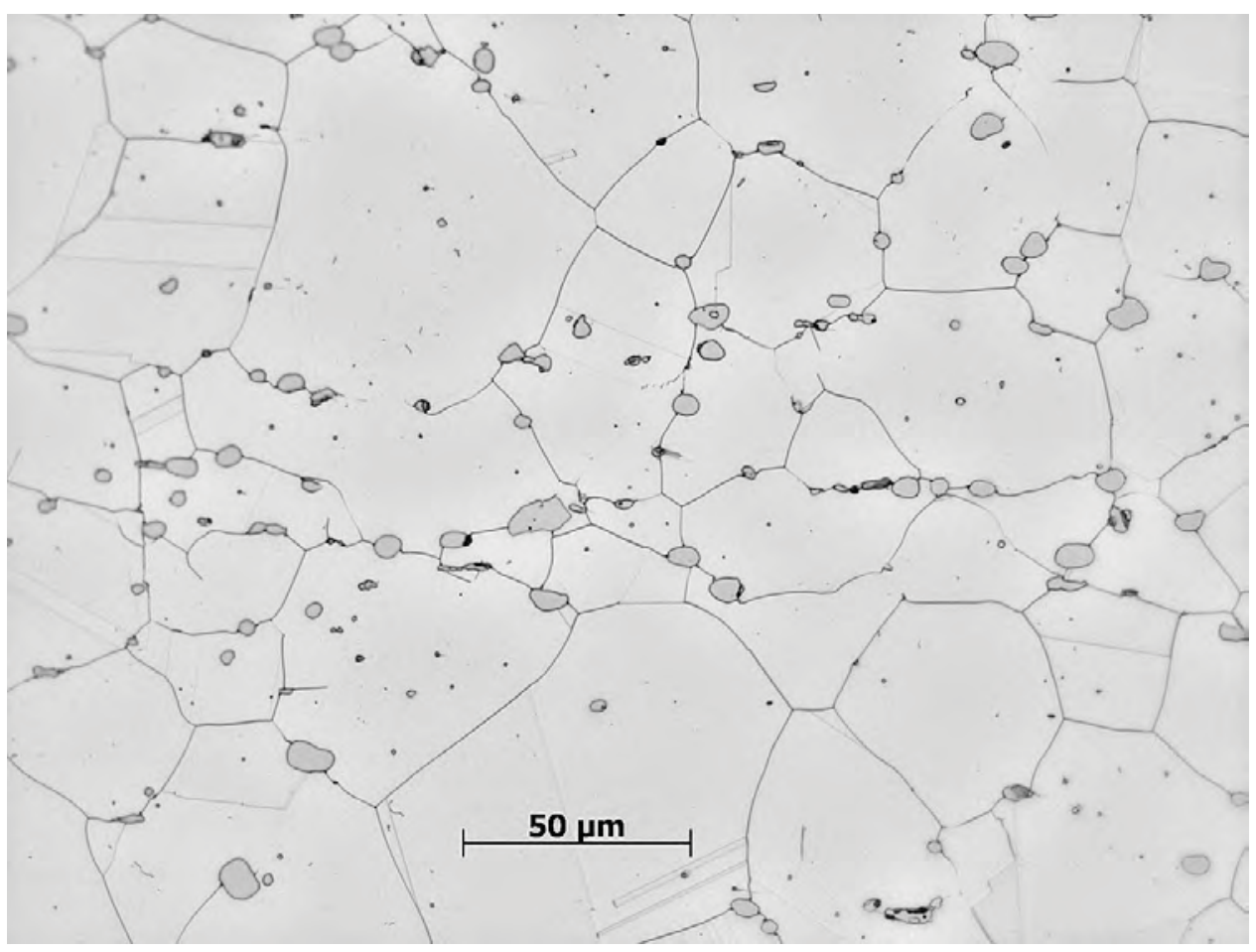

Figure 12. As-received microstructure of Alloy N 0.041 inch sheet.

\subsection{Other Alloys}

Haynes Alloy 242 is an increased-molybdenum versions of Alloy $\mathrm{N}$ with the compositions shown in Table 3. Some diffusion welding studies were done with Alloy 242 early in the program, since it was commercially available and the Alloy $\mathrm{N}$ material had not yet been obtained.

Table 3. Composition of Alloy 242 material used in the present work.

\begin{tabular}{|l|l|l|}
\hline \multicolumn{1}{|c|}{ Heat number } & \multicolumn{1}{c|}{ 242 nominal } \\
\hline Form & 1 in. bar stock 7980 & \\
\hline $\mathrm{Ni}$ & Bal & 65 \\
\hline $\mathrm{Mo}$ & 24.68 & $24.0-26.0$ \\
\hline $\mathrm{Cr}$ & 8.07 & $7.0-9.0$ \\
\hline $\mathrm{Fe}$ & 1.42 & $2.0 \max$ \\
\hline $\mathrm{Si}$ & 0.05 & $0.80 \max$ \\
\hline $\mathrm{Mn}$ & 0.30 & $0.80 \max$ \\
\hline $\mathrm{C}$ & 0.005 & $0.03 \max$ \\
\hline $\mathrm{P}$ & 0.005 & \\
\hline $\mathrm{S}$ & 0.002 & \\
\hline $\mathrm{B}$ & $<0.002$ & $0.006 \max$ \\
\hline $\mathrm{Al}$ & 0.21 & $0.50 \max$ \\
\hline $\mathrm{Co}$ & $<0.05$ & $2.5 \max$ \\
\hline $\mathrm{Cu}$ & & $0.50 \max$ \\
\hline
\end{tabular}




\subsection{Importance of Surface Preparation}

Surface preparation turned out to be an important component of the diffusion welding of these nickelbased alloys. It became apparent during previous diffusion welding work with Alloys 617 and $800 \mathrm{H}$ that the as-received surface relief on these alloys was often not suitable for diffusion welding. Nickel alloys in sheet form are usually provided with a pickled finish, whereas stainless steels are generally supplied with a brushed finish, perhaps because of the different intended uses (for example, stainless steels are commonly used for architectural, appearance, or food service functions). Figure 13 shows some representative surface profiles for as-received and further processed Alloy $800 \mathrm{H}$ sheet material. Surface roughness measurements were performed with a Wyko NT1100 Optical Profiling System.

Surface profiles were not closely examined in early experimental work, but Figure 13 indicates one reason this became a matter of some concern. There is a fairly uniform distribution of pits $50-100 \mu \mathrm{m}$ in extent and as deep as $14 \mu \mathrm{m}$, considerably larger and deeper than might be expected to diffuse away under reasonable diffusion welding time, temperature, and pressure or than can be overcome by the application of plating or foil interlayers. As a result, initial tensile tests showed considerable plastic deformation but ultimate strengths only about $70 \%$ of base metal, a level that roughly corresponded to the observed unbonded area on the relatively planar fracture surface, shown in Figure 14.

A number of methods were tried within the laboratory. Figure 13(b) shows the result of using a double-acting sander and grits through 240 , followed by brushing with an abrasive Scotch-brite pad. The occasional deeper pit is still in evidence, although the overall relief has been reduced to random scratches with a relief of perhaps 1-2 $\mu \mathrm{m}$. This involved a great deal of manual labor, and eventually an outside contractor was found (Harrison) who specializes in surface preparation for oilfield corrosion applications and was able to process relatively large sheets. In this case, a graded grinding approach was selected, but other methods such as chemical treatment and electropolishing would not be out of the question.

The very smooth surface seen in Figure 13(c) resulted from grinding in a metallographic environment, with a fixture to hold the 0.5 in. diameter material vertical, and a progression from a cut surface through 600 grit. Uniformly grinding a small area like this where length is not critical (because it is compensated by the Gleeble fixturing) is relatively easy, but the processing of the large areas of sheet stock required for plate-type heat exchangers to a similar finish is another matter. Uniformity of sheet thickness and similar treatment across a wide sheet area are important for component fitup and uniformity of bonding.

For comparison, surface profiles for three as-received sheet materials are shown in Figure 15 through Figure 17. Of these particular sheet materials, the 617 showed a very rough surface, the $800 \mathrm{H}$ showed some pits that might be expected not to be filled in by diffusion welding processes, and Alloy $\mathrm{N}$ was quite smooth (Figure 17). Nonetheless, a sample of the Alloy N material was sent to Harrison. The results are shown in Figure 18, where it can be seen that the relief of 1-2 $\mu \mathrm{m}$, oriented in the rolling direction of the sheet, has been reduced to a much more uniform and more isotropic surface.

The as-received Alloy $\mathrm{N}$ sheet did not show as much surface relief as the 617 and $800 \mathrm{H}$ sheet stock examined. 

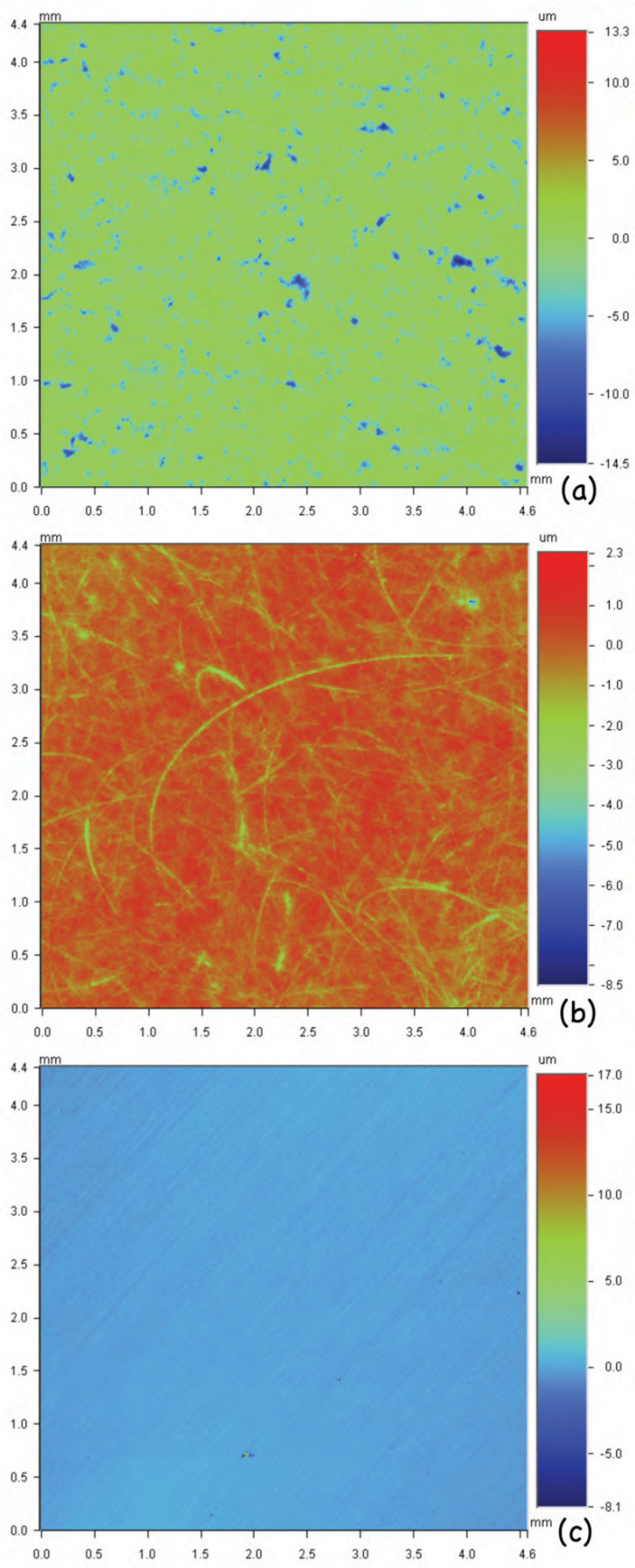

Figure 13. Surface profiles (area approximately 4.4 x $4.6 \mathrm{~mm}$, color coded for surface height in $\mu \mathrm{m}$ ) for Alloy $800 \mathrm{H}$ material (a) as received; (b) after processing with double-acting sander through 240 grit and polishing with Scotch-brite abrasive pad; (c) metallographic 600-grit surface for comparison. 


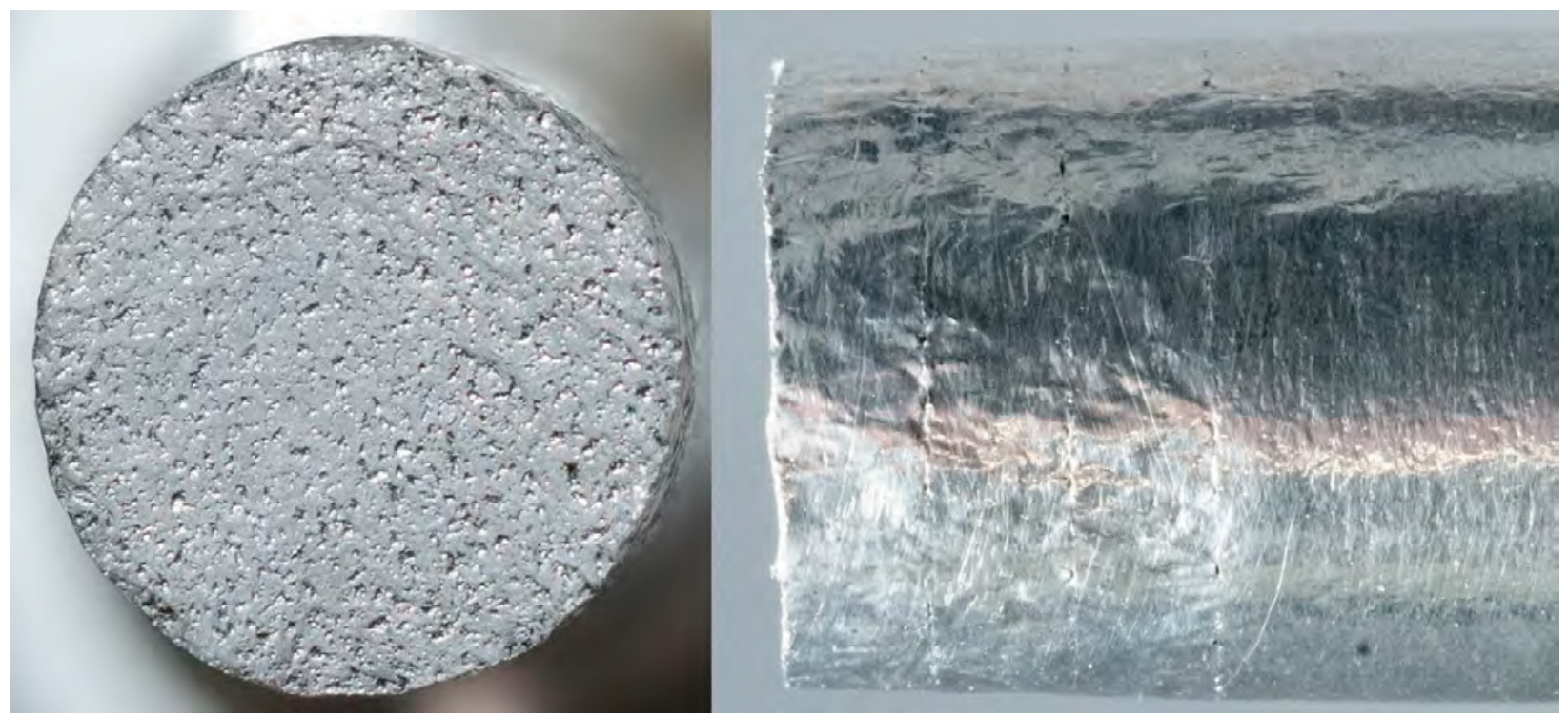

Figure 14. Multilayer $800 \mathrm{H}$ diffusion weld after tensile testing ( 3 of 9 layers of sheet material shown) showing effects of surface roughness, including reduced tensile strength.

Suface Statistics:
Ra: 2.67 um
Rq: 3.29 um
Rz:
Rt: 27.23 um
Set-m Parameters:
Size: 2452 X 2102
Sampling: 815.53 nm
Processed Options:
Temms Removed:
Tilt
Filtering:
None

Mag: $10.3 \mathrm{X}$

Mode: VSI

\section{Surface Data}

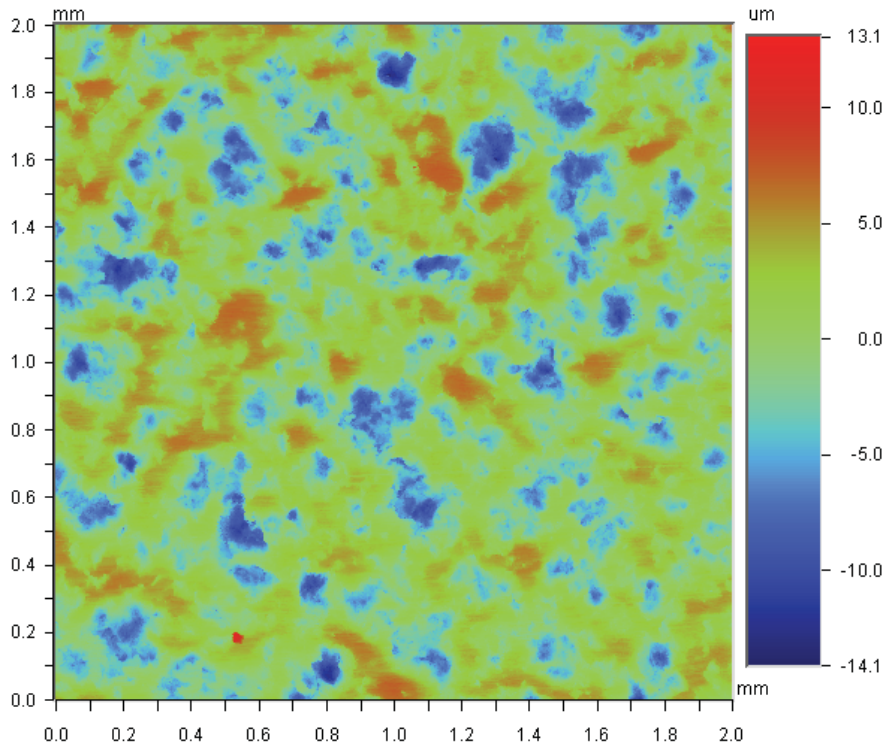

Title: In $617 \mathrm{AR}$ finish

Note: Rolling direction horizontal

Figure 15. Surface finish, Alloy 6170.062 in. sheet, as received. 


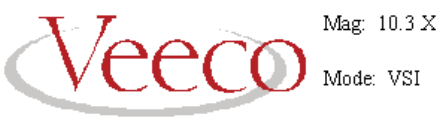

Surface Data

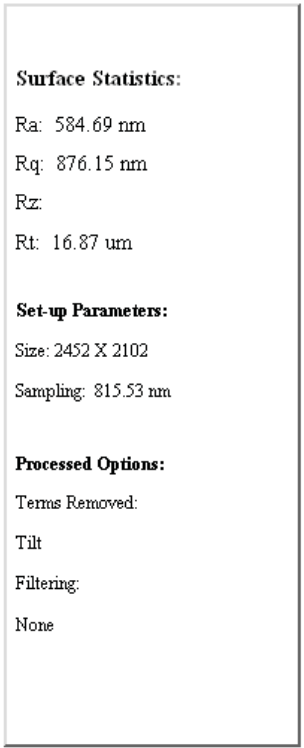

Title: $800 \mathrm{H} \mathrm{AR}$ finish

Note: Rolling direction horizontal
Date: $02 / 02 / 2012$

Time: 14:29:30

Figure 16. Surface finish, Alloy $800 \mathrm{H} 0.062$ in. sheet, as received.

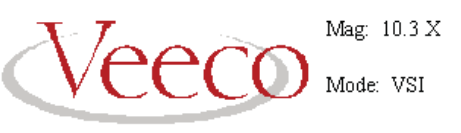

Surface Data

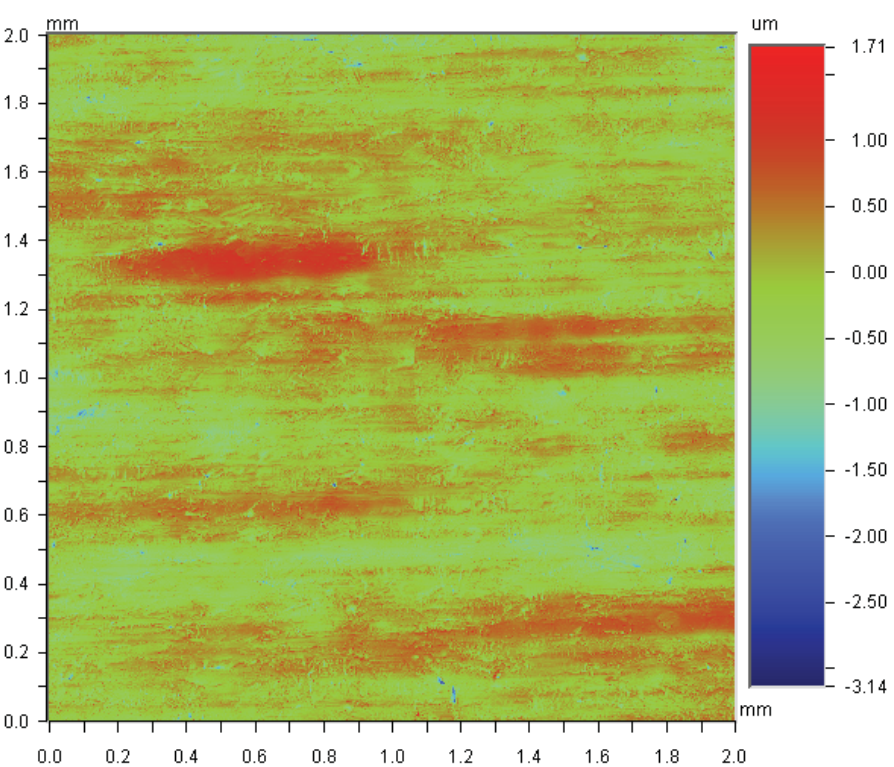

Title: Hastelloy N AR \#2

Note: Rolling direction horizontal

Figure 17. Surface finish, Alloy N 0.041 in. sheet, as received. 


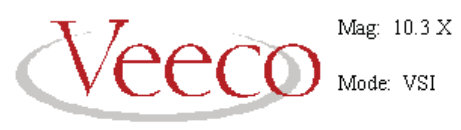

Surface Data

Date: $02 / 27 / 2012$

\begin{tabular}{|l|}
\hline Sufface Statistics: \\
Ra: $113.17 \mathrm{~nm}$ \\
Rq: $146.73 \mathrm{~nm}$ \\
Rz: \\
Rt: 2.71 um \\
Set-u Parameters: \\
Size: 2452 X 2102 \\
Sarnpling: $815.53 \mathrm{~nm}$ \\
Processed Options: \\
Terms Removed: \\
Tilt \\
Filtering: \\
None \\
\hline
\end{tabular}

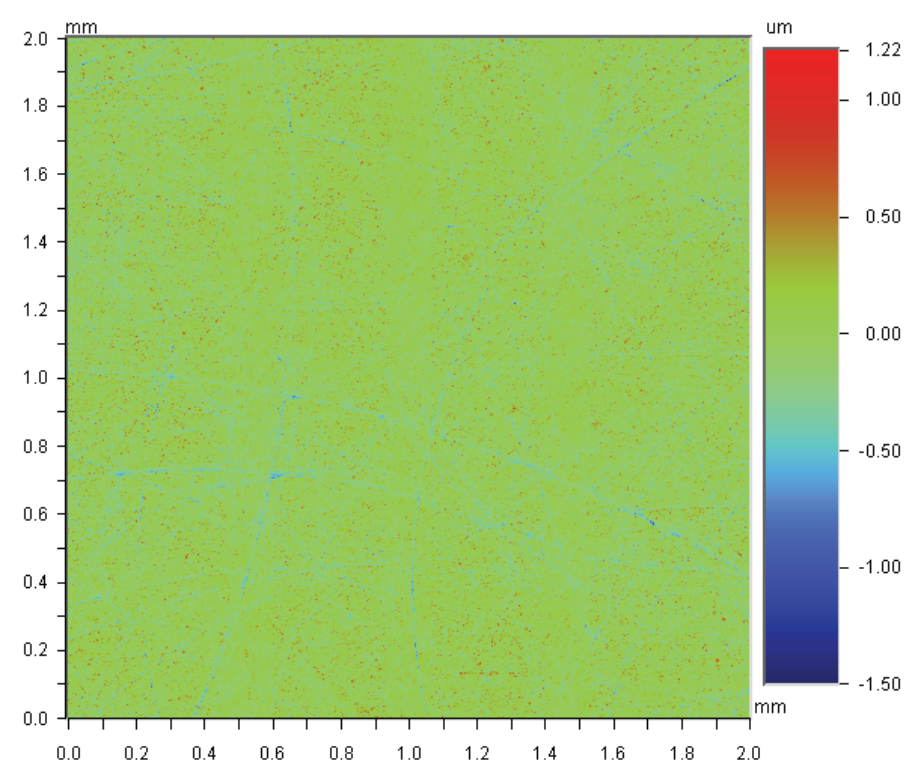

Title: Hastelloy N

Note: Harrison 600 grit

Figure 18. Surface finish, Alloy N 0.041 in. sheet, after vendor surface finishing. 


\section{EXPERIMENTAL}

\subsection{Gleeble Limits}

As noted earlier, the Gleeble has some practical upper limits on specimen size and other parameters. One-inch-diameter material was successfully welded as shown in Figure 19. Because 1-in.-diameter grips were not available, the ends were turned down to a smaller diameter. This decreased the heat extraction through the grips and led to a lower temperature gradient in the specimen, but it also greatly increased the radiating surface area, causing some problems with radiative overheating of the vacuum chamber that had to be solved on subsequent similar specimens with extra heat shields.

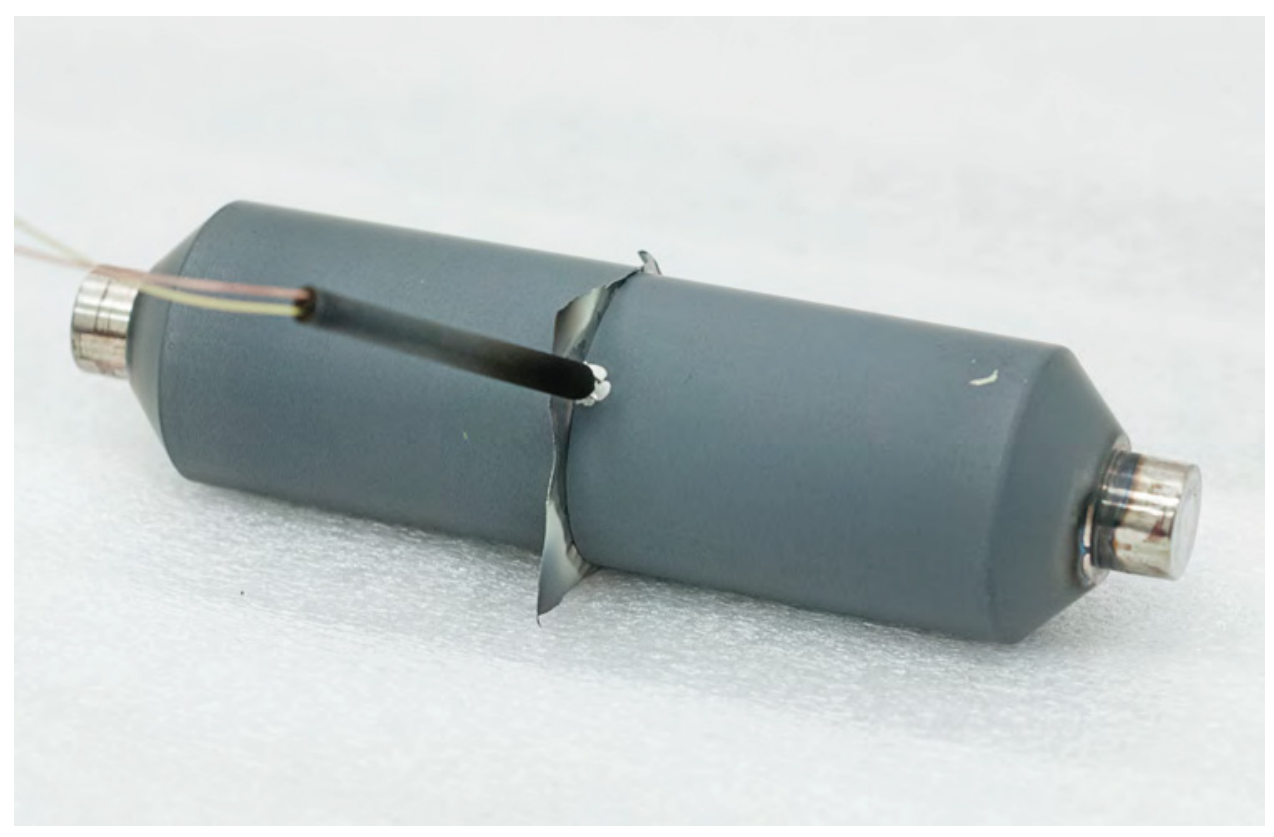

Figure 19. 1-inch diameter Gleeble diffusion welded joint.

Stacking of sheet elements (useful for evaluating more realistic sections of CHXs) was tested, in this case with 9 sheets of $800 \mathrm{H}$ material, shown in Figure 20. The control thermocouple was attached to the center disk. This specimen was machined into a tensile bar; the results of this tensile test were shown above in Figure 14.

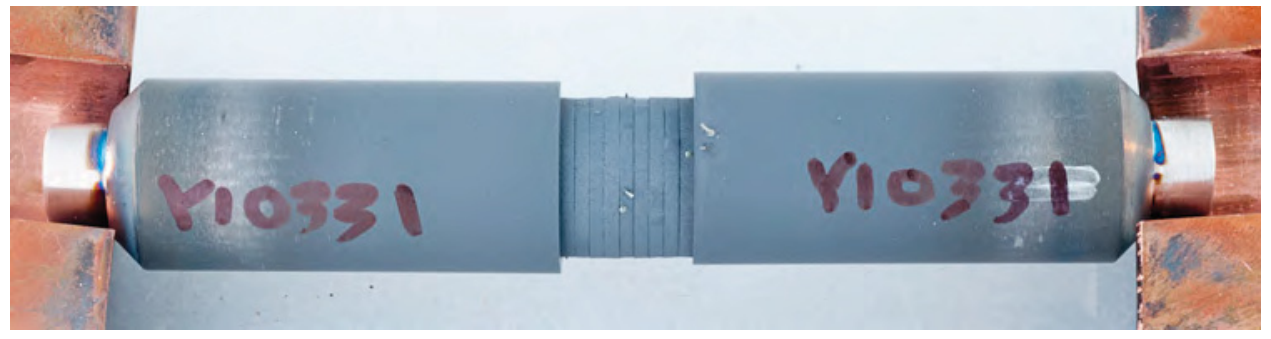

Figure 20. Nine sheets of Alloy $800 \mathrm{H}$ material joined to form simulated CHX stack.

The degree of surface oxidation seen after 3 hours at $1150{ }^{\circ} \mathrm{C}$ varied somewhat unpredictably. Figure 21 shows one of the less oxidized results, which occurred when, because of test scheduling, the specimen was left under vacuum overnight before testing, presumably leading to less residual oxygen in the vacuum system. 


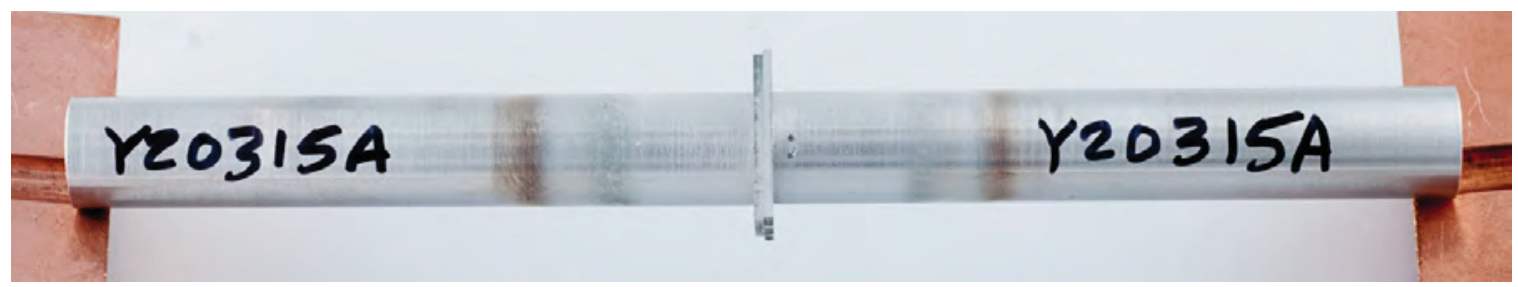

Figure 21. Gleeble diffusion weld Y20315B, Alloy N, nickel-plated, as welded.

Short specimens could be welded with appropriate spacers in the Gleeble jaws. Two diffusion welds in Alloy $\mathrm{N}$ are shown in Figure 22 and Figure 23.

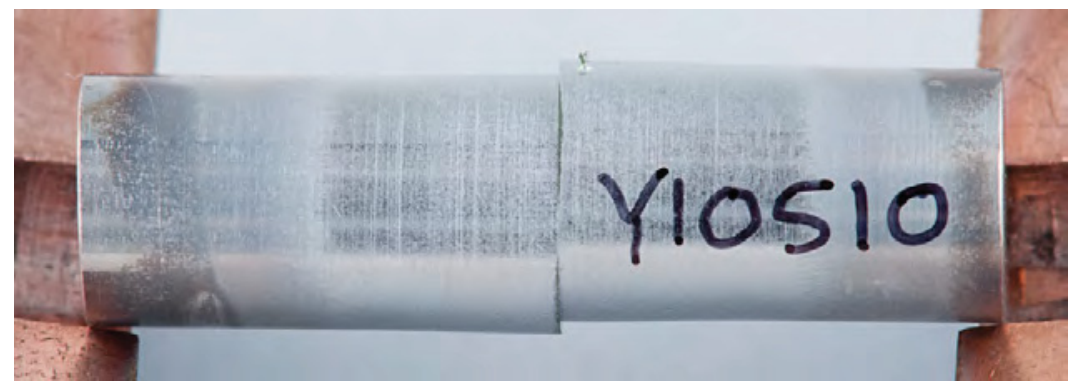

Figure 22. Weld Y10510, as welded, $\sim 1$ in. length specimens from slab material. Alignment is more difficult with short specimens.

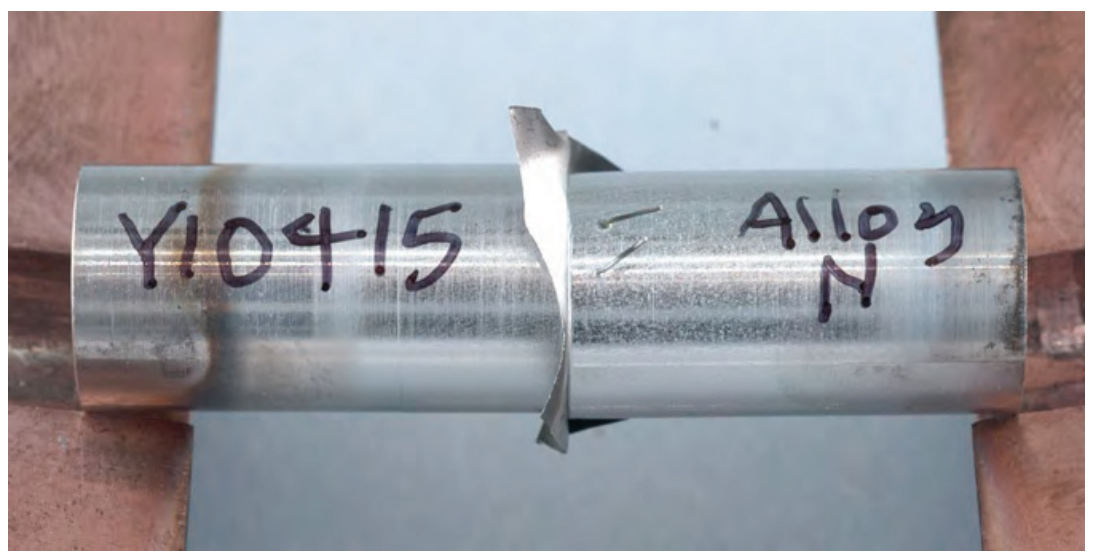

Figure 23. Weld Y10415, welded with $15 \mu \mathrm{m}$ nickel foil.

\subsubsection{Manufacture of Specimens}

Since the Alloy N material was available in slab form, wire electrical discharge machining (EDM) was used to cut cylindrical specimens (nominal diameter $0.5 \mathrm{in}$.) for Gleeble diffusion welding. For the Alloy 242 welds, it was machined from 0.75 in. diameter bar stock. Figure 24 shows the EDM techniques.

\subsubsection{Welds Produced}

Table 4 is a list of the diffusion welds made for the present work, in both Alloy 242 and Alloy N. Much of the original parameter development was performed under the NGNP program and is reported there (Mizia R. , 2010), (Mizia, Clark, Galzoff, Lister, \& Trowbridge, December 2011). 


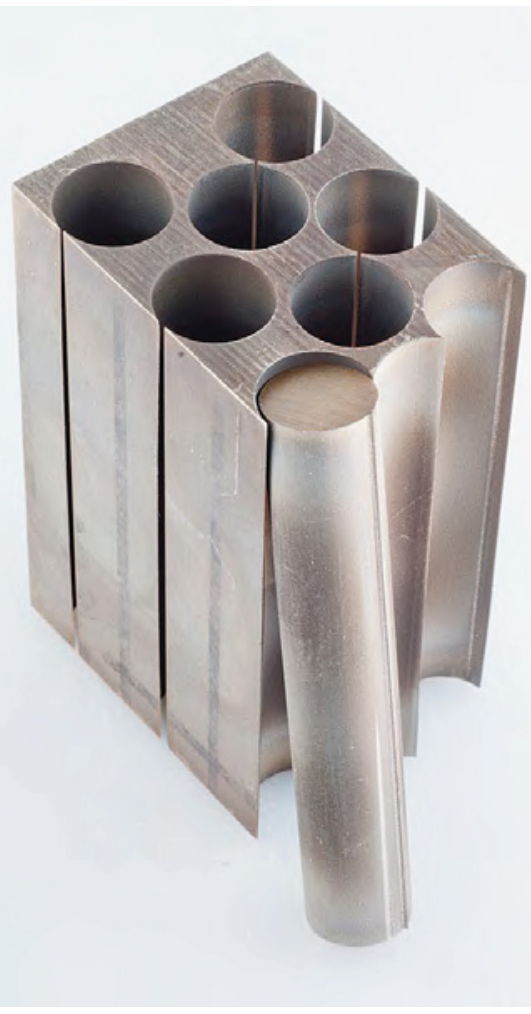

Figure 24. EDM method for obtaining bar stock from plate.

Table 4. Diffusion welds produced in Alloys N and 242.

\begin{tabular}{|l|c|c|c|c|l|}
\hline Weld ID & Material & Time (hr) & Temp $\left({ }^{\circ} \mathbf{C}\right)$ & Interface & \multicolumn{1}{|c|}{ Comments } \\
\hline Y10127 & 242 & 3 & 1150 & $15 \mu \mathrm{m} \mathrm{Ni}$ & $3 / 4$ in. diameter \\
\hline Y10307 & 242 & 3 & 1150 & plated & $3 / 4$ in. diameter \\
\hline Y10309 & 242 & 3 & 1150 & plated & $3 / 4$ in. diameter - tensile \\
\hline Y10310 & 242 & 3 & 1150 & plated & $3 / 4$ in. diameter - tensile \\
\hline Y10415 & N & 3 & 1150 & $15 \mu \mathrm{m} \mathrm{Ni}$ & Short direction from slab \\
\hline Y10505 & N & 3 & 1150 & plated & Short direction from slab \\
\hline Y10510 & N & 3 & 1150 & plated & Short direction from slab \\
\hline Y10511 & N & 3 & 1150 & plated & $=$ Y20511; TC broke \\
\hline Y10608 & N & 3 & 1150 & plated & 6 in. length - tensile \\
\hline Y10609 & N & 3 & 1150 & plated & 6 in. length - tensile \\
\hline Y10622 & N & 3 & 1150 & plated & Gleeble program glitch \\
\hline Y10623 & N & 3 & 1150 & plated & TC broke, partial melting \\
\hline Y10629 & N & 3 & 1150 & plated & 6 in. length \\
\hline Y20308 & N & 3 & 1150 & plated & 2 plated N sheets, UW tests \\
\hline Y20313 & N & 3 & 1150 & plated & \\
\hline Y20314 & N & 3 & 1150 & plated & \\
\hline Y20315A & N & 3 & 1150 & plated & \\
\hline Y20315B & N & 3 & 1150 & plated & N sheets fell out, plated weld \\
\hline
\end{tabular}

Date can be derived from the Weld ID: e.g., Y10127 = 2001 January 27 


\subsection{Tensile Testing}

The Gleeble diffusion welds normally used here are 6 inches long. One advantage of this geometry is that the weld strength can be tested economically by machining tensile specimens from these bars, with a gauge section as per ASTM E8 and a nominal diameter of 0.375 in. and straight grip sections. Early welds made with bare surfaces (ground to 600 grit but not plated) were inconsistent, and some of the lower tensile strengths were a result of partial bonding across the face of the joint, perhaps aided by oxidation and the buildup of an oxide layer during the initial heat-up — some heat tinting was observed in these cases.

\subsection{Modeling}

Modeling was performed with Thermocalc/DICTRA using the appropriate nickel databases (Shi \& Sundman, 2010), (Thermo-Calc, 2010). For model verification purposes, it was convenient to use a joint design that involved a pure nickel interlayer, and to produce actual diffusion welds of the same geometry for comparison and verification. A typical arrangement was a $15 \mu \mathrm{m}$ nickel foil at the center of a model mesh about $120 \mu \mathrm{m}$ in length, which in actual use covered most of the diffusion effect around the joint for the standard conditions of $1150{ }^{\circ} \mathrm{C}$ and $1.5-7$ hours. Because the joint design is planar, the model could be one-dimensional, and convergence times were short, typically well under an hour on PC-based computer hardware. Modeling details are covered elsewhere (Mizia, Clark, Glazoff, Lister, \& Trowbridge, 2011).

No attempt was made to measure oxide layers, or to model their chemical potential and diffusion rates relative to the base metal. Although this would be an interesting fundamental study to pursue and potentially quite useful in designing diffusion welding parameters, it was beyond the scope of this work.

\subsection{Corrosion Testing}

Corrosion testing of welds is part of the investigation required for incorporation into codes and assurance that welded structures will be fit for long-term service (Prybylowski, Floreen, Sherwood, \& Wittimeier). Diffusion welds properly made should have microstructures very close to that of the base metal. Nonetheless, specimens were prepared for testing by colleagues under the direction of Prof. Kumar Sridharan at the University of Wisconsin, where substantial corrosion work for molten salt media has been ongoing for some years (Olson, Ambrosek, Sridharan, Anderson, \& Allen, 2009).

Although a circulating loop is available, these initial tests in $\mathrm{KF}^{-\mathrm{ZFF}_{4}}$ were performed in still, molten salt. Weld specimens were made with two pieces of 0.041 in. Alloy $\mathrm{N}$ sheet material sandwiched between two bars of Alloy N material from the slabs, as in Figure 10 (a) and (b). The specimens were machined mainly by EDM from the 6 in. long cylindrical weld as shown in Figure 25 and Figure 26. Each specimen was ground with metallographic techniques to a 600-grit finish on one side (standard for corrosion exposure), and to a mirror polish on the other. Figure 27 shows one such specimen, with the two Alloy N sheet layers visible because of slight polishing differences (unetched at 600-grit).

Unwelded sheet material as shown in Figure 28 was also supplied, which was exposed both submerged and partially submerged in the salt bath shown schematically in Figure 29. Temperatures of 650,700 , and $850^{\circ} \mathrm{C}$ were used for various exposure times up to 1000 hours. 


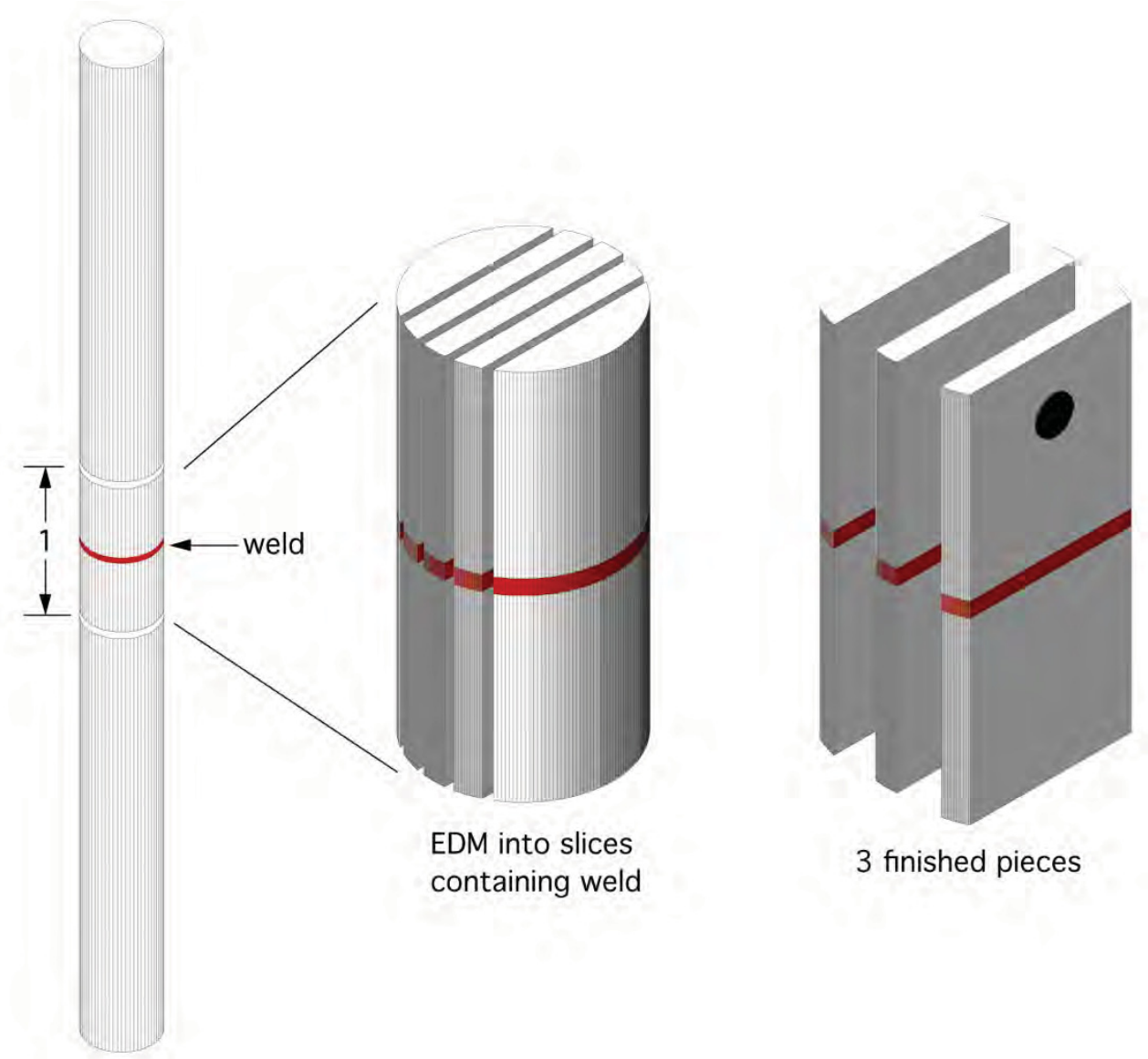

Figure 25. Weld specimens for University of Wisconsin corrosion testing.
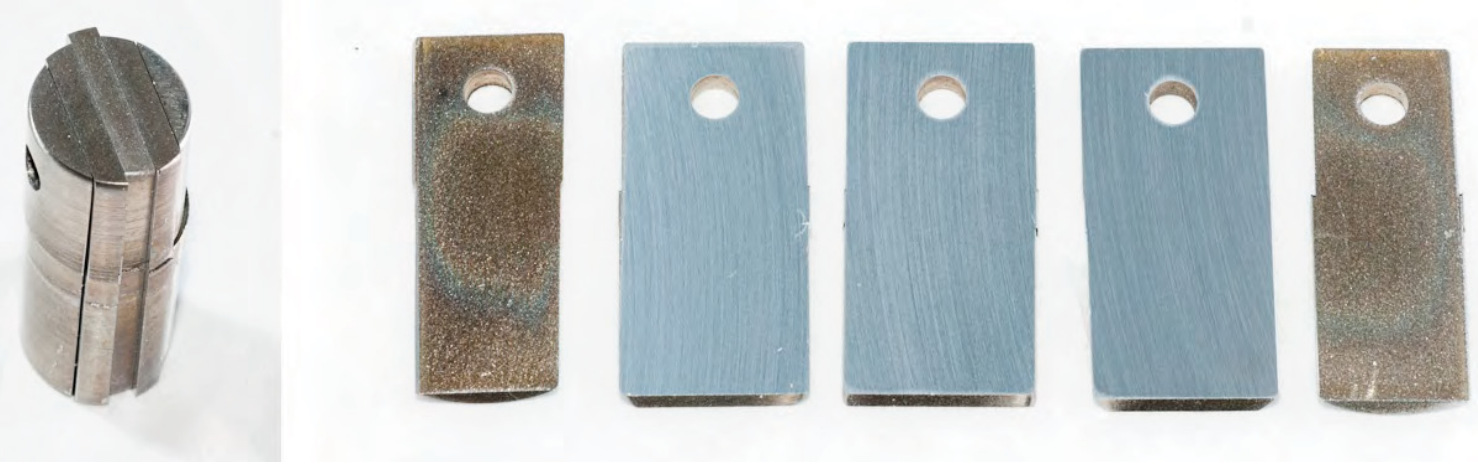

Figure 26. Weld Y20314, sectioned for corrosion testing. Center three pieces are corrosion coupons, outer slices reserved for as-welded metallography. 


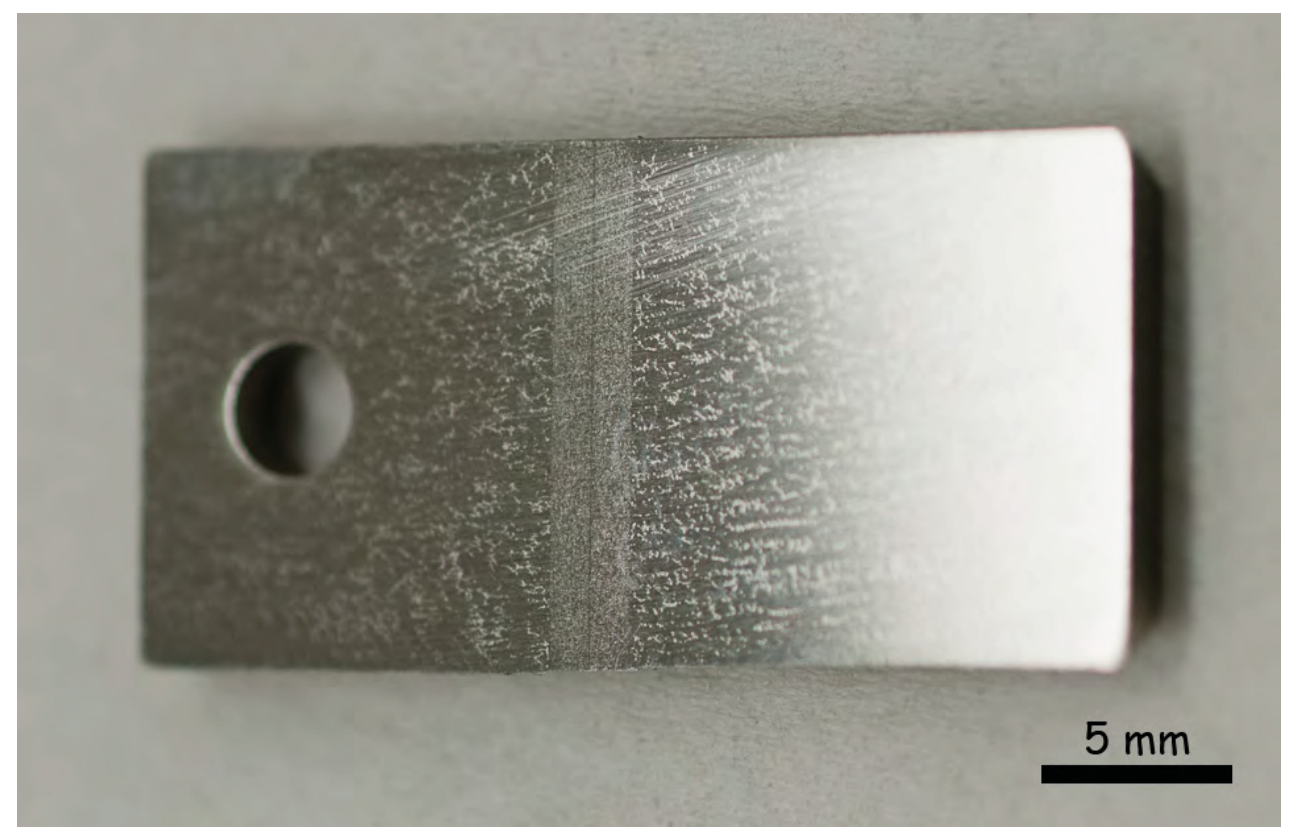

Figure 27. Corrosion specimen from weld Y20314 showing two layers of Alloy $\mathrm{N}$ sheet material between Alloy $\mathrm{N}$ base material. As-ground, 600 grit.

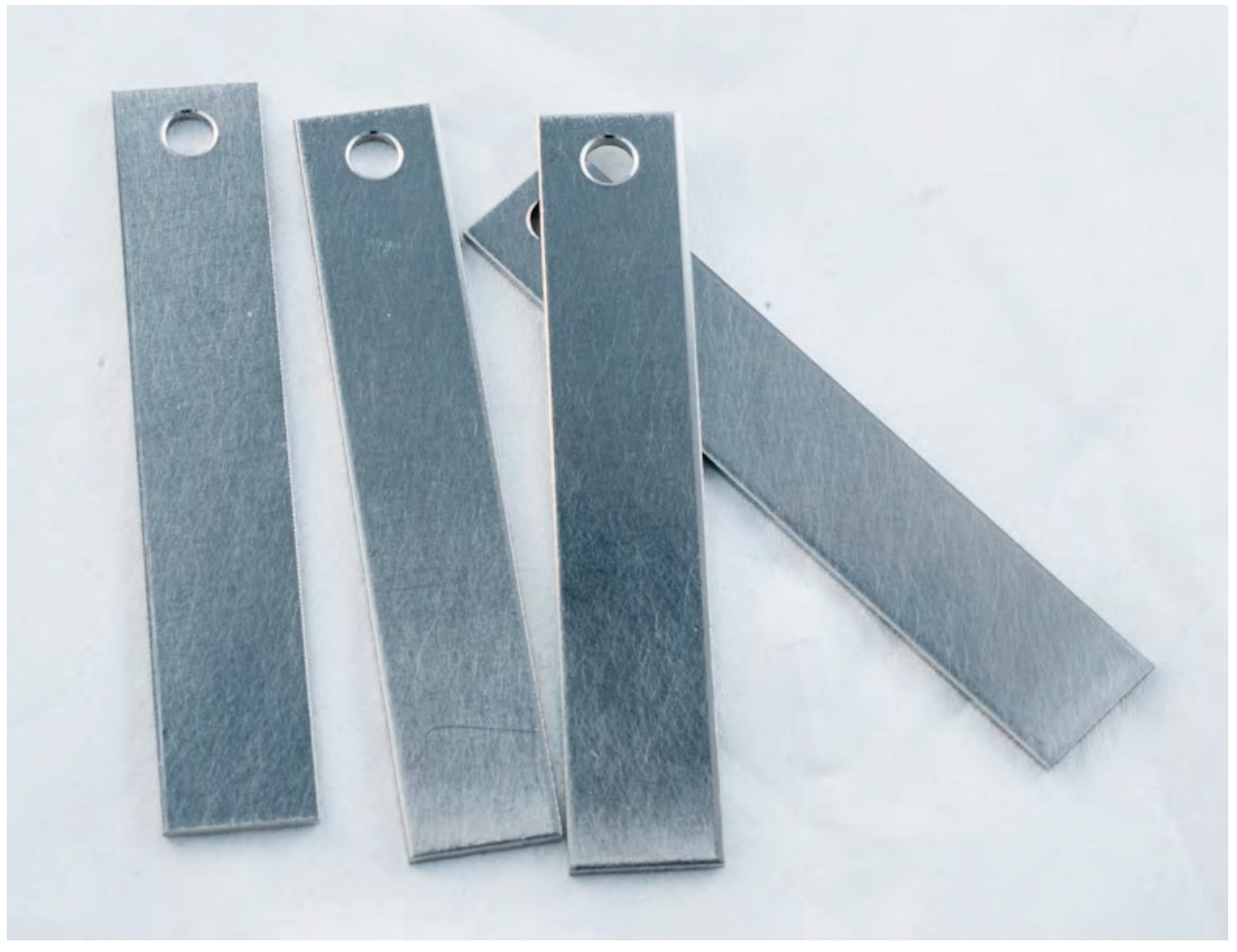

Figure 28. Coupons of Alloy $\mathrm{N}$ for corrosion testing; may be suspended partially immersed in salt to investigate corrosion at salt/gas interface. 


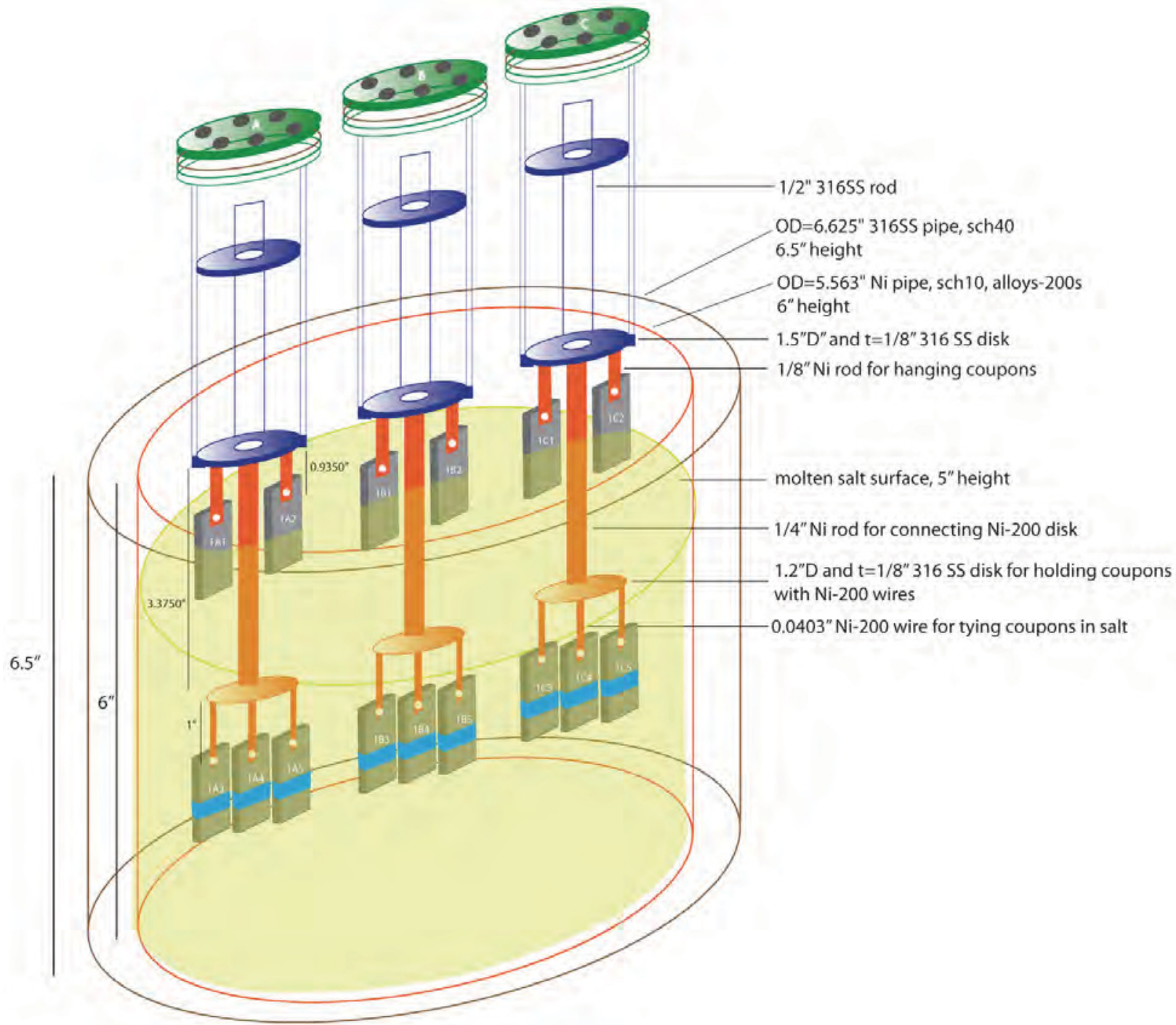

Figure 29. Schematic view of corrosion testing at the University of Wisconsin.

\subsubsection{Salt Exposure Parameters}

The salt used for this exposure was a mixture of $58 \mathrm{~mol} \%$ of $\mathrm{KF}$ and $42 \mathrm{~mol} \%$ of $\mathrm{ZrF}_{4}$, based on the phase diagram shown in Figure 30. This mixture has been proposed for the secondary heat transfer fluid. While $\mathrm{Li}_{2} \mathrm{BeF}_{4}$ ("Flibe") has been proposed for the primary coolant because of its desirable nuclear as well as physical properties, $\mathrm{KF}-\mathrm{ZrF}_{4}$ is a candidate for the secondary heat transfer fluid because it avoids some of the handling problems of beryllium. It was chosen for these corrosion tests also because data on the corrosion of Alloy $\mathrm{N}$ in this mixture currently do not exist, and this work would thus fill a gap.

The temperatures chosen were 650,700 , and $850{ }^{\circ} \mathrm{C}$. $700{ }^{\circ} \mathrm{C}$ is the nominal operating temperature of the proposed reactor; $650{ }^{\circ} \mathrm{C}$ may also be an operating point, and the $850^{\circ} \mathrm{C}$ temperature was chosen because even higher temperatures are desirable for process heat applications.

The atmosphere above the molten salt was argon gas. Oxygen, and particularly water, in the salt system can produce highly corrosive HF or fluorine gases. For this reason, good chemistry control, often referred to as "redox control," is needed in these systems. The partially submerged Alloy N sheet 


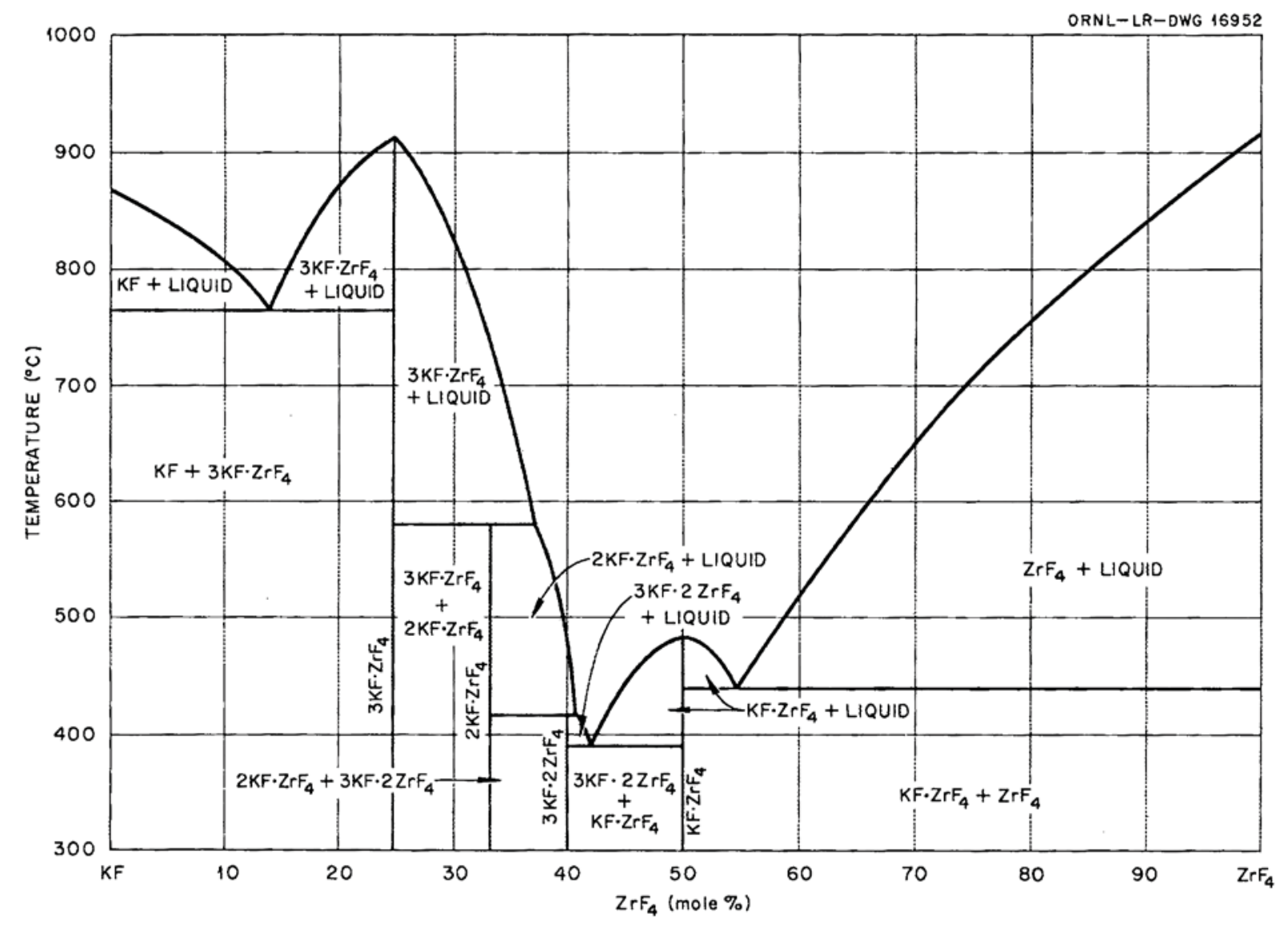

The System $\mathrm{KF}_{-\mathrm{ZrF}}$.

Figure $30 . \mathrm{KF}-\mathrm{ZrF}_{4}$ phase diagram.

specimens served as an indicator of such corrosion, which often occurs at the salt/gas interface. Such an interface will also exist in proposed molten salt reactors.

\subsubsection{Salt Procurement and Processing}

The $\mathrm{KF}$ and $\mathrm{ZrF}_{4}$ were purchased separately and mixed before melting in the corrosion chambers. KF is relatively common and inexpensive, but the $\mathrm{ZrF}_{4}$ proved more troublesome experimentally. Several vendors were evaluated; the price for $100 \mathrm{~kg}$ of $\mathrm{ZrF}_{4}$ from Alfa Aesar, an American supplier, was about $\$ 30,000$, while that from a Chinese supplier, Jinan Boss Chemical Industry Co., Ltd., in Shangdong, China, was approximately $\$ 3,000$. Samples were obtained and independently analyzed, as shown in Table 5. The relatively high silicon values probably arose from partial dissolution of the glass beakers used.

Salts are typically hygroscopic, and the $\mathrm{ZrF}_{4}$ material proved especially so. As received, it was stable in weight on exposure to air, but contained up to $26 \%$ moisture. As indicated above, residual moisture in the salt can lead to aggressive corrosion environments, and needs to be controlled. This can be achieved by heating, although excessive heat can increase the oxidation rate of the zirconium, leading to an excess of fluorine. In developing the drying procedure, corrosion was noted in the glove box and vacuum system before the procedure was finalized.

The final procedure developed to overcome this, based on weight change in the salt, involved heating while sparging from the bottom of the crucible with dry nitrogen. At $220{ }^{\circ} \mathrm{C}$, weight loss was about $19 \%$ 
and did not apparently convert $\mathrm{ZrF}_{4}$ to $\mathrm{ZrO}_{2}$. Further heating at $300^{\circ} \mathrm{C}$ for $27 \mathrm{~h}$ until weight loss stopped, indicating a final moisture content of $26 \%$.

Table 5. Composition of Salt Samples from Vendors

\begin{tabular}{|c|c|c|c|c|c|c|c|c|c|c|c|c|}
\hline & & Vendor & $\mathrm{K}$ & $\mathrm{S}$ & $\mathrm{Zn}$ & $\mathrm{Mn}$ & $\mathrm{Fe}$ & $\mathrm{Al}$ & $\mathrm{Si}$ & $\mathrm{Ti}$ & $\mathrm{Pb}$ \\
\hline $\begin{array}{c}\text { Sample } \\
\underline{\text { ID }}\end{array}$ & & & \multicolumn{7}{|c|}{ weight ppm } \\
\hline 1 & $\mathrm{LiF}$ & Jinan Boss & 175.93 & 17.46 & 1.76 & 0.53 & 18.05 & 12.80 & 1377.46 & 2.34 & $<3$ \\
\hline 2 & $\mathrm{LiF}$ & Alfa Aesar & 534.98 & 223.91 & 2.11 & 0.35 & 20.09 & 12.64 & 1068.09 & 0.42 & $<3$ \\
\hline 3 & $\mathrm{KF}$ & Alfa Aesar & 493751 & 49.90 & 1.76 & 0.34 & 31.78 & $<8$ & 950.30 & $<0.4$ & $<3$ \\
\hline 4 & $\mathrm{KF}$ & Jinan Boss & 490906 & 22.31 & 1.33 & 0.28 & 32.54 & $<8$ & 854.49 & $<0.4$ & $<3$ \\
\hline 5 & $\mathrm{ZrF} 4$ & Jinan Boss & 392.91 & 202.01 & 9.90 & 3.94 & 85.60 & $<24$ & 22239 & 2.56 & $<10$ \\
\hline
\end{tabular}

\subsubsection{Salt exposure}

Samples were exposed according to Table 6. Corrosion results are shown below in Section 7.4.

Table 6. Exposure Conditions, $\mathrm{KF}-\mathrm{ZrF}_{4}$ Corrosion of Alloy N Sheet and Welds

\begin{tabular}{|c|c|c|c|c|c|c|c|c|c|}
\hline & \multicolumn{3}{|c|}{ Corrosion can $\mathrm{C}$} & \multicolumn{3}{|c|}{ Corrosion can B } & \multicolumn{3}{|c|}{ Corrosion can A } \\
\hline \multirow{2}{*}{$\begin{array}{l}\text { At salt/Ar } \\
\text { interface }\end{array}$} & 201 & 201 & 201 & 201 & 201 & 201 & 201 & 201 & 201 \\
\hline & Ns & $\mathrm{Ns}$ & Ns & $\mathrm{Ns}$ & $\mathrm{Ns}$ & Ns & Ns & Ns & $\mathrm{Ns}$ \\
\hline \multirow{3}{*}{$\begin{array}{c}\text { Submerged } \\
\text { in salt }\end{array}$} & $\mathrm{Nw}$ & $\mathrm{Nw}$ & $\mathrm{Nw}$ & $\mathrm{Nw}$ & $\mathrm{Nw}$ & $\mathrm{Nw}$ & $\mathrm{Nw}$ & $\mathrm{Nw}$ & $\mathrm{Nw}$ \\
\hline & $\mathrm{Ns}$ & $\mathrm{Ns}$ & $\mathrm{Ns}$ & $\mathrm{Ns}$ & $\mathrm{Ns}$ & $\mathrm{Ns}$ & $\mathrm{Ns}$ & $\mathrm{Ns}$ & $\mathrm{Ns}$ \\
\hline & 201 & 201 & 201 & 201 & 201 & 201 & 201 & 201 & 201 \\
\hline Temp, ${ }^{\circ} \mathrm{C}$ & 650 & 650 & 650 & 700 & 700 & 700 & 850 & 850 & 850 \\
\hline Time, $\mathrm{h}$ & 200 & 500 & 1000 & 200 & 500 & 1000 & 200 & 500 & 1000 \\
\hline tube no. & $\mathrm{C}-1$ & $\mathrm{C}-2$ & $\mathrm{C}-3$ & B-1 & B-2 & B-3 & A-1 & A-2 & A-3 \\
\hline $\begin{array}{l}\text { Completion } \\
\text { date }\end{array}$ & $7 / 21 / 12$ & $8 / 2 / 12$ & $8 / 23 / 12$ & $6 / 29 / 12$ & $7 / 12 / 12$ & $8 / 2 / 12$ & $6 / 30 / 12$ & $7 / 12 / 12$ & $8 / 2 / 12$ \\
\hline can material & \multicolumn{9}{|c|}{ Ni 201, sch 10} \\
\hline shell material & \multicolumn{9}{|c|}{$316 \mathrm{SS}, \mathrm{OD}=6.625^{\prime \prime}, \operatorname{sch} 40$} \\
\hline specimens & \multicolumn{9}{|c|}{ 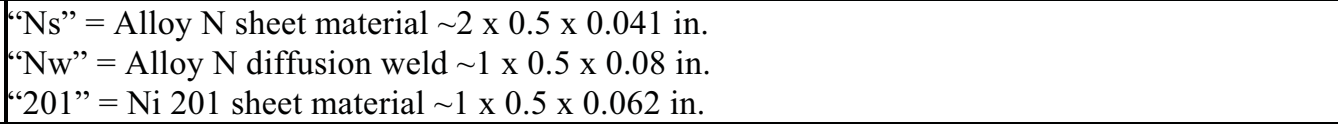 } \\
\hline
\end{tabular}




\subsubsection{Post-exposure cleaning}

These fluoride salts are not very water soluble, so the following cleaning procedure was adopted to produce a clean metal surface for analysis:

1. Ultrasonic cleaning 1 hour with $\mathrm{Al}\left(\mathrm{NO}_{3}\right)_{3}$ solution $(375 \mathrm{~g} / \mathrm{L})$.

2. Change $\mathrm{Al}\left(\mathrm{NO}_{3}\right)_{3}$ solution and repeat step 1 .

3. Change $\mathrm{Al}\left(\mathrm{NO}_{3}\right)_{3}$ solution and repeat step 1 .

4. Ultrasonic cleaning 1 hour with D.I. water.

5. Change water and repeat step 4 for 0.5 hour.

6. Ultrasonic cleaning 0.5 hour with Ethanol.

7. Dry sample with heat gun. 


\section{RESULTS \\ 7.1 Metallographic Examination}

\subsubsection{Alloy 242}

Alloy 242 was examined early in the program because bar stock was commercially available, and Alloy $\mathrm{N}$ material had not yet been obtained. It is similar to Alloy $\mathrm{N}$, with a similar chromium level but increased molybdenum ( 25 instead of $16 \mathrm{wt} \%$ ) and reduced iron ( 2 instead of $4 \mathrm{wt} \%)$. A summary of nominal composition differences is found in Table 7.

Table 7. Nominal composition comparison between Alloys N and 242.

\begin{tabular}{|l|c|c|}
\hline & Alloy N & Alloy 242 \\
\hline $\mathrm{Ni}$ & 71 & 65 \\
\hline $\mathrm{Mo}$ & 16 & $24.0-26.0$ \\
\hline $\mathrm{Cr}$ & 7 & $7.0-9.0$ \\
\hline $\mathrm{Fe}$ & $5 \max$ & $2.0 \max$ \\
\hline $\mathrm{Si}$ & $1 \max$ & $0.80 \max$ \\
\hline $\mathrm{Mn}$ & $0.80 \max$ & $0.80 \max$ \\
\hline $\mathrm{C}$ & $0.08 \max$ & $0.03 \max$ \\
\hline $\mathrm{W}$ & $0.50 \max$ & - \\
\hline $\mathrm{Al}+\mathrm{Ti}$ & $0.35 \max$ & - \\
\hline $\mathrm{B}$ & - & $0.006 \max$ \\
\hline $\mathrm{Al}$ & - & $0.50 \max$ \\
\hline $\mathrm{Co}$ & $0.20 \max$ & $2.5 \max$ \\
\hline $\mathrm{Cu}$ & $0.35 \max$ & $0.50 \max$ \\
\hline
\end{tabular}

Diffusion welds were made in Alloy 242, both with $15 \mu \mathrm{m}$ nickel foil interlayers and with nickel electroplating only. An interesting case was weld Y10127. One side of the weld cross section showed complete bonding, but the other showed more evidence of the grain structure of the original nickel foil as can be seen in Figure 31 as a composite scanning electron microscope (SEM) micrograph of the areas.

Figure 32 shows the EDS elemental analysis for four elements for the spots visible in Figure 31 . The values for the more completely bonded material show an increased amount of diffusion (a slightly flatter profile) with more of the pure nickel interlayer having diffused away into the base material, and more of the 242 alloying elements having diffused into the place formerly occupied by the nickel foil.

The probable explanation for the difference in microstructure within this single weld is that there was a slight tilt of the two pieces relative to one another, leading to increased pressure on one side and little pressure on the other. The less completely bonded material probably had the lower pressure, and perhaps less time at that pressure, depending on a small amount of creep (the more completely bonded side would have taken most of the applied load) to finally bring it into contact and apply pressure.

This, in turn, suggests something about the two primary phenomena involved in diffusion weldingthe actual diffusion of elemental species and grain growth (coupled with grain boundary migration) which is responsible for the desirable continuous microstructure observed in high-quality diffusion welds. The amount of diffusion was definitely less in the less continuously bonded area, although only by a 

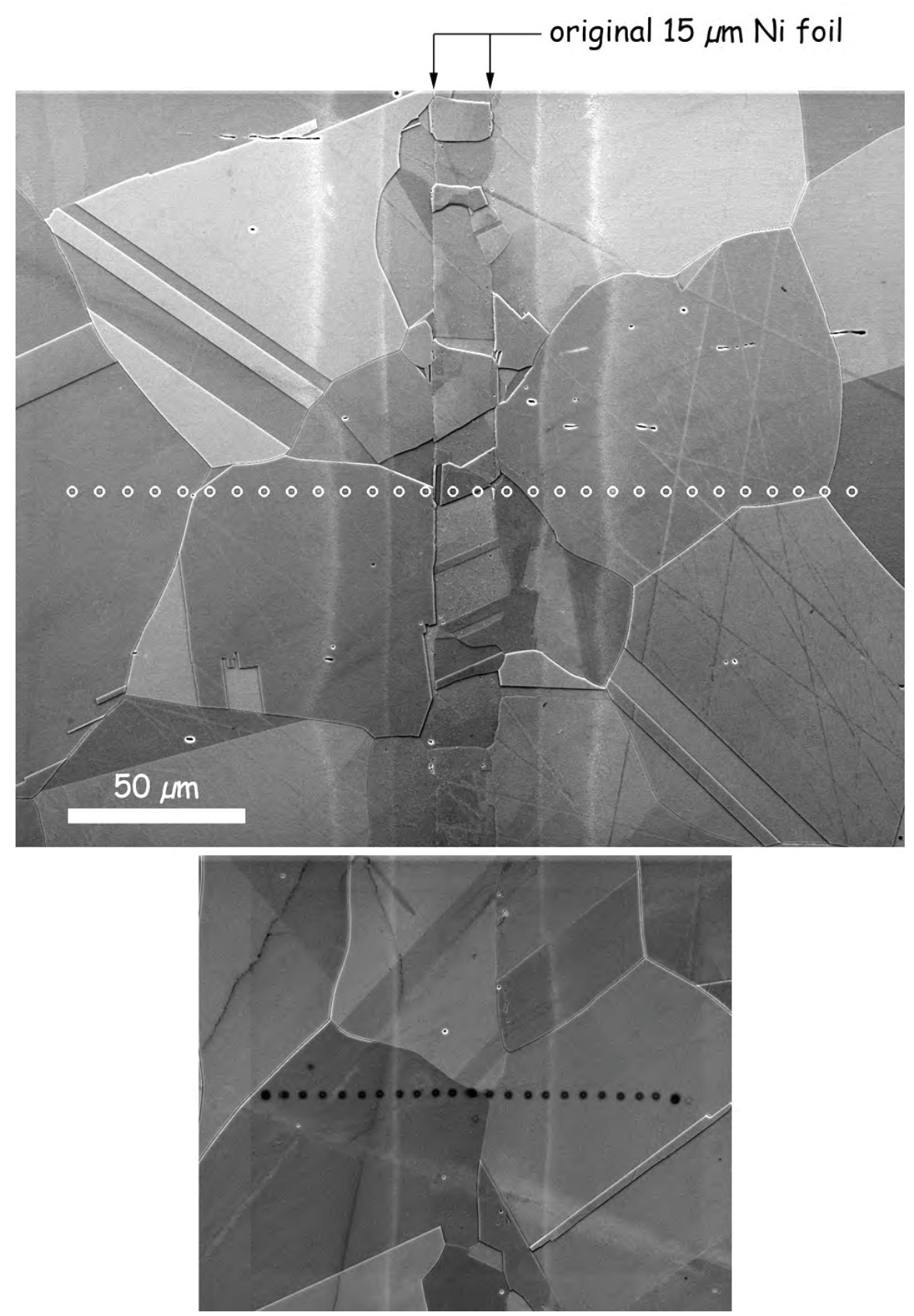

Figure 30. Incomplete (top) and complete (bottom) disappearance of the nickel foil interface in Weld Y10127 in Alloy 242. Marks indicate spots for EDS analysis. 


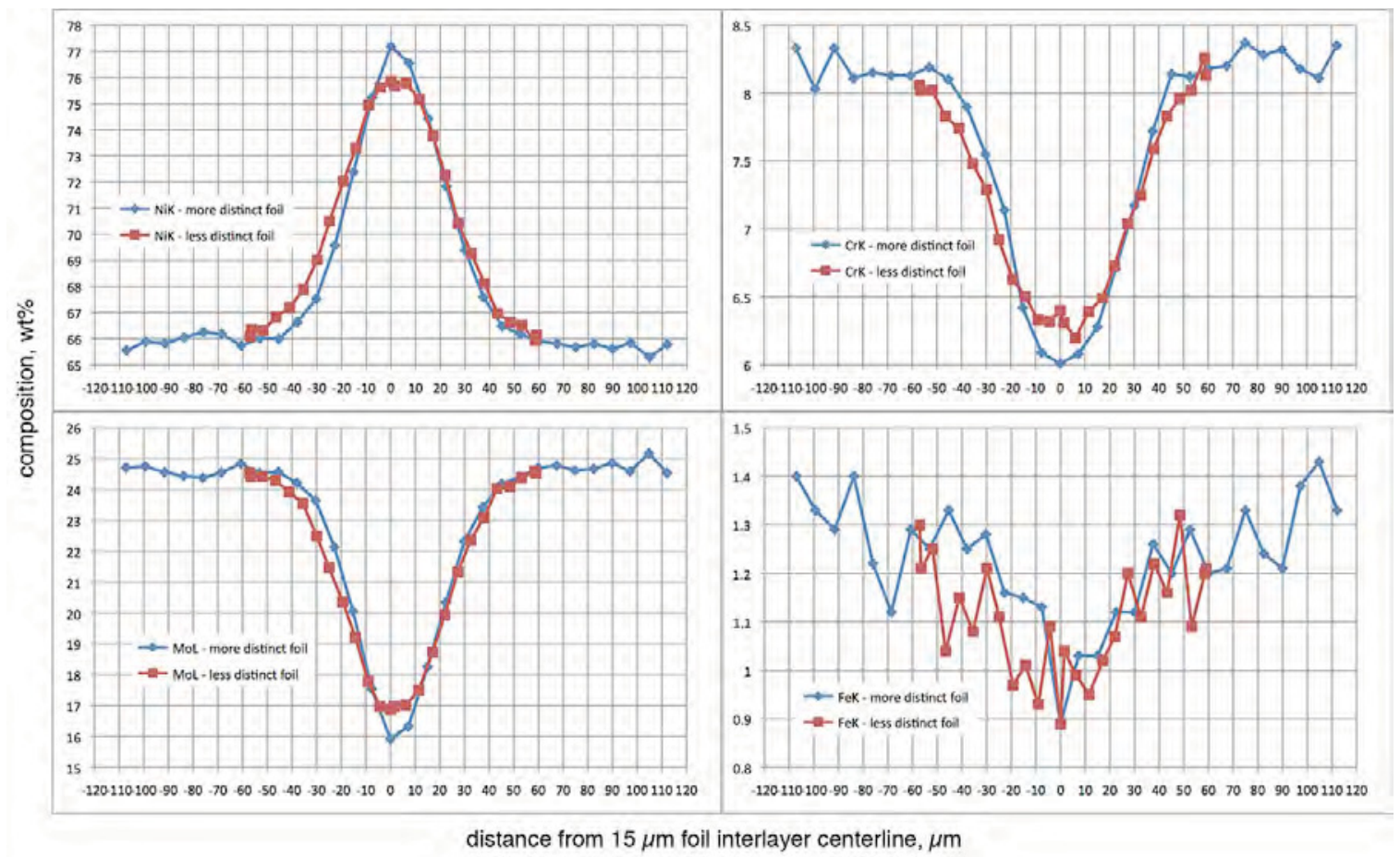

Figure 31. Composition profiles in less complete (more distinct) and more complete (less distinct) weld areas of Weld Y10127 in Alloy 242 shown in Figure .

matter of about $1 \mathrm{wt} \%$, suggesting that if the interdiffusion of dissimilar metals is important from a corrosion standpoint, it seems not to depend strongly on uniform pressure, as long as some contact is made. The development of the cross-bond grain structure, however, is a somewhat longer-term phenomenon.

The chemical diffusion is relatively easily modeled with thermodynamic and kinetic software such as Thermocalc/DICTRA, and, as noted elsewhere in this report, the agreement with experiment is good. Grain growth and grain boundary motion modeling is somewhat less developed, however Monte Carlo methods have been used, and might be an interesting area for further exploration in the area of diffusion welding.

\subsubsection{Crystallographic Effects}

The effects of crystallographic orientation most often appear in welding studies in connection with solidification, where fast and slow epitaxial growth directions with respect to isotherms have an influence on grain structure in fusion welds. A less common appearance is in very large-grained (or single-grain) materials, or strongly textured materials, such as magnetic alloys.

Figure 33 shows a somewhat fortuitous indication of the influence of crystal orientation in the area of diffusion welding, in this case in Alloy 242. Like most of the other welds discussed here, this weld originally contained a $15 \mu \mathrm{m}$ nickel foil, and after welding showed complete interpenetration of base metal grains across the interface. However, a quirk of the etching process (bromine in methanol) brings out a pale line perhaps $20 \mu \mathrm{m}$ from the original foil centerline, on both sides. It is unclear exactly what this is, although it seems to mark a critical composition for the etchant's interaction with the surface. It is also visible in optical micrographs and with Alloy $\mathrm{N}$, although it is especially clear in this specimen. 


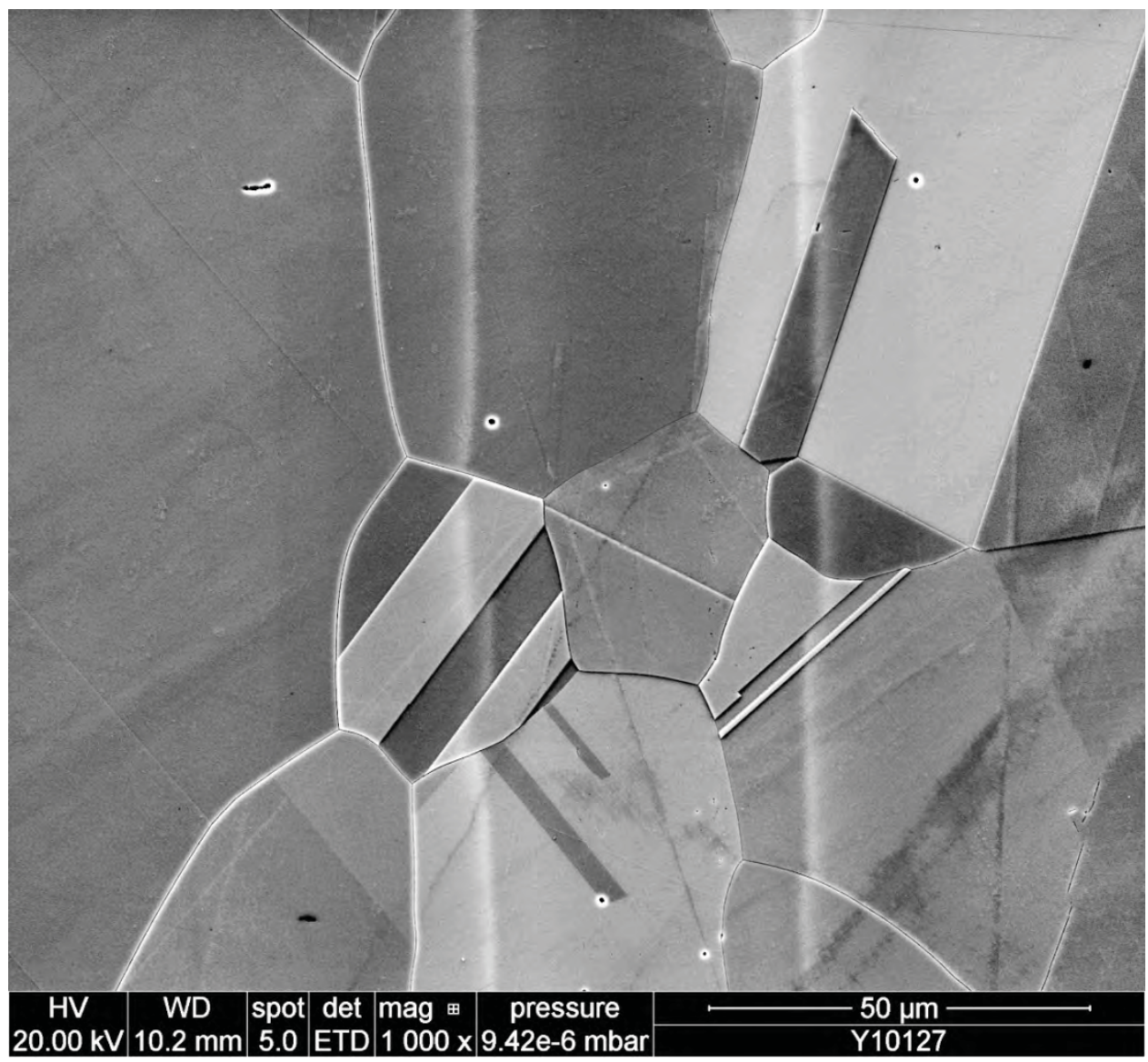

Figure 32. Weld in Alloy 242 bar showing different diffusion characteristics, depending on crystal orientation.

The step changes in the position of this line when it crosses grain or twin boundaries is most easily explained by enhanced or retarded diffusion rates, because of changes in crystallographic orientation in these neighboring regions. The program effort did not allow for the detailed exploration of this phenomenon, for example, obtaining electron backscatter diffraction (EBSD) data to identify the absolute direction of the crystals, or fine scale (e.g., transmission electron microscope [TEM] or very high resolution SEM) examination of the compositional gradient within each grain. But it is an interesting side effect of the planar nature of these diffusion welded joints.

\subsubsection{Alloy $\mathbf{N}$}

Figures 34 and 35 show cross sections of Weld Y10415, Alloy N with a $15 \mu \mathrm{m}$ nickel foil interlayer. Figure 34 is an optical micrograph - the interlayer can be seen outlined by a trace of small etch pits at the foil boundaries. In general, grain structure is influenced by these boundaries but grains have grown across the weld.

Figure 35 shows a different area of the weld where an EBSD) image is superimposed on the normal SEM image. EBSD identifies the crystal orientation of the grains, and illustrates that complete grain growth has occurred; the weld line is identifiable in the EBSD image as a slight rippling. 


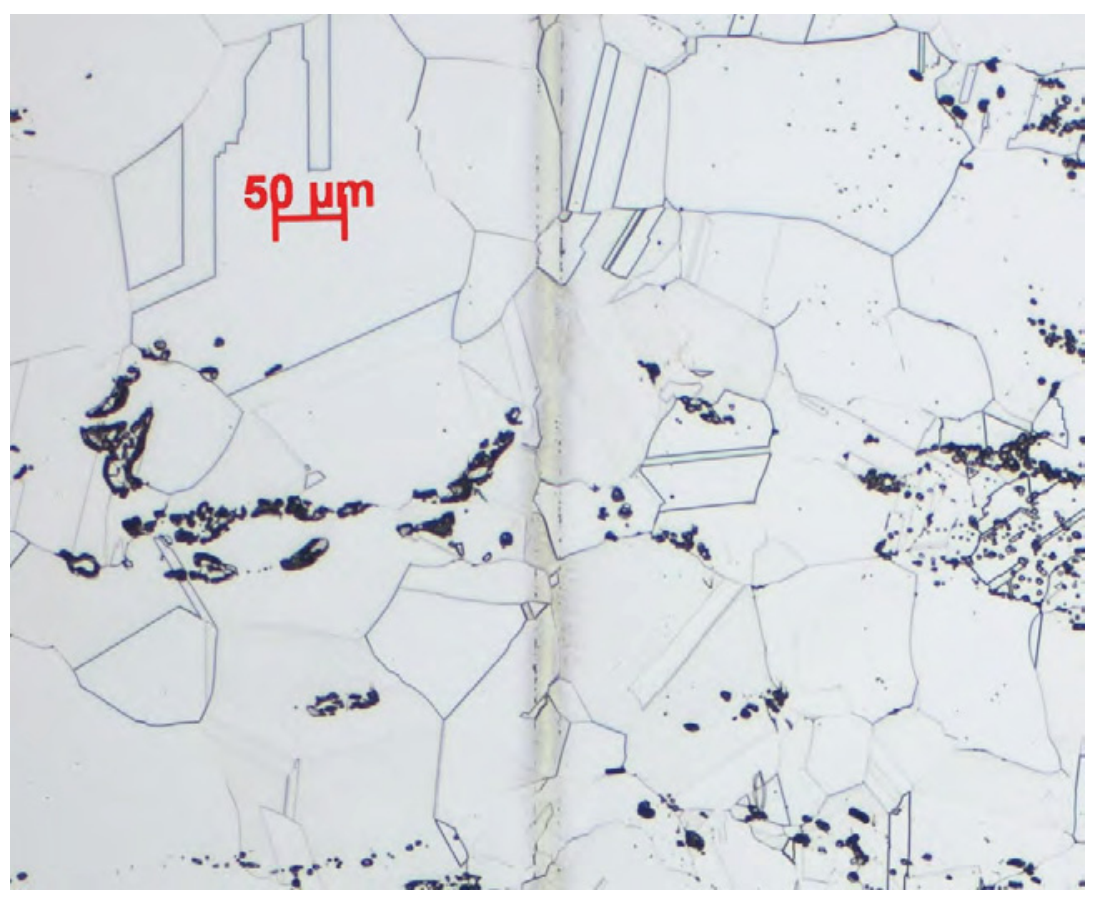

Figure 33. Weld Y10415 in Alloy N; $15 \mu \mathrm{m}$ foil layer is visible at weld line.

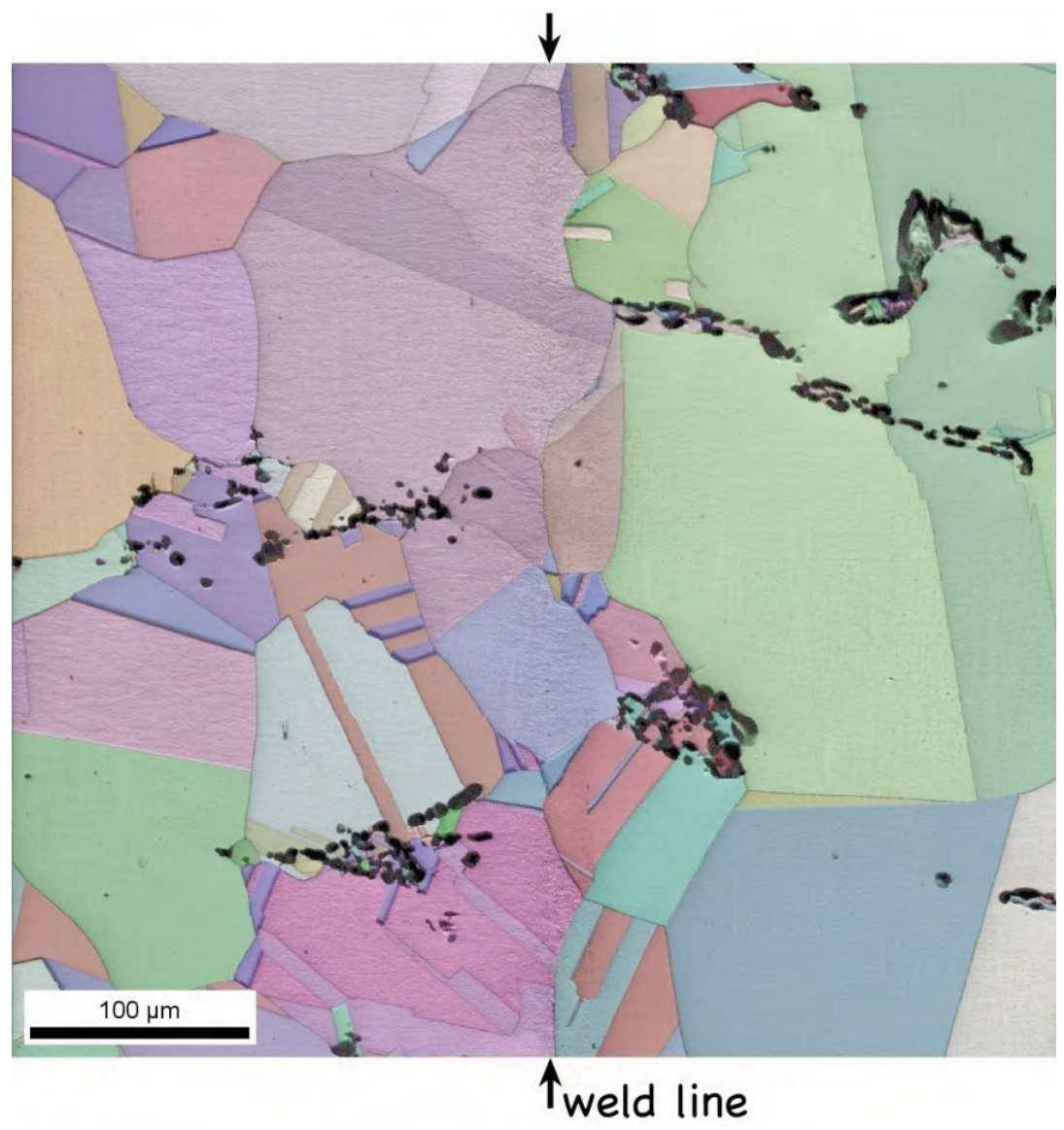

Figure 34. Weld Y10415 in Alloy N with EBSD and SE images superimposed to show grain growth across interface, which has essentially disappeared. 


\subsection{Tensile Tests}

Tensile specimens were machined from Welds Y10608 and Y10609 as per ASTM E8 with a 0.375 in. gauge diameter. The results are shown in Table 8 . An all base metal specimen tested in the same batch produced no results because of an error in the tensile machine's data acquisition system. This will be retested, but the Certified Material Test Report for the sheet material indicated a tensile strength of $115 \mathrm{ksi}$. The average ultimate tensile strength achieved in these welds was $90.0 \%$ of this value. Base metal properties of the welded bar material might be expected to be lower because of the coarser microstructure.

The pulled tensile specimen is shown in Figure 36. Substantial plastic deformation is evident, and the specimen failed in the weld interface area, but not coplanar with the weld, suggesting the achievement of near-base metal properties.

Table 8. Tensile results, Alloy $\mathrm{N}$ diffusion welds.

\begin{tabular}{|lcccc|}
\hline & $\begin{array}{c}\text { YS } \\
(\mathrm{ksi})\end{array}$ & $\begin{array}{c}\text { Ultimate Tensile } \\
\text { Strength (ksi) }\end{array}$ & $\begin{array}{c}\text { Elongation } \\
(\% \text { 1 in. })\end{array}$ & $\begin{array}{c}\text { RA } \\
(\%)\end{array}$ \\
\hline Y10608 & 42.9 & 104.6 & 45 & 44.5 \\
Y10609 & 42.8 & 102.4 & 40.8 & 44.6 \\
Average & 42.8 & 103.5 & 42.9 & 44.5 \\
\hline
\end{tabular}

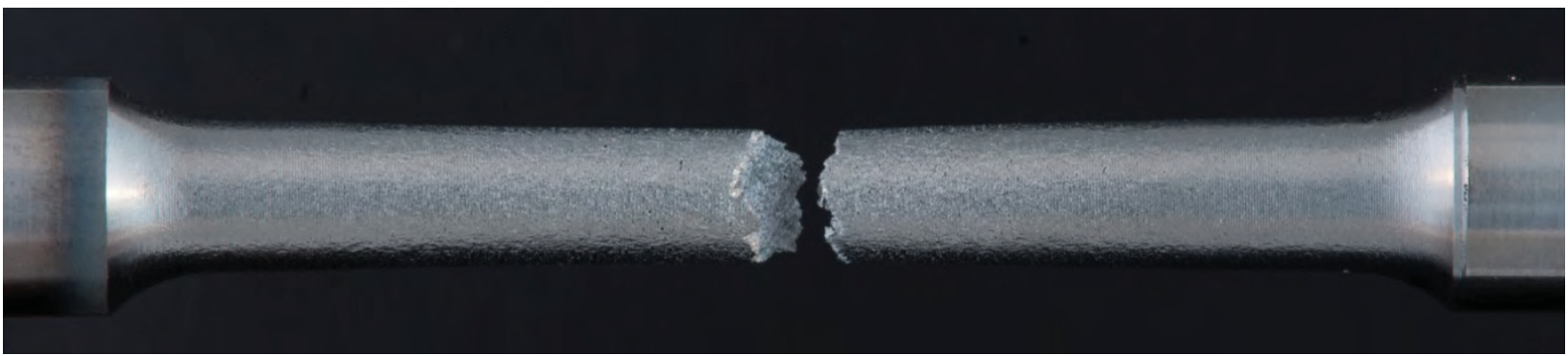

Figure 35. Pulled tensile specimen Y10608. Fracture was near weld line but not coplanar with weld interface. 


\subsection{Model/Experiment Correlation}

Figure 37 shows the correlation between modeled and experimentally measured compositions for Alloy $\mathrm{N}$. The $15 \mu \mathrm{m}$ foil served as a diffusion marker and shows reasonable agreement between model and experiment.
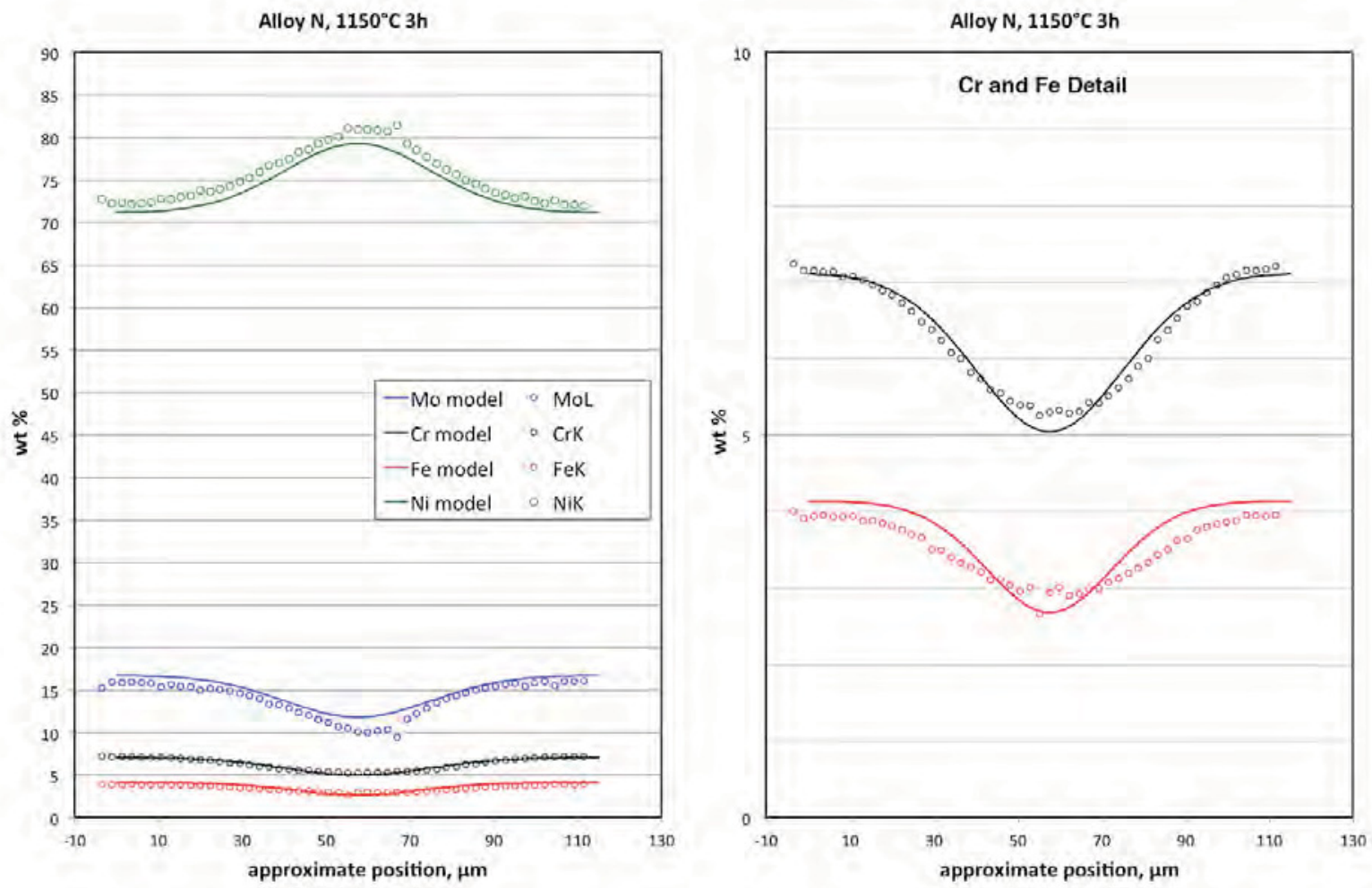

Figure 36. Correlation between calculated and experimental compositional gradients in Alloy $\mathrm{N}$ diffusion weld with $15 \mu \mathrm{m}$ nickel foil interlayer. 


\subsubsection{1-Micron Model}

Modeling is also of interest in diffusion welding with very thin plated layers, where the experimental techniques for measuring gradients across such small distances are more complicated, for example, using very high resolution SEM or TEM methods. It seems logical that such a thin layer would be diffused away rapidly, and a model was run for a $1 \mu \mathrm{m}$ thickness of pure nickel in a diffusion weld - the results shown in Figure 38- confirm this.

The compositions are so close to level that Figure 38 plots the variations as normalized total fractions. It can be seen that even in the case of iron, the least diffusible of the solute elements in this system, the composition is within $1 \%$ of homogeneity after the 3 hour weld cycle at $1150{ }^{\circ} \mathrm{C}$, suggesting that this time and temperature would result in minimal concentration variations leading, for example, to preferential corrosion at the joint.

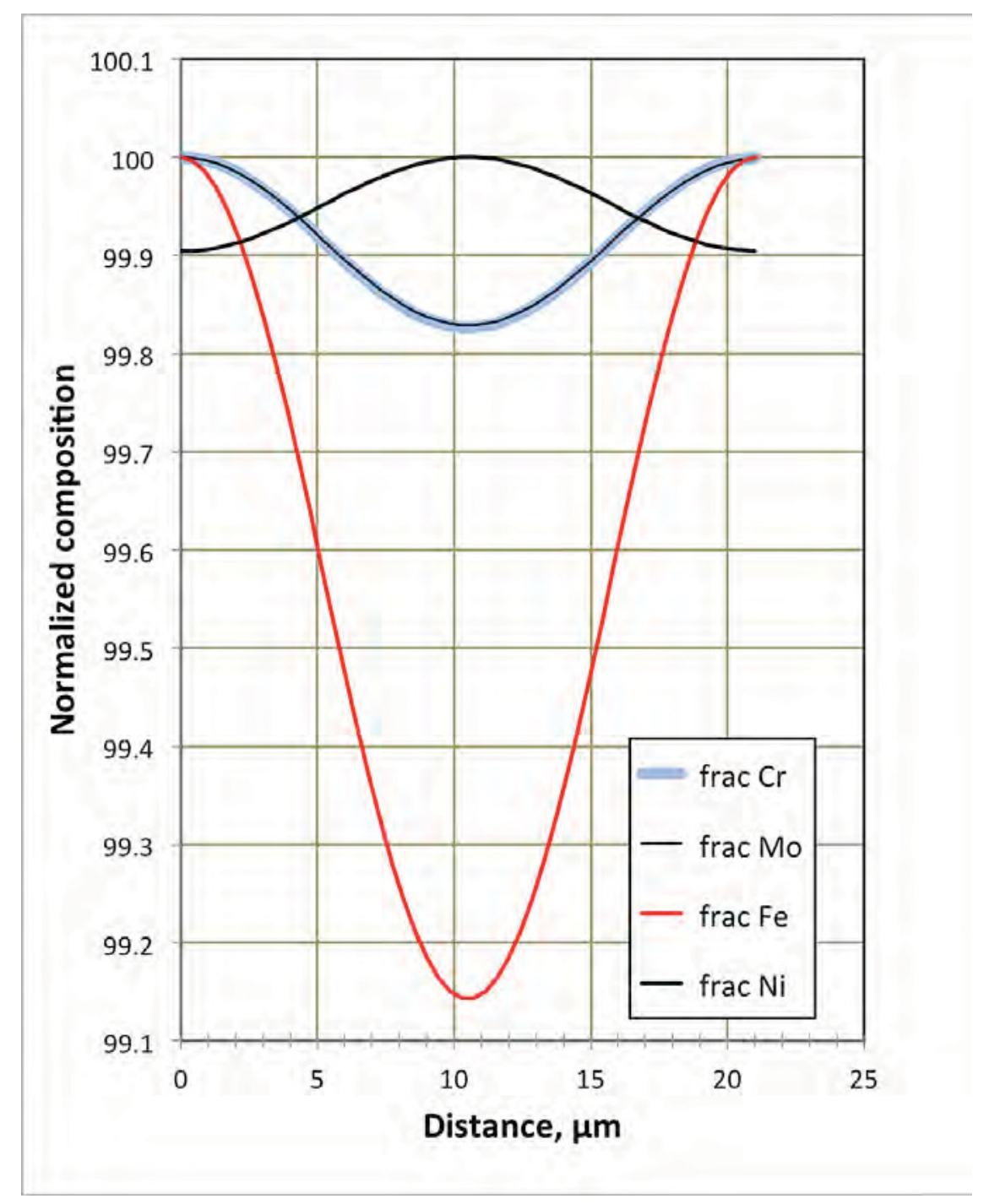

Figure 37. 1- $\mu \mathrm{m}$ foil diffusion normalized. 


\subsection{Corrosion Results}

The samples prepared as indicated in Section 6.4 above were sent to the University of Wisconsin and exposed to a $\mathrm{KF}-\mathrm{ZrF}_{4}$ molten salt bath at the temperatures and times indicated in Table 6. Before immersion in the salt, one side of each specimen was polished to a mirror finish and the other was left in the ground condition (600 grit finish) as received from INL.

Corroded samples were analyzed in several ways: optical photography and optical surface profilometry for all specimens, and, for selected specimens, optical micrography and SEM examination of the corroded surface, and cross sections of the corroded surface including elemental X-ray analysis. In addition, careful measurement of specimen weight and dimensions before and after corrosion allowed the calculation of weight loss and surface corrosion rates.

\subsubsection{Optical Photography}

Photomacrographs of the corroded specimens are shown in Figures 39 through 41. (There are only 200- and 500-hour exposures for the $650^{\circ} \mathrm{C}$ condition because this was still running at the close of the report window: $650{ }^{\circ} \mathrm{C}$ was a lower priority than the higher temperatures.) Before exposure, the appearance of all specimens was similar to Figure 27.

Qualitatively, the effects of the progression in time and temperature are not obvious at this scale, and the gross dimensions of the specimens are similar to the untreated case. In most cases, the diffusion welded sheets apparent in Figure 27 are obvious on the corroded specimens, because the edges were not machine finished and a visible bump is apparent. There appears to be a difference in attack on the sheet material versus the base material, though this is subtle and not well correlated with severity of exposure. Closer examination with a metallographic microscope does not reveal any particular attack along the lines of the three diffusion weld interfaces each specimen contains.
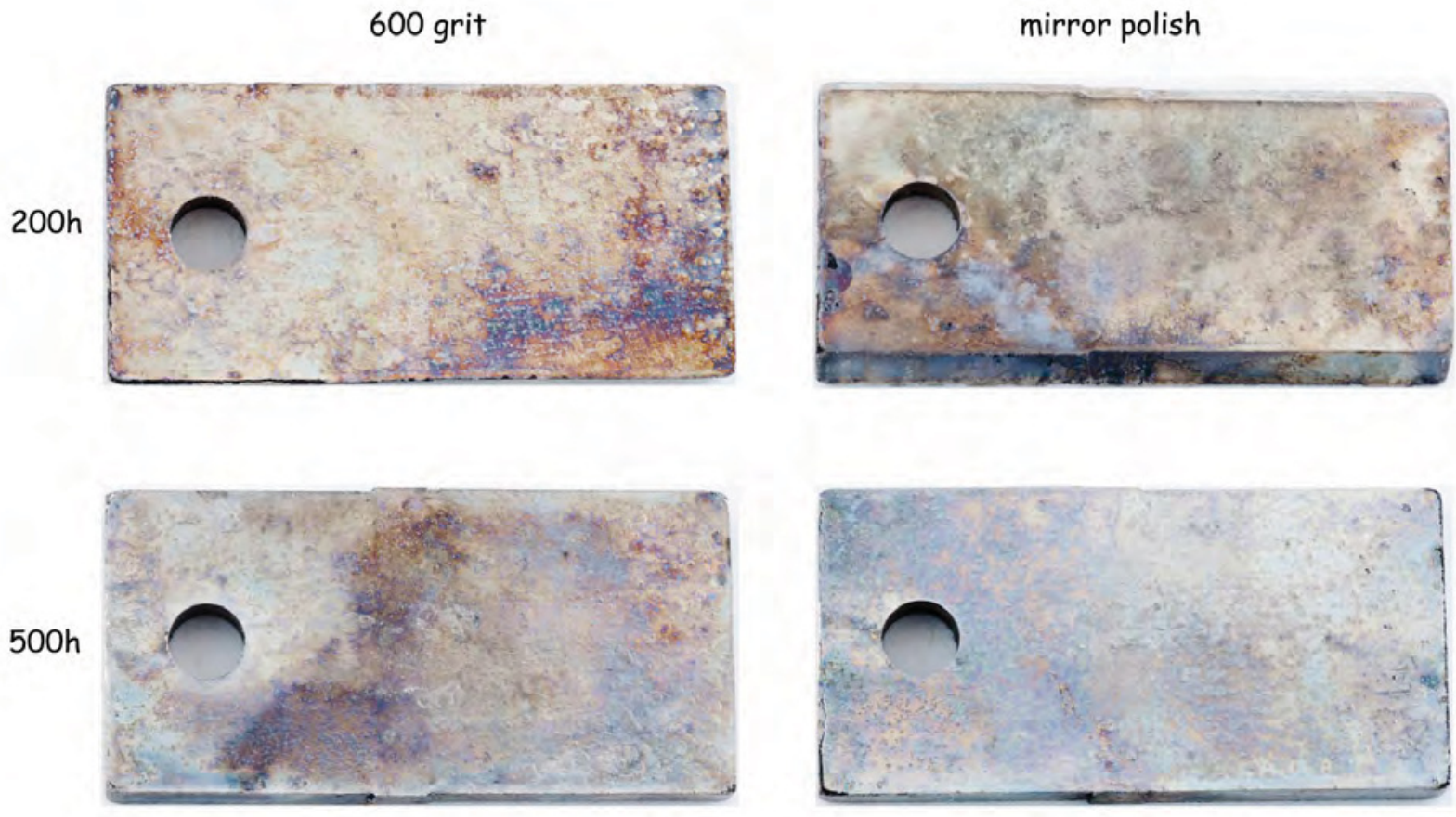

Figure 39. Alloy $\mathrm{N}$ diffusion welds exposed at $650^{\circ} \mathrm{C}$. 

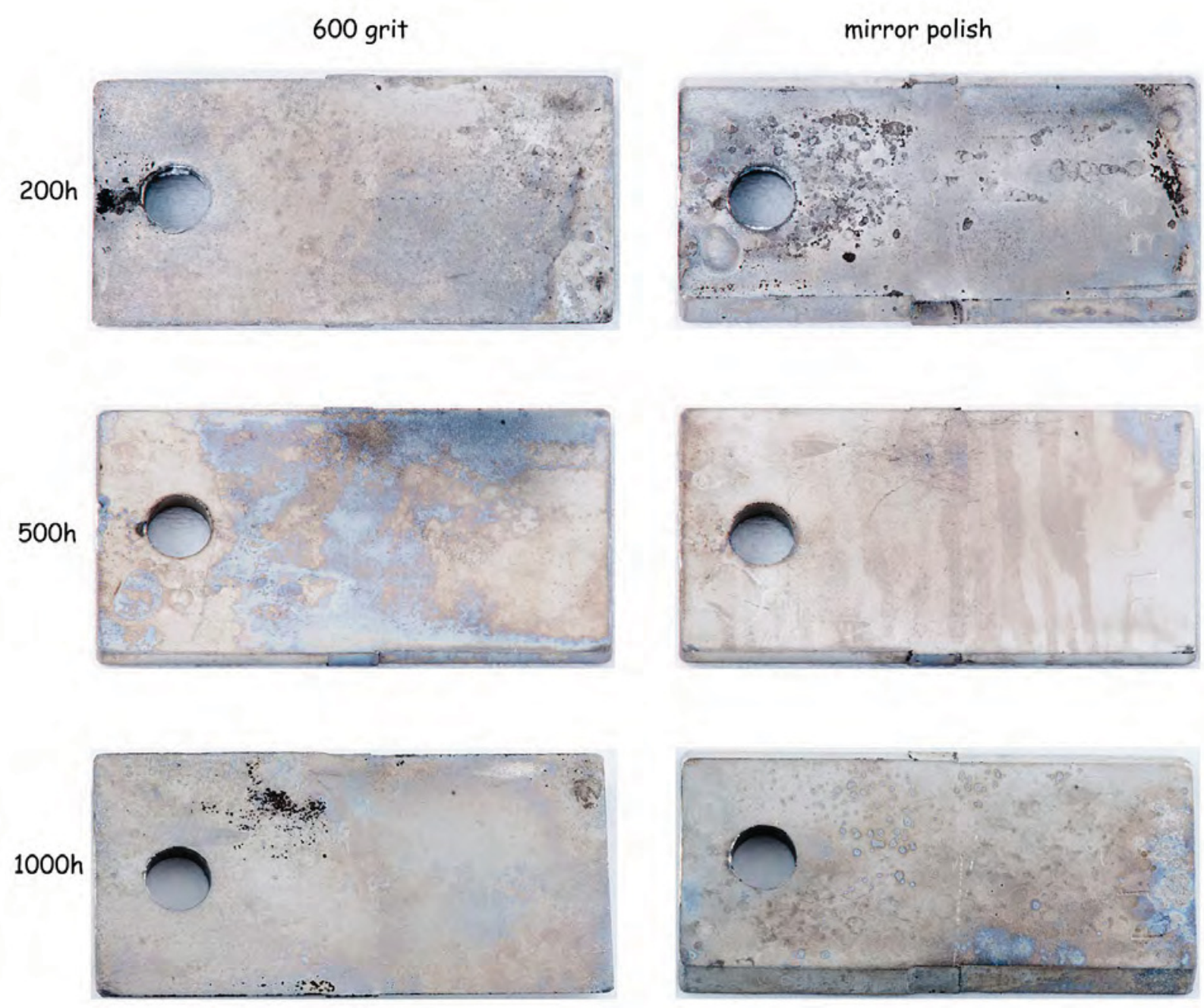

Figure 40. Alloy $\mathrm{N}$ diffusion welds exposed at $700^{\circ} \mathrm{C}$. 

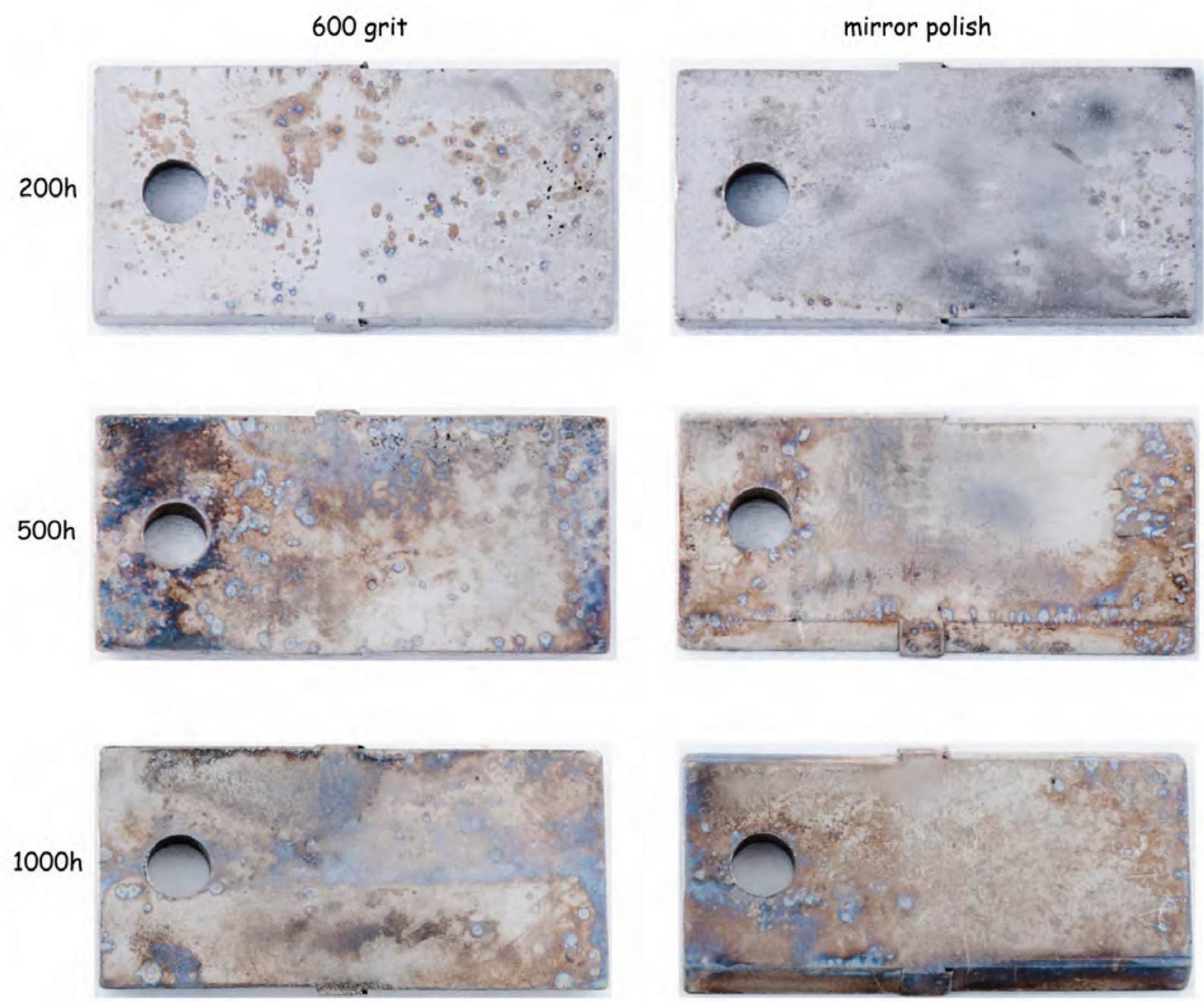

Figure 41. Alloy $\mathrm{N}$ diffusion welds exposed at $850{ }^{\circ} \mathrm{C}$. 
The difference in appearance may be due to the different materials conditions, as described above, obvious, for example, in Figure 34. The base material comes from a slab of Alloy N, cut normal to the working direction, about $5 \times 18 \times 1$ in. in dimension. The sheet material, cold rolled to $0.041 \mathrm{in}$., has a finer microstructure in which the Mo-rich particles seen in both conditions have been broken down and refined. SEM images of both conditions can be seen in Figure 42.

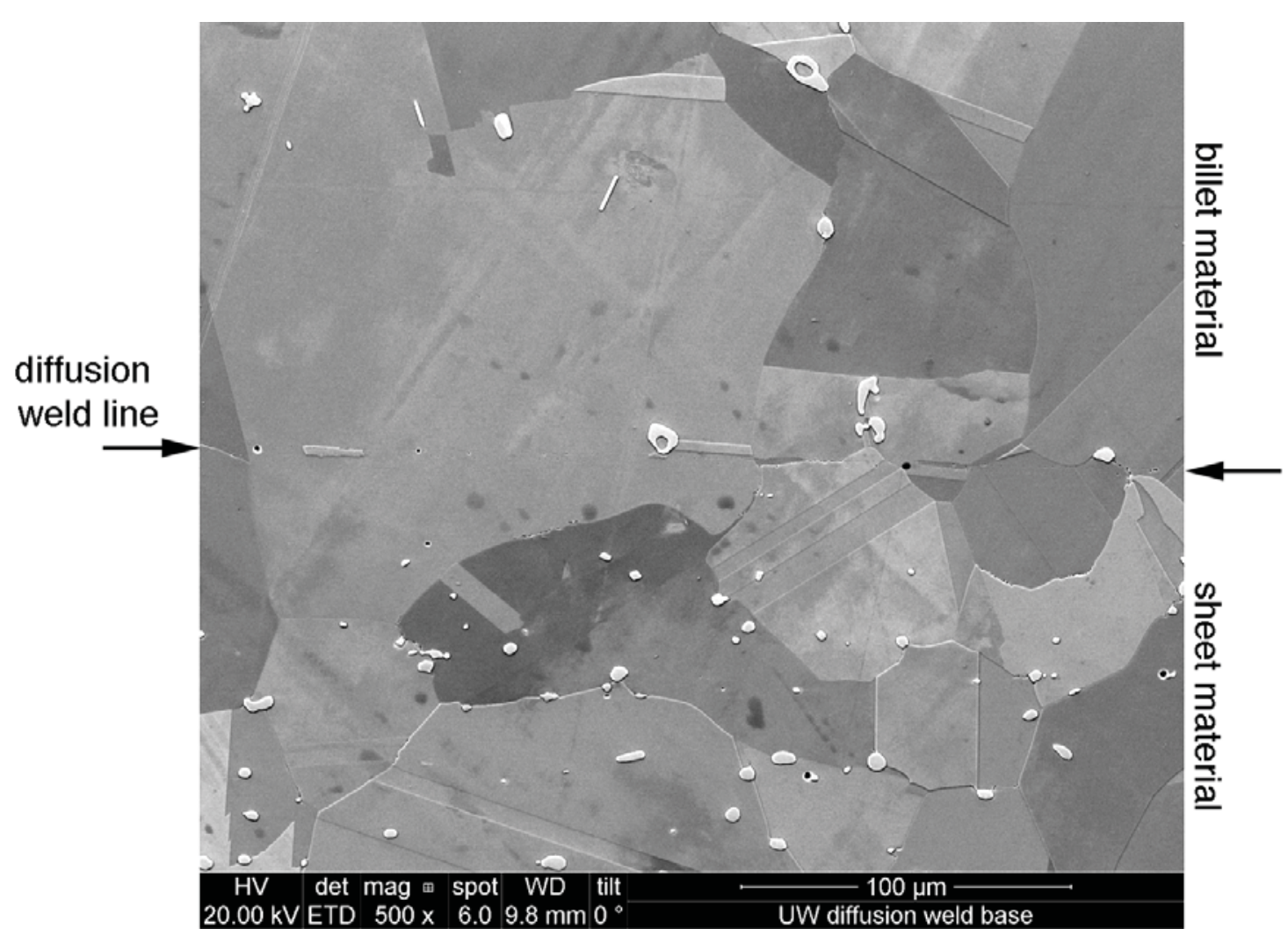

Figure 42. Base material from billet; sheet material from 0.041 in. wrought material.

\subsubsection{Surface Profilometry}

All specimens were examined with the optical profilometer described earlier (Wyko NT1100 Optical Profiling System), since this is a relatively efficient way to quantify surface features. A typical image is shown in Figure 43, which may be compared with a different area of the same specimen in Figure 44. The quantitative information provided by this equipment suggested that longer times and higher temperatures produced smoother or more uniform surfaces. This makes sense qualitatively, in that corrosion tends to start locally and spread to a more uniform attack, and higher temperatures and longer times would promote this. There was too much scatter in the data to rely on this technique for quantitative information about corrosion surfaces in the cases at hand. It seems, however, that this technique might provide such information with a more rigorous statistical choice of image locations, and might discriminate corrosion phenomena across different materials or corrosive media. 


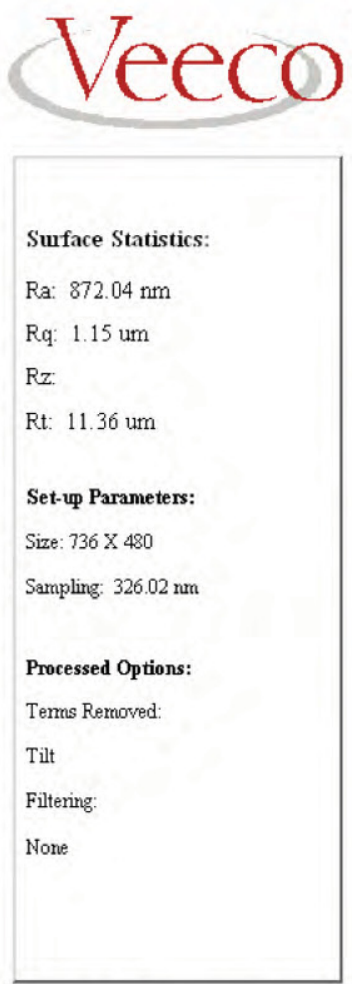

Mag: $25.8 X$

Title: B15 1000hr 700C

Note: ID side weld area

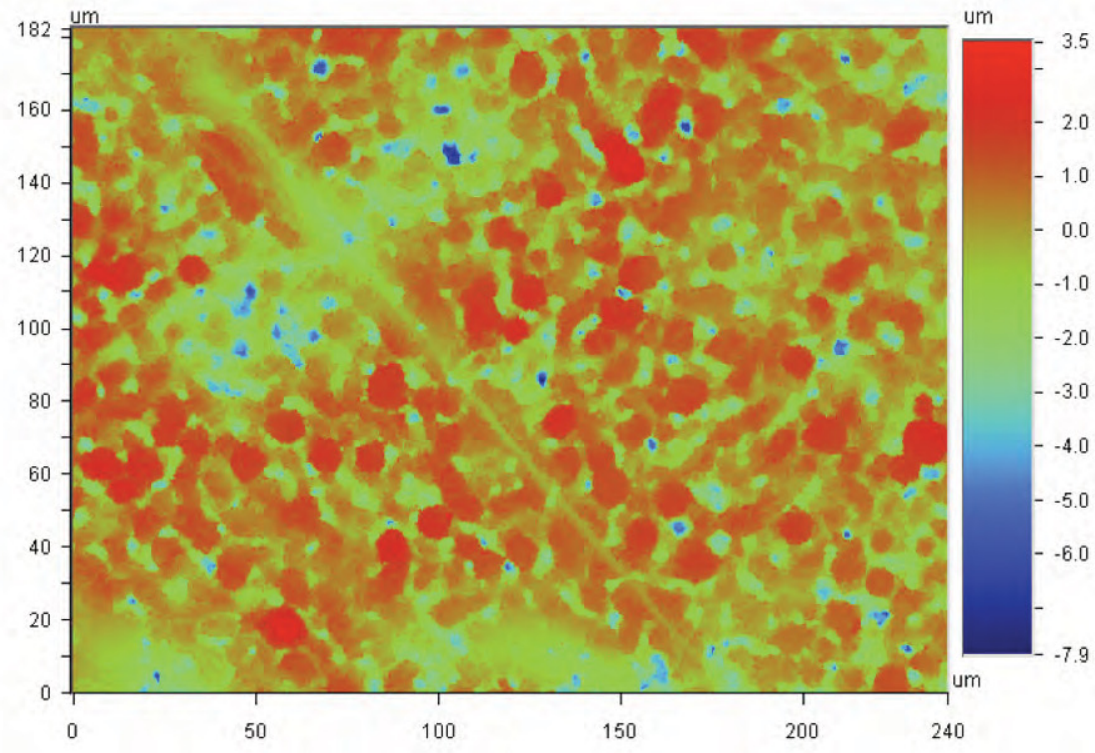

Figure 43. Image of Diffusion weld specimen B15, $1000 \mathrm{~h}, 700{ }^{\circ} \mathrm{C}$.

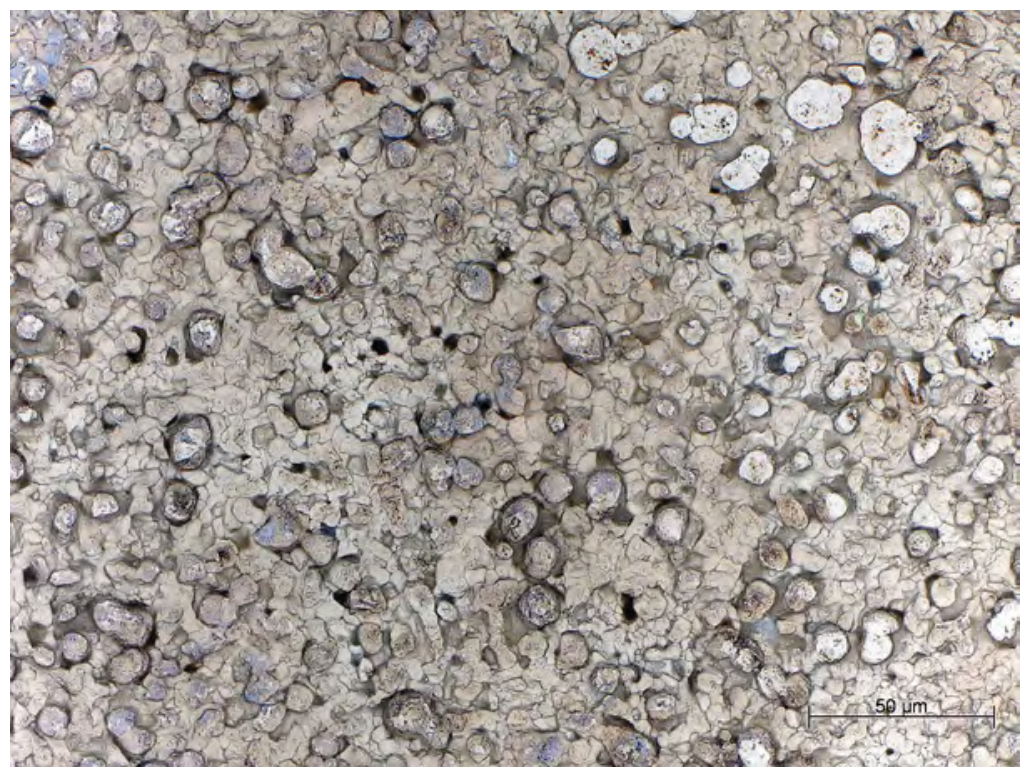

Figure 44. Diffusion weld specimen B15, 1000 h, $700{ }^{\circ} \mathrm{C}$. Magnification is similar to Figure 43, a different area of the same specimen 


\subsubsection{Higher Resolution Surface Images}

Figure 44 is an optical micrograph showing the surface appearance of Specimen B15 after 1000 hours at $700{ }^{\circ} \mathrm{C}$, and Figure 45 shows the surface appearance of specimen A15 after 1000 hours at $850{ }^{\circ} \mathrm{C}$. These images are consistent with the finding that the corrosion rate was higher at $700{ }^{\circ} \mathrm{C}$ than at $850{ }^{\circ} \mathrm{C}$; the surface of the $700{ }^{\circ} \mathrm{C}$ specimen shows greater attack and more holes.

Figure 46 is an SEM image of the surface of A15 at higher magnification.

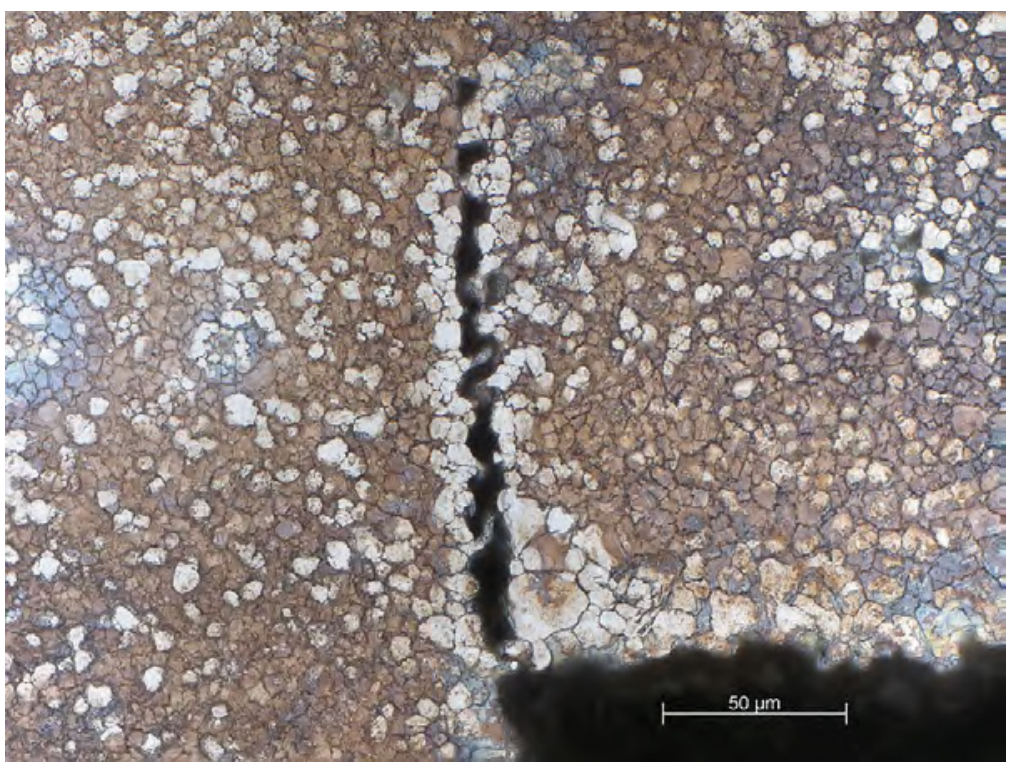

Figure 45. Diffusion weld specimen A15 after 1000 hours at $850^{\circ} \mathrm{C}$. Crack is unbonded area at edge of specimen.

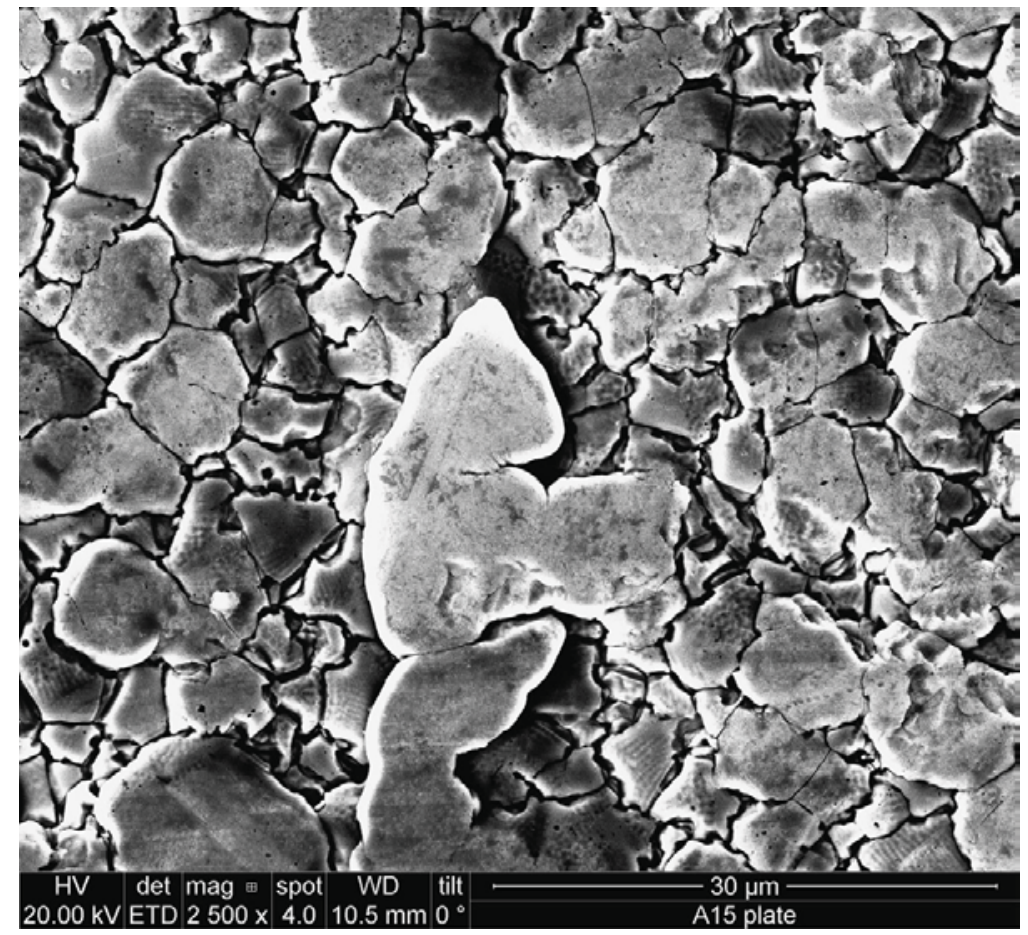

Figure 46. SEM image of weld specimen A15 after 1000 hours at $850{ }^{\circ} \mathrm{C}$. 


\subsubsection{Cross Section Images}

Figure 47 is a cross section of the $850{ }^{\circ} \mathrm{C} 1000 \mathrm{~h}$ specimen, showing that the holes visible in the previous figures correspond to a network of corrosion cavities underneath the surface. Figure 48 shows qualitatively that $\mathrm{Cr}$ in particular is depleted in the corroded layer, with a lesser depletion of $\mathrm{Fe}$ and $\mathrm{Ni}$.

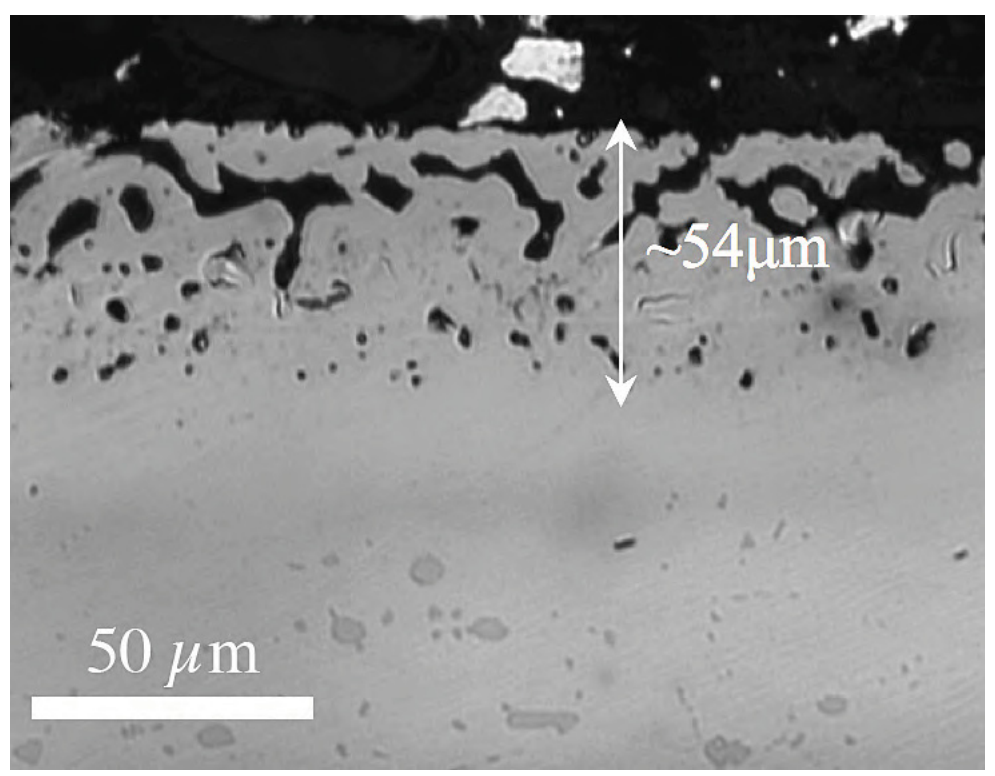

Figure 47. Cross section of $\mathrm{A} 15,850^{\circ} \mathrm{C}, 1000 \mathrm{~h}$.
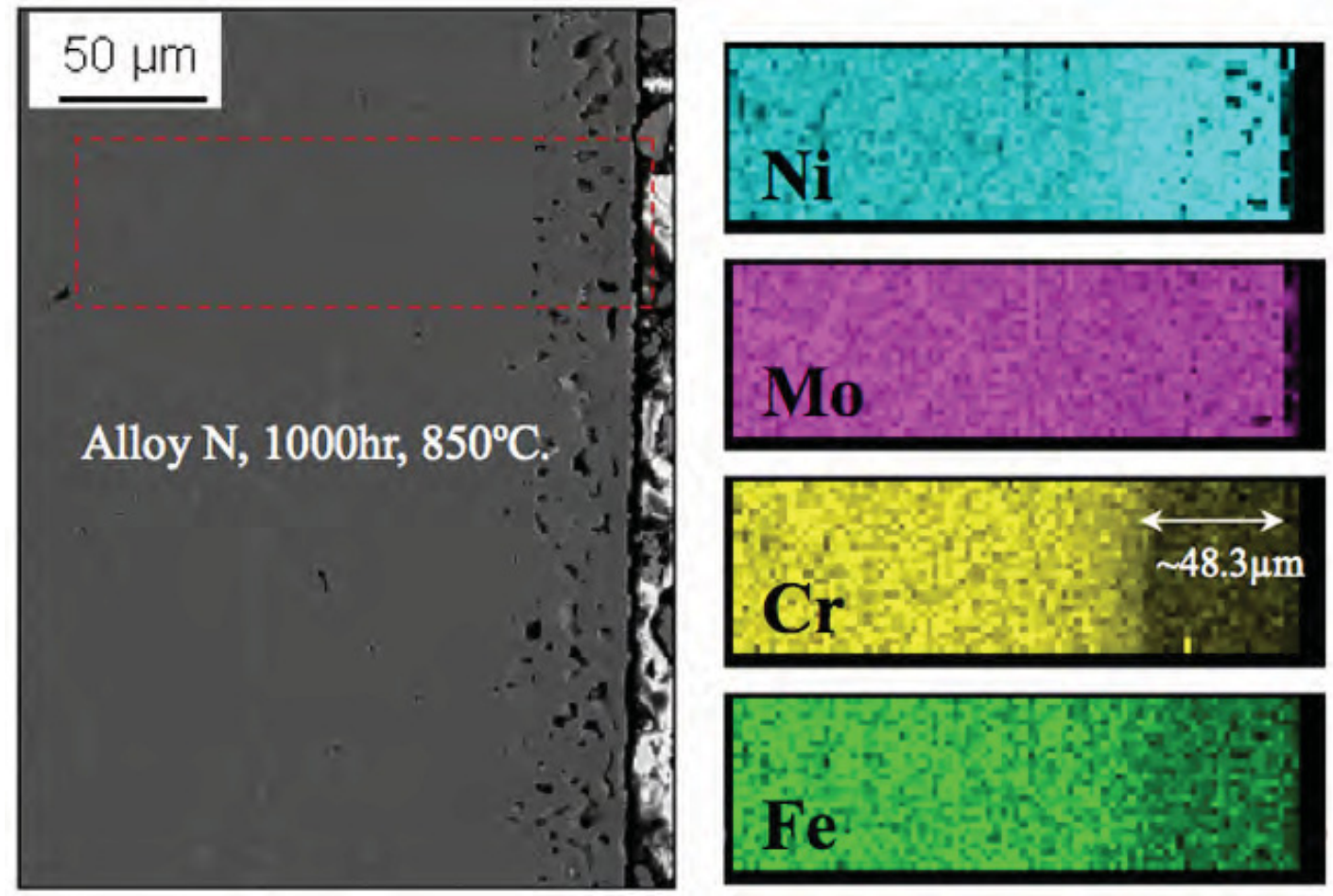

Figure 48. Cross section of $\mathrm{A} 15,850^{\circ} \mathrm{C}, 1000 \mathrm{~h}$, showing elemental changes with corrosion. 


\subsubsection{Corrosion Rates from Weight Loss and Area Measurements}

From measurements of specimen area, weight, and material density, a corrosion rate can be calculated, as shown in Table 9. These data are plotted in Figures 49 and 50. Figure 49 is the corrosion rate as a function of time, and Figure 50 is the corrosion rate as a function of temperature.

Table 9. Corrosion rates for Alloy $\mathrm{N}$ in $\mathrm{KF}_{-} \mathrm{ZrF}_{4}$.

\begin{tabular}{|c|c|c|c|c|}
\hline & Time & Temperature & \multicolumn{2}{|c|}{ Corrosion rate } \\
\hline & $\mathrm{h}$ & ${ }^{\circ} \mathrm{C}$ & $\mathrm{mm} / \mathrm{yr}$ & mils/yr \\
\hline Alloy N sheet & 200 & 850 & -0.437 & -17.19 \\
\hline Alloy $\mathrm{N}$ welded & 200 & 850 & -0.363 & -14.28 \\
\hline Alloy N sheet & 500 & 850 & -0.163 & -6.43 \\
\hline Alloy N welded & 500 & 850 & -0.145 & -5.69 \\
\hline Alloy N sheet & 1000 & 850 & -0.071 & -2.79 \\
\hline Alloy $\mathrm{N}$ welded & 1000 & 850 & -0.067 & -2.65 \\
\hline Alloy N sheet & 200 & 700 & -0.852 & -33.55 \\
\hline Alloy $\mathrm{N}$ welded & 200 & 700 & -0.575 & -22.62 \\
\hline Alloy N sheet & 500 & 700 & -0.196 & -7.71 \\
\hline Alloy $\mathrm{N}$ welded & 500 & 700 & -0.198 & -7.81 \\
\hline Alloy N sheet & 1000 & 700 & -0.089 & -3.49 \\
\hline Alloy $\mathrm{N}$ welded & 1000 & 700 & -0.096 & -3.77 \\
\hline Alloy N sheet & 200 & 650 & -0.031 & -1.24 \\
\hline Alloy N welded & 200 & 650 & -0.059 & -2.33 \\
\hline Alloy N sheet & 500 & 650 & -0.073 & -2.86 \\
\hline Alloy N welded & 500 & 650 & -0.027 & -1.05 \\
\hline Alloy N sheet & 1000 & 650 & -0.036 & -1.43 \\
\hline Alloy $\mathrm{N}$ welded & 1000 & 650 & -0.039 & -1.52 \\
\hline Alloy N sheet Run 2 & 200 & 850 & -0.071 & -2.80 \\
\hline Alloy N sheet Run 2 & 200 & 700 & -0.033 & -1.31 \\
\hline
\end{tabular}




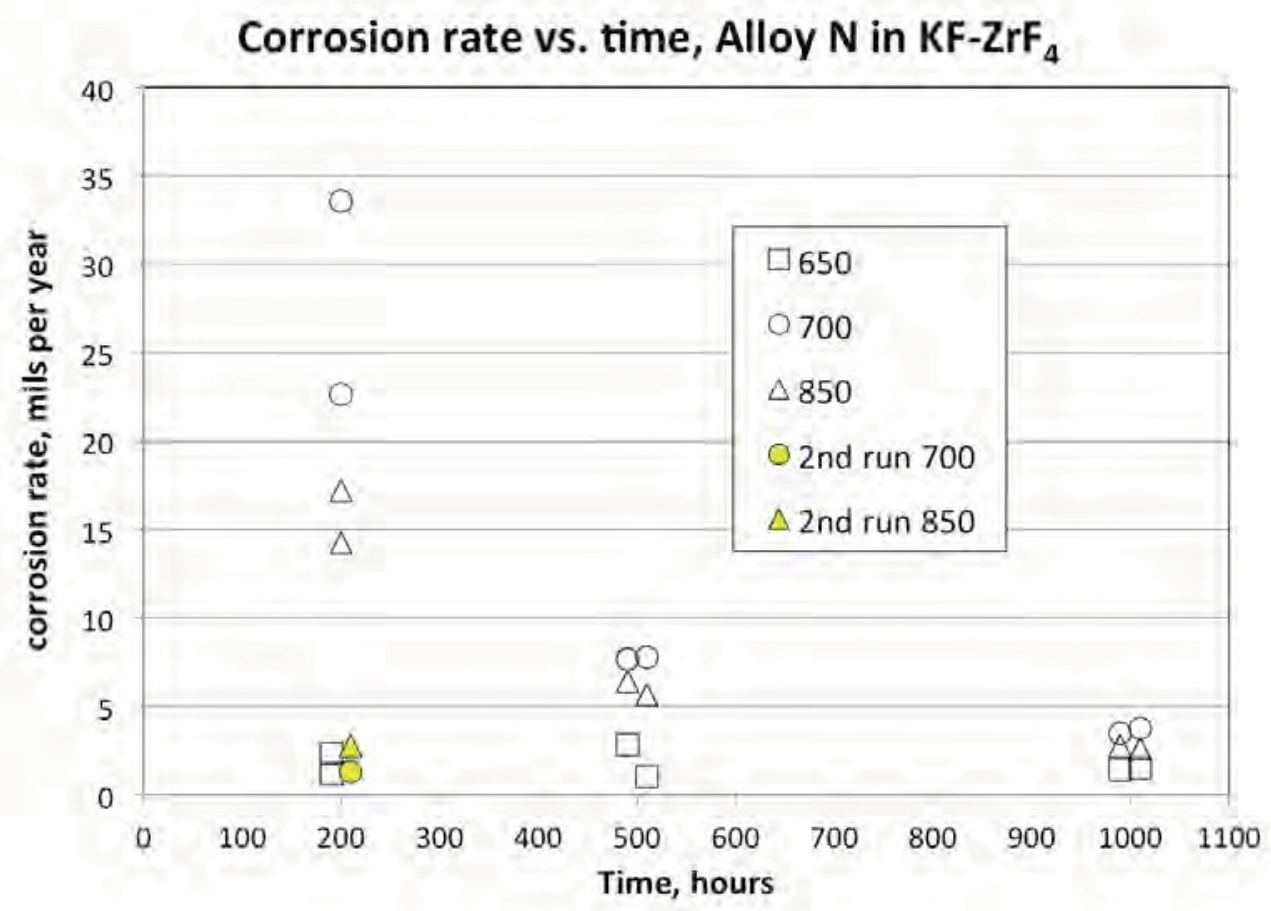

Figure 49. Corrosion rate vs. time, Alloy $\mathrm{N}$ in $\mathrm{KF}-\mathrm{ZrF}_{4}$.

Corrosion rate vs. temperature, Alloy $\mathrm{N}$ in $\mathrm{KF}^{-\mathrm{ZrF}_{4}}$

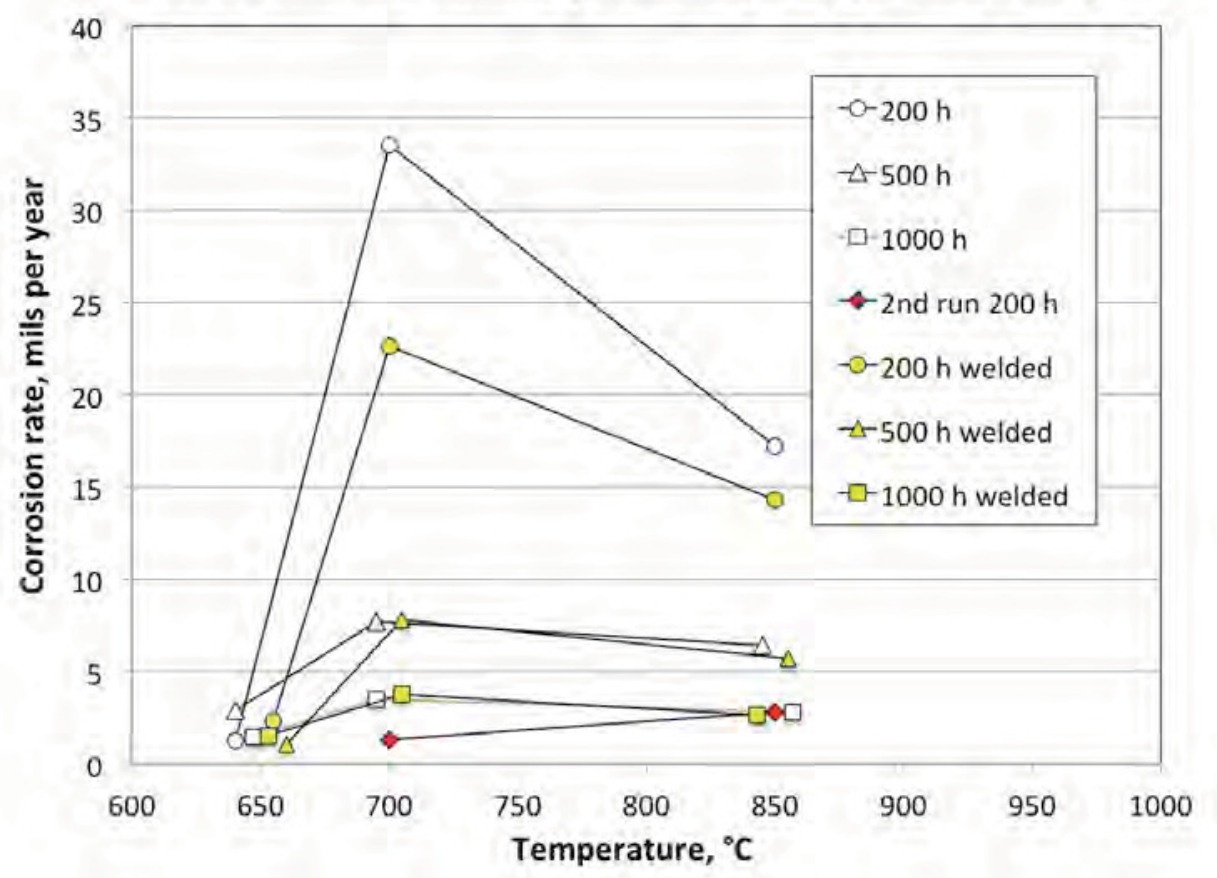

Figure 50. Corrosion rate vs. temperature, Alloy $\mathrm{N}$ in $\mathrm{KF}-\mathrm{ZrF}_{4}$. 
These results are anomalous in two ways: one would expect the corrosion rates to increase with temperature, and to be more or less linear over time. The answer seems to lie in our relative inexperience with this salt system. The "second run" values indicated here, which were made at 700 and $850{ }^{\circ} \mathrm{C}$ for 200 hours in the same salt that had been running for 1000 hours, showed a more logical trend in this regard, with low corrosion rates and greater corrosion at 850 than at $700{ }^{\circ} \mathrm{C}$. There is a sense in which the salt has become "conditioned" and closer to equilibrium. It is unclear exactly why the corrosion rates are switched in this instance; it may have to do with differences in the way the salt batches were prepared. Nonetheless it seems that if work is to continue with this salt system, some kind of conditioning run may need to be performed, for example, running a corrosion test on some standard material for about 1000 hours before introducing the material of actual interest. This would also more closely mimic the situation in a molten salt reactor, which is at temperature for many thousands of hours and freezing of the salt is undesirable.

These "second run" specimens also cast light on a possible reason the corrosion rates seem to decline with time. This is a common phenomenon in corrosion work, where corrosion occurs at a fairly high rate until the system reaches a steady state once rate limiting corrosion product layers or local polarization is established. Molten salt systems are relatively poorly understood in this regard compared with aqueous systems, and have the potential to produce fluorine or HF that can be very corrosive. This is one reason redox control is a major issue in the molten salt reactor. 


\section{CONCLUSIONS}

Alloy $\mathrm{N}$ is readily joined by diffusion welding; joints made with both nickel foil and electroplated nickel interfaces exhibited full grain growth across the joints.

Surface preparation is an important aspect of diffusion welding, and, particularly with nickel alloy sheet materials typical of the construction of proposed compact heat exchangers, needs to be carefully considered along with other welding parameters.

Tensile strengths were approximately $90 \%$ of base metal values, and joints exhibited ductility similar to base metal levels, suggesting that the material will be usable in code-qualified construction.

Thermocalc/DICTRA calculations of compositions across the joint indicate that this modeling is predictive and should be a useful tool in evaluating weld parameters and developing experimental matrices.

Both diffusion welds and sheet material in Alloy $\mathrm{N}$ were corrosion tested in $58 \mathrm{~mol} \% \mathrm{KF} /$ $42 \mathrm{~mol} \% \mathrm{ZrF}_{4}$ at 650,700 , and $850{ }^{\circ} \mathrm{C}$ for 200,500 , and 1000 hours. Corrosion rates were similar between welded and nonwelded materials, typically $<10$ mils per year. Anomalies were noted in the corrosion rates that may be attributable to salt preparation techniques. 


\section{CURRENT STATUS}

Approximately 18 diffusion welds were made in Alloy $\mathrm{N}$ and Alloy 242, with various interlayers, generally with parameters of $1150{ }^{\circ} \mathrm{C}$ for 3 hours with a welding pressure of $\sim 5 \mathrm{MPa}$.

A number of welds were examined with SEM and compositional gradients measured; these were compared with modeled gradients via Thermocalc/DICTRA. These models are now developed and further modeling, such as examining other times and temperatures, will be more efficient. 


\section{FUTURE WORK \\ 10.1 Further Diffusion Welding Development}

Alloy $\mathrm{N}$ and 242 diffusion welding was done for 3 hours at $1150^{\circ} \mathrm{C}$ and $\sim 5 \mathrm{MPa}$ pressure. This was based on experience with alloys $800 \mathrm{H}$ and 617 in the previous NGNP work. It would be useful to investigate parameters further, for example, using lower temperatures and shorter and longer times. This can be supported by thermodynamic modeling, but a certain amount of experimentation is required.

The NGNP alloys of interest included about $20 \%$ chromium, since they are designed for service in high temperature oxidizing environments. Diffusion welding without an interlayer was not investigated for Alloys $\mathrm{N}$ and 242, though their lower chromium content suggests that this might be successful with proper surface treatment.

Surface treatment was investigated but not optimized in the present work. In the future, the development of a procedure for this is necessary and should be developed, and the surfaces well characterized. Chemical pickling (treatment with an acid solution) would be preferable from a production standpoint, though some mechanical abrasion component may be necessary. The oxide layer in high temperature alloys is seldom well characterized, but is instead removed or minimized by cleaning procedures that empirically produce good diffusion welds. Some characterization of various surface treatment by well known surface science methods would be useful in identifying which are really the most useful and what they are doing.

The Gleeble can also be used to make diffusion welds that more closely approximate compact heat exchangers, for example, welding sheets with grooves to investigate the temperature/pressure limits for making multilayer CHX's without distortion of the channels. Fabricability will be an integral part of design optimization for these components.

\subsection{Modeling and Model/Experiment Correlation}

The accuracy of the Thermocalc/DICTRA modeling was demonstrated in the test welds made thus far. There are several areas where this can be further applied.

\subsubsection{Diffusion Welding}

The diffusion welding process itself can be further modeled, examining the time/temperature implications for composition of different welding parameters. It is likely that an optimal diffusion weld does not include simple heating to a steady temperature, followed by simple cooling. Models allow the exploration of potentially useful experiments that will give the final word on weld quality and qualification.

\subsubsection{Oxide Layer Dissolution}

This is the modeling analog to the experimental surface science work suggested in the previous section. The chemical potential of the various oxides or other surface contaminants (for example, the residual of pickling operations) can be modeled in relation to the base metals being joined, leading to new insights into the process dynamics at the atomic scale. This in turn may lead to new, more reliable surface preparation and welding procedures.

\subsubsection{Dissimilar Metal Joints}

Dissimilar metal joints are an obvious point of attack for modeling. Compared with the expense of experimental evaluation, Thermocalc/DICTRA results can identify potential problems and solutions much more cheaply. A combination of likely pairs might be investigated, for example, $617 / \mathrm{N}$ or $800 \mathrm{H} / \mathrm{N}$. Promising interlayer materials or diffusion barriers can also be investigated. 


\subsubsection{Metal-Ceramic Joints}

The joining of metals to ceramics would allow the integration of high performance ceramic materials into heat exchangers and other high performance energy systems. Overcoming the inherent differences between these classes of materials (different bonding mechanisms and lattice parameters, thermal expansion coefficients, and mechanical properties) is a substantial challenge. However, the advantages in material performance make the effort worthwhile. Diffusion welding with appropriate transition layers is a possible method for such joining.

\subsubsection{Welding vs. Service Temperatures}

The study of long term aging effects, whether in a particular environment or in the internal chemistry and microstructure of a material, is one of the most expensive aspects of materials science. Modeling is less well developed in characterizing aggressive environments such as molten salts or the effects of neutron irradiation, but for judging the internal material effects of long term service, it can be quite useful by simulating years of service at elevated temperatures. Whether dissimilar materials or identical materials that may have been through a variety of welding cycles prior to service, an ongoing modeling effort can identify problems, suggest solutions, and try solutions on a much compressed time scale compared with experimentation.

\subsubsection{Vacuum Hot Press Welding at Oregon State University}

Because of funding reductions, a $2.1 \times 2.1$ in. stack similar to those used in the NGNP work on Alloy $800 \mathrm{H}$ (shown in Figures 51 and 52) cannot be made from Alloy $\mathrm{N}$ this program year. This is, however, the next logical step in the progression towards a testable compact heat exchanger of this alloy for molten salt testing. 


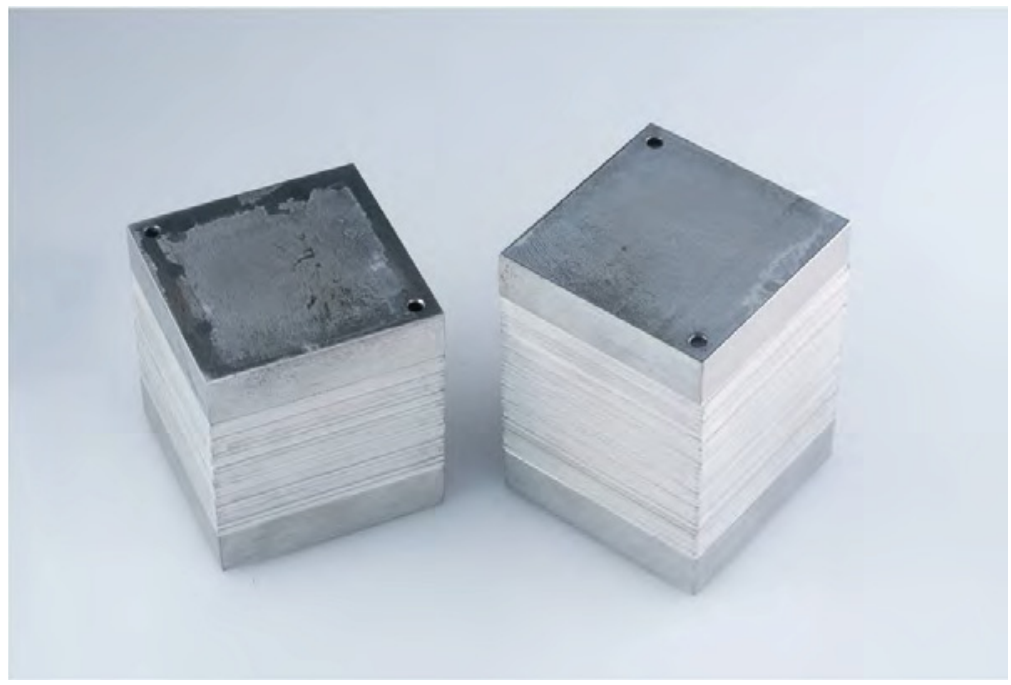

Figure 51. Alloy $800 \mathrm{H}$ stacks, 0.062 in. material with 0.5 in. end caps.

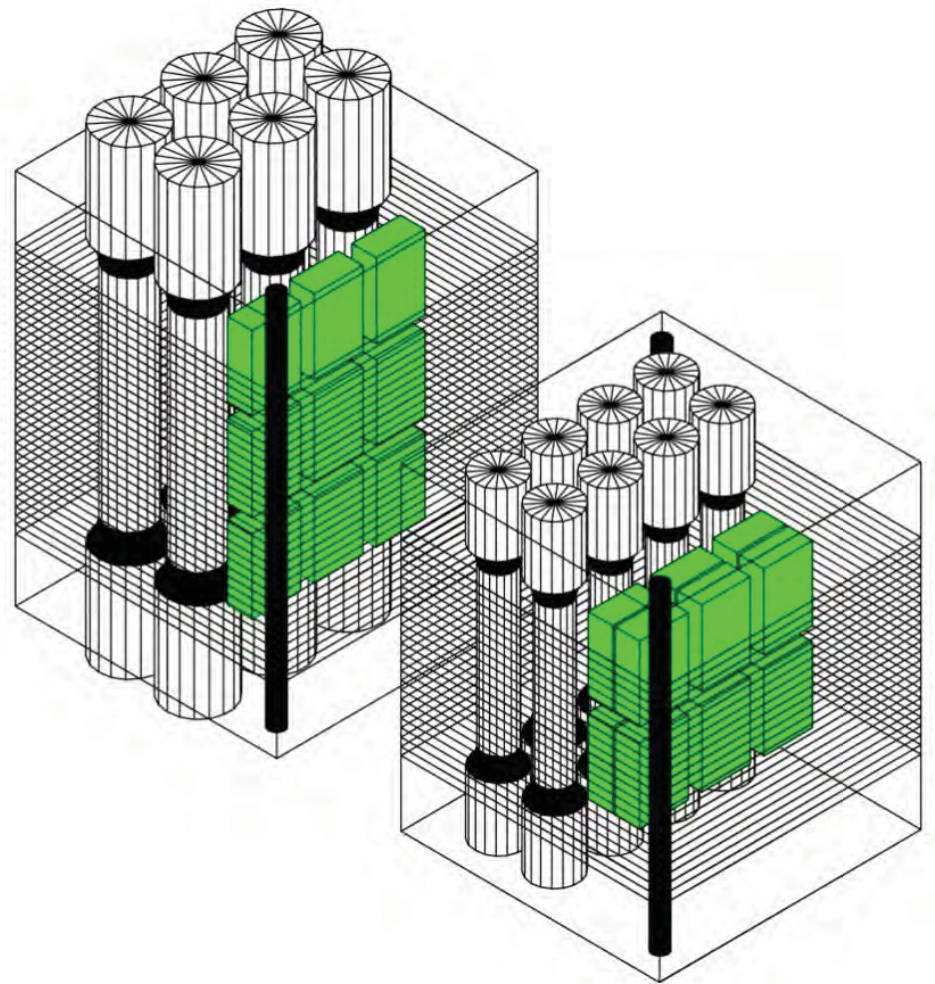

Figure 52. Tensile bar and micrography specimens from diffusion welded stacks, $2.1 \mathrm{in}$. on a side. 


\section{BIBLIOGRAPHY}

American Welding Society. (2007). Diffusion Welding and Diffusion Brazing. In Welding Handbook, 9th Edition, v. 3 (pp. 421-450). Miami: American Welding Society.

Dupont, J. N., Lippold, J. C., \& Kiser, S. D. (2009). Welding Metallurgy and Weldability. Hoboken, NJ: John Wiley and Sons.

Haubenreich, P. R., \& Engel, J. R. (February 1970). Experience with the Molten-Salt Reactor Experiment. Nuclear Applications and Technology, Vol. 8, 118-136.

Hochanadel, P. W., Cola, M. J., Dave, V. R., Kelly, A. M., Casey, R. S., Bramlett, R. D., et al. ( 2005). Diffusion Bonding of Alloy 690- Initial Studies. Proceedings of the 7th International Conference on Trends in Welding Research (pp. 889-894). Pine Mountain, Georgia: ASME.

LeBlanc, D. (2010, May). Too Good to Leave on the Shelf. Mechanical Engineering , p. 4.

Li, X., Smith, T., Kinimont, D., \& Dewson, S. J. (2009). Materials for Nuclear Diffusion-Bonded Compact Heat Exchangers. Proceedings of ICAPP'09 (p. Paper 9058). Tokyo: ICAPP.

McCoy, H. E., Beatty, R. L., Cook, W. H., Gehlbach, R. E., Kennedy, C. R., Koger, J. W., et al. (1970). New Developments in Materials for Molten-Salt Reactors. Nuclear Applications \& Technology Vol. 8 , 156-169.

Miller, T. (2011). personal communication at Oregon State University. (D. E. Clark, Interviewer)

Mizia, R. E., Clark, D. E., Galzoff, M. V., Lister, T. E., \& Trowbridge, T. L. (December 2011). Progress Report for Diffussion Welding of the NGNP Process Heat Application Heat Exchangers, INL/EXT-1121817 Rev. 1. Idaho Falls, Idaho: Idaho National Laboratory.

Mizia, R. E., Clark, D. E., Glazoff, M. V., Lister, T. E., \& Trowbridge, T. L. (2011). Optimizing the Diffusion Welding Process for Alloy 800H: Thermodynamic, Diffusion Modeling, and Experimental Work. Metallurgical and Materials Transactions A .

Mizia, R. (2010). Scoping Investigation of Diffusion Bonding for NGNP Process Application Heat Exchangers, PLN-3565. Idaho Falls: Idaho National Laboratory.

Mylavarapu, S. K. (2011). Dissertation: Design, Fabrication, Performance Testing, and Modeling of Diffusion Bonded Compact Heat Exchangers in a High-Temperature Helium Test Facility. Colombus, Ohio: The Ohio State University.

Mylavarapu, S. K., Sun, X., Christensen, R. N., Unocic, R. R., Glosup, R. E., \& Patterson, M. W. (2011). Fabrication and design aspects of high-temperature compact diffusion bonded heat exchangers. Nuclear Engineering and Design, doi:10.1016/j.nucengdes.2011.08.043.

NGNP. (2009). Next Generation Nuclear Plant Project Technology Development Roadmaps: The Technical Path Forward, INL/EXT-08-15148. Idaho Falls, Idaho: Idaho National Laboratory.

Olson, L. C., Ambrosek, J. W., Sridharan, K., Anderson, M. H., \& Allen, T. R. (2009). Materials corrosion in Molten LiF-NaF-KF salt. Journal of Flourine Chemsitry 130, 67-73.

Park, C., Patterson, M., Maio, V., \& Sabharwall, P. (2009). Dependable Hydrogen and Industrial Heat Generation from the Next Generation Nuclear Plant, INL/CON-09-15576. Idaho Falls, Idaho: Idaho National Laboratory.

Prybylowski, J. W., Floreen, S., Sherwood, W., \& Wittimeier, R. The Stress Corrosion Performance of Diffusion Bonded Nickel Base Alloys, KAPL-4713 UC-25. Schenectady: General Electric Company, Knolls Atomic Power Laboratory. 
Ren, W., Muralidharan, G., Wilson, D. F., \& Holcomb, D. E. (July 17-21, 2011). Considerations of Alloy $\mathrm{N}$ for Fluoride Salt-Cooled High-Temperature Reactor Applications. Proceedings of the ASME 2011 Pressure Vessels \& Piping Division Converence (pp. PVP2011-57029). Baltimore: ASME.

Sessions, C. E., \& Lundy, T. S. (1969). Diffusion of Titanium in Modified Hastelloy N. Journal of Nuclear Materials Vol 31 , 316-322.

Shi, E. P., \& Sundman, B. (2010). Thermo-Calc Classic Verion S User's Guide. Stockholm: ThermoCalc Software AB.

Thermo-Calc. (2010). DICTRA version 25 User's Guide. Stockholm, Sweden: Thermo-Calc Software AB.

Totemeier, T. C., Tian, H., Clark, D. E., \& Simpson, J. A. (2005). Microstructure and Characteristics of Alloy 617 Welds, INL-EXT-05-00488. Idaho Falls: Idaho National Laboratory.

White, H. J. (2010, September). Haynes International Capabilities: HASTELLOY N Alloy. Oak Ridge National Laboratory, Tennesee.

Wilson, D. (2010, July 20). Flouride Salt Cooled High Temperature Reactors (FHRs) Present Materials Challenges. Oak Ridge, Tennessee: Oak Ridge National Laboratory. 